Universidad de Lima

Facultad de Comunicación

Carrera de Comunicación

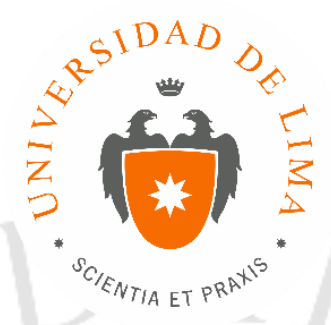

\title{
CRISIS DE COMUNICACIÓN CORPORATIVA ONLINE EN LA RED SOCIAL FACEBOOK. CASO: LATAM AIRLINES DURANTE LA EMERGENCIA CLIMÁTICA DEL FENÓMENO DEL NIÑO DE MARZO DE 2017
}

Trabajo de investigación para optar el Título Profesional de Licenciado en

Comunicación

\section{Mauricio Antonio Lozano Campos \\ Código 20120749}

\section{Asesora}

Julianna Paola Ramírez Lozano

Lima - Perú

Mayo de 2018 


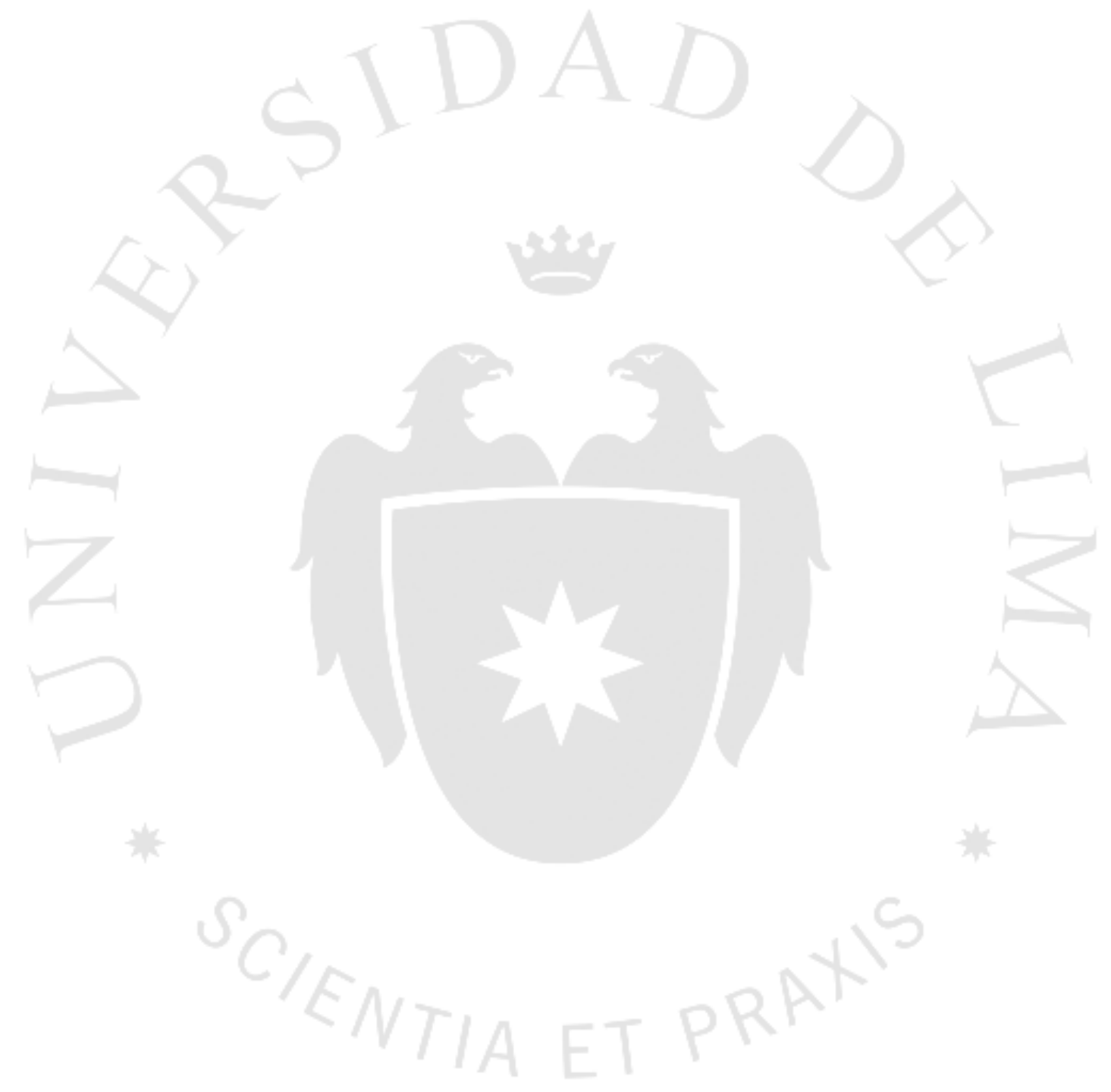




\section{CRISIS DE COMUNICACIÓN CORPORATIVA ONLINE EN LA RED SOCIAL FACEBOOK. CASO: LATAM AIRLINES DURANTE LA EMERGENCIA CLIMÁTICA DEL FENÓMENO DEL NIÑO DE MARZO DE 2017}




\section{TABLA DE CONTENIDO}

\section{INTRODUCCIÓN}

1

CAPÍTULO I: REDES, CRISIS Y USUARIOS................................3

1.1 Las redes sociales y la reputación online...............................3

1.2 La gestión de crisis .........................................................................

1.3 Las redes sociales desde un punto de vista sociológico ............................5

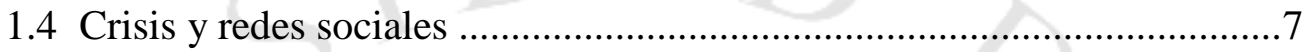

$1.5 \mathrm{El}$ origen de las crisis online: los clientes descontentos.........................9

1.6 La teoría de las redes sociales .............................................................11

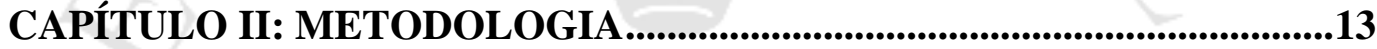

CAPÍTULO III: LATAM Y EL IMPACTO DE LA CRISIS........................16

3.1 La comunicación de LATAM Airlines ....................................................16

3.2 La respuesta de los usuarios ante la crisis ..........................................18

$3.3 \mathrm{El}$ impacto de la crisis y la repercusión en la imagen ...............................20

CAPÍTULO IV: DISCUSIÓN Y ANÁLISIS ........................................................28

CONCLUSIONES.............................................................................................31

LIMITACIONES DE LA INVESTIGACIÒN................................33

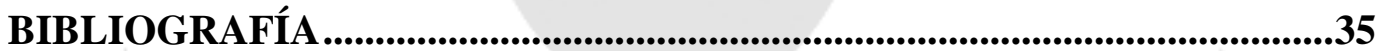

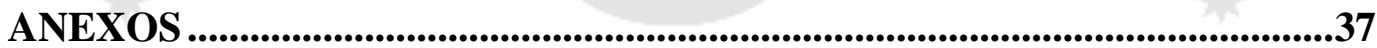




\section{ÍNDICE DE FIGURAS}

Figura 4. 1. Percepción de la imagen de los consumidores sobre LATAM Airlines.....21

Figura 4. 2. Uso de canales de comunicación virtual y su nivel de satisfacción.........21

Figura 4.3. Importancia de los canales de comunicación............................22

Figura 4.4. Conocimiento sobre la crisis de lluvias de marzo de $2017 \ldots \ldots \ldots \ldots \ldots \ldots \ldots . .23$

Figura 4.5. Factores de origen de la crisis....................................23

Figura 4.6. Percepción de la afección de la crisis sobre LATAM Airlines...............24

Figura 4.7. Cambio de la percepción de la imagen de LATAM en los usuarios luego del

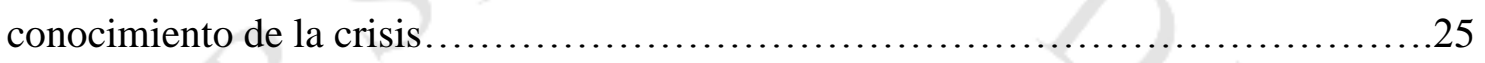

Figura 4.8. Razones por las cuales los usuarios volverían a viajar con LATAM

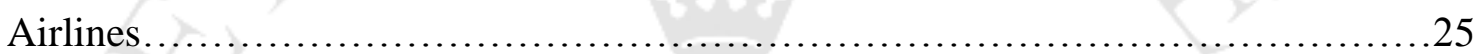

Figura 4.9. Percepción sobre si la crisis fue un hecho aislado.......................26 


\section{ÍNDICE DE ANEXOS}

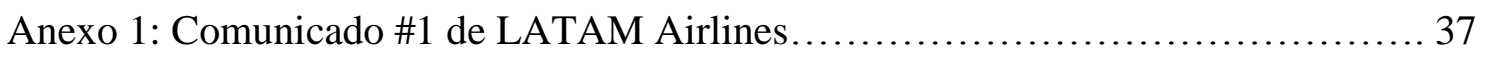

Anexo 2: Comunicado \#2 de LATAM Airlines...................................... 38

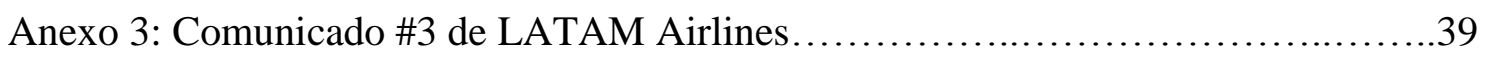

Anexo 4: Leyenda para la lectura de tablas...................................40

Anexo 5: Tablas de comentarios y respuestas del comunicado $1 \ldots \ldots \ldots \ldots \ldots \ldots \ldots \ldots . . \ldots 1$

Anexo 6: Tablas de comentarios y respuestas del comunicado $2 \ldots \ldots \ldots \ldots \ldots \ldots \ldots \ldots 6 . \ldots \ldots 2$

Anexo 7: Tablas de comentarios y respuestas del comunicado $3 \ldots \ldots \ldots \ldots \ldots \ldots \ldots . \ldots 8$

Anexo 8: Capturas de pantalla de los comentarios y respuestas de los comunicados

publicados por LATAM Airlines..........................................116

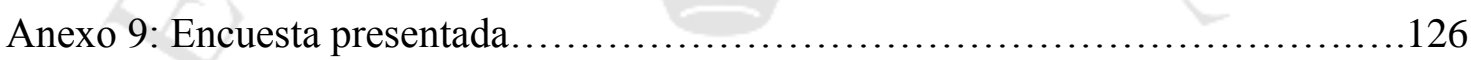




\section{INTRODUCCIÓN}

A principios del año 2017, un fenómeno denominado "Niño Costero" azotó la zona norte y centro del Perú. A diferencia del Fenómeno del Niño, que acaece a las costas del Pacífico cada verano con diferente intensidad, el Niño Costero es una eventualidad local (que afecta a Ecuador y Perú) que es ocasionada por el calentamiento inusual de las aguas costeras del Pacífico, y que desemboca, a causa del calentamiento de las aguas, en lluvias anómalas que, a su vez, bloquean el paso de vientos fríos y forman un proceso de retroalimentación (López, 2017). Así, las lluvias e inundaciones invadieron pueblos, cultivos, ciudades y demás, causando pérdidas materiales para más de 900 mil personas, además de carreteras, viviendas e instituciones públicas dañadas (Schmitt, 2017).

Tanto el Estado peruano como gobiernos regionales y provinciales prestaron ayuda humanitaria a los damnificados, al igual que numerosas ONG y equipos de voluntarios. Por parte del sector privado, se tomaron muchas medidas favorables, como el extender prórrogas crediticias para los empresarios afectados, o la redirección de acciones de las corporaciones en beneficio de estas poblaciones afectadas.

Es dentro de este contexto que se da origen a nuestro objeto de estudio. Como parte de las acciones de Responsabilidad Social de la empresa, LATAM Airlines planteó dar apoyo a sus clientes a través de beneficios en sus viajes. Éstos se vieron reflejados en tres comunicados (publicado el primero de ellos el 15 de marzo, y los dos siguientes el día 16 del mismo mes) emitidos en su página de Facebook, en los cuales mencionaban dichos beneficios, que incluían "excepciones comerciales a los pasajeros que no deseen viajar o prefieran cambiar de fecha (...) sin pagar penalidad", así como la reducción de las tarifas para quienes deseen adquirir pasajes, el coordinar ayuda voluntaria para Piura y poner a disposición dos vuelos humanitarios para el norte del país (información extraída de los comunicados, con link del primero en goo.gl/1Gxga1; el segundo en goo.gl/6y1Sri; y el tercero en goo.gl/TtYU0G).

Frente a esta comunicación, los usuarios de la página de Facebook de LATAM reaccionaron contestando que esta información era falsa, pues al comunicarse con la empresa para hacer uso de los beneficios que los comunicados pregonaban, aún tenían que pagar penalidades (Anexo 5: comentario 1C02 en su respuesta 014: “Acabo de 
llamar al call center para hacer el cambio de mi reserva ya que viajó el 20 de abril y me dicen que no aplica y q tengo q pagar la penalidad!!! [sic]) o adquirir boletos aéreos a precios normales o hasta con un costo mayor de lo normal (Anexo 5: comentario $1 \mathrm{C} 01$ en su respuesta 199: "Es mentira los precios por las nubes cambias de fecha y peor te cobran de todas maneras lo mismo q nada [sic]).

La pregunta que nos planteamos es ¿cuál fue la naturaleza de la crisis de comunicación online sufrida por Latam Airlines en su plataforma de Facebook durante la emergencia de lluvias de marzo de 2017? Esta pregunta reconocerá si se debió a una naturaleza social (exógena), a una naturaleza corporativa (endógena), o a una mezcla de ambas. Además, plantearemos identificar cuáles fueron los errores por los cuales esta comunicación resultó fallida, de tal manera que este conocimiento oriente futuros planes comunicativos online. 


\section{CAPÍTULO I: REDES, CRISIS Y USUARIOS}

\subsection{Las redes sociales y la reputación online}

Desde hace ya más de dos décadas, internet se ha vuelto una herramienta indispensable de nuestro proceso de socialización. A través de esta red, vamos aprehendiendo estímulos que ayudan a consolidar una imagen del entorno en el que vivimos, ya sea local, nacional, o a nivel global. Dentro de este contexto, las redes sociales van ocupando un lugar primigenio en la generación y obtención de contenido, convirtiéndose así en uno de los principales canales de acceso a este en toda la red (Pérez, Genaut, Meso, Mendiguren, Galdospín, Marauri, Iturregui, Rodríguez \& Rivero, 2013). Con usuarios de todo tipo meramente sumergidos en el mundo virtual al día de hoy, la figura del prosumer - entendido como aquel usuario crítico, bien informado y activo- ha devenido en la del produser - un usuario que no necesariamente es consciente de su producción pero que participa activamente en la creación de un entorno virtual(Bruns, 2009). Este nuevo tipo de usuarios son los que van a empezar a darle una nueva cara a las redes sociales e irán transformándola de acuerdo a sus intereses.

Es así, que las empresas han visto en esta transformación la oportunidad para crear un capital social que le genere beneficios de una u otra manera. Han identificado que, en la actualidad, las redes sociales se configuran más como una larga conversación entre partes que un largo índice de contenidos. Y el hecho de estar presentes en dicha conversación les puede otorgar beneficios en cuanto a capital social que no hubieran podido obtener sino introduciéndose en redes como Facebook o Twitter (Pérez et al., 2013).

De esta manera, vislumbramos el nacimiento de la reputación online (Vaquero, 2012) como combinación de las ideas de reputación corporativa y el mundo de las redes sociales. Entendida como "el reconocimiento del carácter de una corporación por parte de sus públicos" (Piazzo, 2012, p. 75), la reputación corporativa se hace campo en el mundo virtual y "humaniza" a la empresa a ojos del usuario. En este sentido, las empresas, a través de su gestor reputacional, inician un proceso de escucha de los usuarios, tomando en cuenta sus costumbres y hábitos, para así identificar sus expectativas para con la empresa con el fin de crear y consolidar relaciones entre estos y dar pie al capital social antes mencionado. Partiendo de que el usuario o 
cliente/consumidor más crítico, severo e incendiario en el mundo online que en el offline, es deber de las empresas alinear totalmente la gestión online de la empresa con los acontecimientos offline de la misma, para evitar rendimientos ausentes de planificación que desemboquen en una experiencia pobre para el usuario, y peor aún, en un deterioro de la reputación online de la empresa.

\subsection{La gestión de crisis}

Toda empresa está, en algún momento, expuesta a pasar por una situación de crisis de comunicación. Esta crisis se define como "un cambio repentino entre dos situaciones, cambio que pone en peligro la imagen y el equilibrio natural de una organización porque (...) se produce un acontecimiento súbito al cual una organización tiene que reaccionar comprometiendo su imagen y su equilibrio interno y externo ante sus públicos" (Piazzo, 2012, p. 83).

Es así, que la comunicación de crisis se encarga de gestionar la comunicación dentro de un contexto crítico determinado. En la actualidad, los medios digitales se han convertido en un nuevo escenario (el más álgido, a veces) de situaciones críticas para las empresas: es la facilidad con la que los contenidos se crean, comparten y proliferan lo que ayuda a la rápida extensión de las crisis online (Aced, 2013), definida como "el resultado de la mala gestión de las expectativas (...) cuya repercusión negativa es creada o amplificada dentro de internet” (Piazzo, 2012, pp. 96-97).

Se identifican 5 etapas por las que atraviesa un hecho susceptible de convertirse en crisis para la empresa (Enrique, 2013):

1. Tranquilidad: momento sin conflictos en las redes sociales.

2. Crítica moderada: etapa en la que se vislumbra un malestar debido al lanzamiento de un nuevo producto o a un mal servicio por parte de la empresa. Momento clave para poder actuar y recoger toda la información disponible (quejas, sugerencias, etc.) para así crear un plan de gestión de crisis para un futuro en la que la situación pase de moderada a crítica. 
3. Conflicto: cuando la crítica escapa de la plataforma en cuestión y pasa a reflejarse en otras (como blogs, sitios web, videos, etc.). ${ }^{1}$ En esta etapa, el gestor de crisis de la empresa implementará el plan de crisis y averiguará el origen del problema.

4. Crisis: si no se frena la situación en la fase de conflicto, puede llegar a constituirse en una crisis para la marca. Involucrará a altos directivos de la empresa y podría dañar la marca de la empresa.

5. Post crisis: momento que acaece cuando la crisis ya desapareció. Se debe tomar en cuenta todas las acciones efectuadas por la empresa y evaluar la viabilidad del plan efectuado para futuras crisis. La principal tarea es continuar emitiendo mensajes y contenido que reflejen la preocupación de la empresa en que dichos hechos no se vuelvan a repetir.

Así también, dentro de la cuarta etapa encontramos que las crisis, de acuerdo al grado de afección que producen, se clasifican en tres: la crisis silenciosa, que afecta a las empresas de perfil bajo en internet; la crisis "de la nota de prensa", que afecta a las empresas grandes con públicos participativos; y la crisis auto-infligida, que recae en el hecho de la ausencia de un plan de crisis por parte de la empresa (Martínez \& Durántez, 2011, pp. 431-432).

Dilucidado el panorama de las redes sociales y la gestión de crisis, podemos aseverar que tanto el accionar offline de las empresas como su desenvolvimiento online acaba reflejada en este último. Y es en este entorno en el que el usuario tiene el poder. Si a esto le sumamos las características de las redes sociales (como es el alto índice de participación y la velocidad de propagación de la información), nos damos cuenta de que es de vital importancia la atención que le deben dar las empresas a sus planes de comunicación implementados en sus perfiles de cada red social que manejan.

\subsection{Las redes sociales desde un punto de vista sociológico}

La comunicación en redes sociales siempre ha sido objeto de grandes interrogantes respecto al valor que tienen dentro de nuestra sociedad, y sobre el papel determinante que éstas desarrollan al momento de ser parte de la comunicación por parte de un

\footnotetext{
${ }^{1}$ Como medio de prevención, algunas empresas optan por cerrar muros, webs o canales de YouTube, pensando que de esta manera se frenará la expansión de la crisis, causando, en realidad, el efecto contrario.
} 
emisor. ¿Qué son las redes sociales? Carlos Lozares define las redes sociales desde un punto de vista sociológico como un grupo delimitado de participantes, que se vinculan entre sí por un conjunto de relaciones sociales que moldean su actuar dentro de la sociedad. A su vez, señala que el total de las características que presentan estos grupos "pueden ser usados para interpretar los comportamientos sociales de las personas implicadas" (1996, p. 108). En su estudio, identifica conceptos fundamentales para el análisis de las redes sociales, de los cuales mencionaremos 3 a continuación:

1. Los actores sociales, como "entidades sociales sujetos de los vínculos de las redes sociales".

2. Los lazos relacionales, que se conforma como la unidad de análisis de las redes sociales.

3. El contenido y la forma de las redes sociales, entendiendo al primero como la información y toda demás idea o manifestación de dicha red que transcurre a través de la misma gracias a las relaciones dadas por la interacción de los actores; mientras que el segundo concepto alude a lo usual entre los pares al momento de relacionarse entre sí, comprendido por modelos o estructuras "establecidas" por consenso social.

Ahora bien, Teun Van Dijk analiza las redes sociales desde un punto de vista discursivo. Concuerda en que, para haber un discurso, es necesario que miembros activos del grupo (actores sociales, para Lozares) se relacionen mediante sus acciones, estableciendo así un comportamiento "promedio". Estas relaciones vienen dadas por un "poder social", proveniente de la existencia de un actor o actores que ordenan el comportamiento dentro de una red social (Van Dijk, 2009, p. 154), así como también se constituye como la capacidad de un actor para poner su voluntad por encima de la de los demás actores (Castells, 2009, p. 74). Además, sostiene que los actores moldean su conducta mediante la convivencia con otros dentro de un mismo entorno de estímulos, y se van formando por imitación: es el contexto el que va moldeando la creación de un discurso. Es así, que no sólo se configura un contexto discursivo desde lo social, sino que se torna cognitivo al momento de involucrar un proceso mental de aprehensión (Van Dijk, 2009, pp. 154-155).

Por otro lado, partiendo de la definición de poder social, cabe mencionar a un término directo derivado. El poder de conectar en red, definido como el poder que 
tienen los actores de una red para llamar la atención, influenciar o adherir a no miembros de la red (Castells, 2009, pp. 72-73), es el poder que se co stituye como núcleo social (entendiendo sociedad como un conjunto de redes sociales), y que da la tarea a cada red social de captar más actores para erigirse como una fuerza particular, y ser la imperante sobre otras redes sociales.

Estas mismas vertientes son acompañadas por el construccionismo social de las redes sociales, que concibe a las relaciones de estos actores sociales como expresión de significados más que de conductas (Perilla \& Zapata, 2009). Se afirma que los sistemas relacionales se organizan en base a "las conversaciones que ocurren entre ellos y acerca de ellos", y son éstas conversaciones las que luego se convierten en significado, y pueden pasar a ser interpretadas por un tercero. Mientras que Lozares, Castells y Van Dijk apuestan por un enfoque que estudia más el fluido de relaciones y la génesis de la estructura de las redes sociales, el construccionismo nos muestra un lado más semántico en cuanto a las interacciones dentro de las mismas.

\subsection{Crisis y redes sociales}

Con la aparición de las redes sociales online, el análisis sociológico se volcó al mundo interactivo digital. Plataformas de comunicación directa, multilaterales y, sobre todo, en tiempo real, proliferaron desde inicios del presente siglo y rápidamente acapararon usuarios alrededor del mundo. Redes como Twitter, Facebook, Instagram o YouTube aprehendieron los modos de comportamiento real de los usuarios (antes explicados por la teoría sociológica de las redes sociales), cuyas relaciones fueron moldeándose en base a estas nuevas formas de interacción del mundo virtual. De una manera particular, Facebook se consolidó como la plataforma líder para la comunicación online a través de las redes sociales.

En el año 2010, Greenpeace acusó a Nestlé de utilizar un aceite natural proveniente de Indonesia para la elaboración de sus Kit Kat, cuyo proveedor, Sinar Mas, deforestaba los bosques de su país para su extracción, repercutiendo negativamente en la población de orangutanes. Esta noticia se difundió rápidamente por redes sociales e instó a los usuarios a boicotear a la marca hasta que dejara de trabajar con Sinar Mas. Nestlé negó toda acusación. Al ver que la crisis se hacía más grande, optó por tomar un plan de censura a todos los comentarios y acciones de usuarios: 
solicitaba a YouTube el bloqueo de videos que vayan en contra de la marca, y eliminaba comentarios y publicaciones negativas por parte de los usuarios en su muro de Facebook. Esta conducta evasiva de Nestlé aumentó el rechazo de los consumidores, que finalmente impulsaron a la marca al cese de sus relaciones con Sinar Mars y a aceptar la culpa del caso (Enrique, 2013).

Este fracaso frente a la crisis de debió a la omisión de los 4 pilares básicos de la comunicación en tiempos de crisis: el dar la cara, plantear una respuesta rápida, el no ser indiferente, y tomar en consideración al usuario (Bustamante, 2016). El primero de ellos aparece casi al mismo tiempo que la crisis. Es imperativo que la empresa de pronuncie respecto al hecho en el que se haya involucrada, aún la responsabilidad del mismo no recaiga sobre ella. Nestlé omitió este primer paso, no dio la cara y omitió toda comunicación acerca de su relación con el hecho en cuestión. Esto incitó a los usuarios a iniciar un bombardeo mediático.

En segundo lugar, al no contar Nestlé con un plan de crisis y no poder ofrecer una rápida respuesta, necesitó de tiempo para la elaboración de uno. Con este insuficiente y la crisis en aumento, mostró una posición de censura fruto de la improvisación, que eliminaba contenido de todas las redes sociales. A raíz de esto, y al no poder manifestar su malestar, la comunidad de usuarios optó por crear páginas alternativas y blogs para ello, como "Boycott Nestlé, "Can this orangutan get more fans than Nestle? (¿Puede este orangután tener más fans que Nestlé?)” o “Nestlé: 'killer”" (haciendo uso de un juego de palabras con 'killer' y Kit Kat) (Rodríguez, 2012). En tercer lugar, la marca se mostró indiferente frente al problema. No buscó otro proveedor, no planteó una investigación al respecto, ni mucho menos se manifestó en cuanto a este problema. Mantuvo su posición reacia hacia el mismo.

Por último, subestimó el poder de los consumidores al creer que siendo una marca grande y con recursos minimizaría el problema. Gainess-Ross señala que no se deben hacer demostraciones de fuerza en redes sociales, pues empeora la situación y que "la batalla por la reputación no siempre favorece al lado que tiene más recursos; por el contrario, tiende a responsabilizarlo con mayores obligaciones" (Bustamante, 2016, p. 8). 


\subsection{El origen de las crisis online: los clientes descontentos}

En estos tiempos digitales, frente a las situaciones desencadenantes de crisis casi siempre se hallan reclamos o denuncias de clientes (provenientes de alguna experiencia con algún producto o servicio) que se manifiestan en sitios web, blogs, o páginas oficiales de marcas en redes sociales.

Estas quejas públicas aparecen en diversas plataformas, casi diariamente y con diferentes finalidades: puede ser para hacer de conocimiento alguna falla en el funcionamiento del servicio o producto de la empresa en cuestión, para algún reclamo en la atención recibida, o para crear una mala imagen de la empresa gracias a una experiencia mala. Así, estas quejas individuales tienen la potestad de encender, avivar o aplacar una crisis, sea cual sea el objetivo del consumidor afectado (Argenti, 2014, pp. 526-528).

Pero cuando son los clientes insatisfechos los que ocasionan un quiebre en la empresa y dan pie a una crisis, generalmente se da por la denominada "desviación doble", y a un sentido de traición (Tripp \& Grégoire, 2012).

La desviación doble aparece cuando un cliente insatisfecho por una falla en algún producto o servicio (que no es ajena a la práctica empresarial) se ve también afectado y frustrado por una no atención a su problema o al intento fallido por parte de la empresa de solucionarlo, aun cuando el cliente pone su esfuerzo en tratar de solucionarlo. He aquí el doble desvío: primero, porque la empresa se ha desviado del ideal de producto o servicio que el cliente piensa que recibirá; y segundo, porque la atención de la empresa se ha desviado al momento de atender las necesidades y quejas que mantienen al cliente insatisfecho. La investigación de Tripp y Grégoire arrojó que las crisis devenidas de una queja pública casi siempre parten de una doble desviación del cliente insatisfecho.

Por otro lado, está también el elemento de la traición. No todas las desviaciones dobles son expuestas en el mundo online en forma de quejas: muchas se dejan pasar. La diferencia entre las que se manifiestan y las que no radica en la fidelidad del cliente hacia la empresa (pág. 45). Al sentir el cliente que la empresa se encuentra en la obligación de enmendar el error ocasionado por ellos mismos, el cliente insatisfecho se 
siente abandonado por la misma, razón por la cual vuelca sus esfuerzos en recurrir a todos los medios posibles para conseguir su cometido.

He aquí que en la presente investigación se plantean los pasos adecuados para la gestión y prevención de este tipo de crisis de comunicación online (Argenti, 2014, pp. 545-551), que atienden al problema per se, las acciones de la empresa, la comunicación con el entorno, y la prevención futura. El primero de ellos se basa en controlar la situación acaecida. Aquí, la principal tarea es delimitar el problema y su alcance, a la vez que recopilamos la mayor cantidad de información para su resolución. Es fundamental informar a los miembros de la organización lo que acontece, acción crucial que deberán desarrollar los ejecutivos de comunicación corporativa de la empresa.

Como segundo paso, se deberá poner en marcha el plan de acción de crisis planteado por el Departamento de Comunicación Corporativa. El vocero de la empresa será el responsable de, cuanto antes, comunicarse con el exterior y sus stakeholders. Es fundamental evitar mantenerse al margen de la situación y mantenerse silente frente a la crisis, ya que son los stakeholders los que, frente a este silencio, pueden llenar de información adversa aquellos vacíos que deja la empresa con su no manifestarse.

Asimismo, cabe comprender al entorno al que nos enfrentamos. Por un lado, los consumidores afectados deberán ser el principal blanco de las acciones a tomar por parte de la empresa. Esta deberá alinear a sus ejecutivos, voceros y empleados bajo una misma premisa para hacer frente a la situación. Así, cada miembro activo de la empresa sabrá qué información manejar y a quién ofrecerla en el entorno exterior. Por otro lado, es fundamental para la empresa el manejo de la comunicación hacia la sociedad, por lo que necesita de los medios de comunicación para hacer llegar su mensaje. Por ello, debe comprender que los medios viven en un entorno de constante competencia, cuya principal meta es obtener la primicia o la exclusiva del momento: se debe siempre tener una buena relación con la prensa, y saber actuar y proveerles del material que ellos más necesiten, pues de esta relación depende que los medios se parcialicen en contra o que puedan emitir información transparente.

Como último paso, hay que tomar en cuenta las prioridades de la empresa durante la post crisis. Primero, hay que velar por el bienestar del negocio al que se dedica la empresa: verificar si esta crisis afectó ventas, accionariado, campañas 
publicitarias, etc. Así, los encargados de todas las áreas involucradas a la crisis podrán realizar acciones para optimizar o enmendar la situación post crisis de esta área. Po último, el departamento de comunicación corporativa deberá plantear mejoras y nuevas acciones para evitar que otras crisis de similar envergadura o tipo vuelvan a afectar a la empresa.

\subsection{La teoría de las redes sociales}

Para el análisis del presente caso nos remitiremos a usar la teoría de las redes sociales. Basándose en una investigación de Wasserman y Faust, Carlos Lozares (1996) conceptualiza 6 ideas fundamentales dentro del estudio de las redes sociales:

1. Los actores sociales: entes sociales (pueden ser individuos, empresas, estados, etc.) condicionados por los vínculos de la red.

2. Los lazos relacionales: vínculos entre actores.

3. Díada: la relación existente que se da, de manera exclusiva, entre un par de actores sociales. Esta relación no existe cuando se habla independientemente de uno de esos actores.

4. Tríada: es el conjunto de relaciones existentes entre tres actores determinados.

5. Subgrupo: conjunto menor de actores sociales y las relaciones entre estos.

6. Grupo: sistema complejo con un número finito de actores sobre los que analizamos sus relaciones.

Ahora bien, para el análisis de la información que recorre a través de las redes sociales, profundizaremos más sobre los conceptos de forma y contenido, mencionado en párrafos anteriores (Lozares, 1996, pp. 109-110):

Por un lado, el contenido es la "sustancia relacional que 'fluye' a través de las unidades por medio de las relaciones que se dan entre ellas a partir del intercambio de dicho contenido". Implica, en la práctica, un determinado comportamiento entre dos actores sociales que es de gran importancia para el estudio de las redes pues, en tal binomio, la conducta que tome uno de los actores será construida en base a su relación con un segundo actor, no pudiendo ser replicada cuando uno de estos dos actores es sustituido por un tercero. Estas relaciones entre actores pueden ser de diversos tipos, y dependerán de varios factores, como el contexto en el que se dan (institucional o informal), su perennidad en el tiempo (permanente o pasajera), el estado de la relación (en proceso o consumada), su objeto (direccional o no), su nivel de arraigo (superficial 
o profunda) o la voluntad de los actores (consciente o inconsciente). (...) Asimismo, la forma en una red es la manifestación del cómo se dan las relaciones en esta. Usualmente se describe como un modelo en el que se basan las relaciones entre actores. La correcta identificación de estas dará pie a "la posibilidad que las redes tienen de modelizar las relaciones".

La premisa principal del análisis de las redes y su posterior teorización se opone a la idea de que atributos sociales individuales como la raza, edad, sexo y demás son la causa de los patrones de comportamiento y de la estructura social; poniendo de manifiesto que las características, formas de pensar y actitudes de los grupos se configuran en base a las situaciones y relaciones que existen entre los actores. Además, su importancia radica en que el estudio de las redes sociales permite conocer cómo la estructura social y sus relaciones afectan de manera determinante la conducta y actitudes de los individuos de un determinado grupo, o hasta al grupo en sí mismo. La unidad de análisis de esta teoría es, pues, tanto los grupos de individuos como los lazos que hay entre ellos, apoyado en el hecho de que la manera de relacionarse de estas partes son definidas mediante un número determinado -finito- de relaciones dentro en un mismo contexto (Cadenas, 2012, p. 209; Lozares, 1996, pp. 110-111; Sanz, 2003, p. 23)

Esta teoría tiene, a su vez, dos puntos de vista: la atomista y la relacional. La primera de ellas separa de las relaciones entre actores a los atributos de los sujetos, tales como ingresos, ocupación, inteligencia, y las mantiene como características intrínsecas. A su vez, sostiene que la sociedad (actores en conjunto), mas no las relaciones entre actores, se estructura en base a la tenencia de determinadas características, o de una combinación de varias de ellas. Por el contrario, la visión relacional observa a las relaciones de los actores como influenciadas por su contexto; alteradas, originadas o erradicadas en base a los mismos. Así, la figura del actor social es tomada en cuenta a partir de su propia interacción con otros actores de la misma red, o no es considerada si es que no está dentro de un contexto determinado (Lozares, 1996, pp. 112-113).

Es así, que la finalidad del presente estudio es comprender la naturaleza de la crisis de comunicación online sufrida por LATAM Airlines en su plataforma comunicacional de Facebook, además de determinar cuáles fueron los errores por los cuales esta comunicación resultó fallida. 


\section{CAPÍTULO II: METODOLOGÍA}

La presente investigación será de tipo explicativa y utilizará un enfoque cualitativo, pues pretende responder al origen de nuestro objeto de estudio, que se centrará en casos específicos, concretamente los tres comunicados antes expuestos, los cuales nos proporcionarán información de primera mano, para luego proceder a su análisis e interpretación. Nos enfocaremos en conocer las causas de este fenómeno, que es de tipo mercadológico tanto como empresarial, y en explicar las razones por las que se origina. Nuestro objeto de estudio se centrará en casos específivos, concretamente los tres comunicados antes expuestos, los cuales nos proporcionarán información de primera mano, para luego proceder a su análisis e interpretación.

Para ello, nos basaremos en el análisis de contenido, entendido como un conjunto de procedimientos cuyo fin es el análisis de la comunicación mediante procedimientos sistemáticos para describir contenidos derivados de los mensajes que fluyen dentro un determinado contexto (Bardin, 1996), como es la cuenta oficial de Facebook de la sucursal peruana de LATAM Airlines (https://www.facebook.com/LATAMPeru/), exactamente en estos tres comunicados emitidos y sus respectivas reacciones por parte de los usuarios: la primera publicación, subida a la red el 15 de marzo (goo.gl/1Gxga1); la segunda, del 16 de marzo (goo.gl/6y1Sri); y la tercera, también publicada el día 16 del mismo mes (goo.gl/TtYU0G).

Sabiendo esto, se ha seleccionado para la elaboración del muestreo la metodología utilizada por Lidia Valera Ordaz (2012) en un estudio sobre las interacciones en Facebook en los muros de tres candidatos presidenciales con miras a los procesos electorales nacionales de España en el año 2011. Utilizando una muestra total de 250 comentarios de los muros de Pérez Rubalcaba, Díez y Rajoy, extraídos dentro de las 24 horas del anuncio del grupo ETA de su cese al fuego, se recogió 15 comentarios en cada una de las 17 publicaciones que hicieron en total estos tres candidatos presidenciales. La razón de escoger 15 comentarios se debió, sobre todo, a dos factores: (1) a la viabilidad del estudio al haber comentarios con cientos de respuestas, y que luego de este número de comentarios, las respuestas tendían a desviarse del tema priorizado y empezaban a mencionar aspectos de otra índole, generando conversaciones sin límite que tornaban el análisis problemático para efectos 
de dicha investigación; (2) así como también al hecho de priorizar la diversidad de comentarios respecto de la verdadera reacción de los usuarios al conocer esta noticia (Valera, 2012).

Reconociendo similares características en los comentarios de nuestro objeto de estudio, y al ser solamente tres comunicados (y no 17 publicaciones), hemos decidido doblar la cantidad de comentarios para tener una mejor aproximación hacia el mismo, utilizando el criterio de relevancia de Facebook, el cual nos permitirá analizar los 30 comentarios más relevantes de cada comunicado. A su vez, contabilizaremos -como máximo- la misma cantidad de respuestas a cada comentario (puesto que de cada comentario puede devenir o no una larga conversación).

Por otro lado, para la respectiva clasificación de los contenidos utilizaremos dos criterios: para los mensajes vertidos por LATAM Airlines como respuesta a los comentarios de sus usuarios en Facebook utilizaremos la clasificación hecha por Jakobson (1975), que contiene 6 funciones de lenguaje bajo las cuales podemos colocar dichas respuestas (Amado \& Tarullo, 2015): la función expresiva, que prioriza la difusión del mensaje antes de tomar en cuenta la reacción de los usuarios; la función referencial, que hace hincapié en el contexto; la función poética, que toma en cuenta el mensaje per se; la función conativa, que entrega el protagonismo al destinatario y busca interacción; la función metalingüística, que busca conocer si tanto emisor y destinatario son comunes al código a emplear, para tener la certeza de que el intercambio de comunicación sea exitoso; y la función fática, cuyo fin prevé que el canal de comunicación sea viable para que ambas partes estén integradas en la comunicación.

Asimismo, para la clasificación de contenido vertido por los usuarios, propondremos utilizar los criterios dados por Valera Ordaz (2012, pp. 335-336), que incluyen (1) si el usuario que comenta es un usuario único o ha comentado ya en otra ocasión, (2) la calidad de la respuesta - nivel argumentativo- del usuario, que nos dará pie a afirmar si cabe la posibilidad de un diálogo alturado, (3) el hecho de que las interacciones contengan palabras soeces e insultos, o si están libres de estos, y (4) saber si el contenido del comentario está a la par con el tema en discusión o si se aleja del mismo y es usado para expresar solamente intereses propios.

Por último, emplearemos una encuesta a una muestra de 300 personas, la cual constará de 10 preguntas en las cuales abarcaremos, principalmente, temas como la 
imagen que tienen los consumidores sobre LATAM Airlines, el uso que se le da a los canales virtuales de comunicación de la empresa, y a la crisis vivida por esta aerolínea y su relación con su mercado de consumidores.

Para resolver las interrogantes planteadas al inicio del presente artículo, plantearemos la siguiente hipótesis: el fracaso de la comunicación se debió a una fallida alineación entre la plataforma de Facebook de Latam Airlines y el funcionamiento real de la empresa (naturaleza corporativa), según lo manifestado por los usuarios en las publicaciones. 


\section{CAPÍTULO III: LATAM Y EL IMPACTO DE LA CRISIS}

\subsection{La comunicación de LATAM Airlines}

Los mensajes de LATAM Airlines serán analizados en base a las seis funciones del lenguaje de Jakobson antes descritas. Para ello, separaremos el análisis de los comunicados del de las respuestas a los comentarios de los usuarios.

Realizado el análisis, notamos que los tres comunicados ponen especial énfasis en la función referencial. Esta función pone especial atención en el contenido, y pone de manifiesto que el principal objetivo de la comunicación es la difusión del mensaje en cuestión, por encima de la interacción con su contraparte. En el primer comunicado, publicado el día 16 de marzo de 2017 (Anexo 1), LATAM Airlines pone a disposición de sus usuarios beneficios para los que no deseen viajar por la emergencia ("Estamos brindando excepciones comerciales a los pasajeros que no deseen viajar o prefieran cambiar de fecha"), exenciones de penalidad ("sin pagar penalidad"), y reducción de tarifas de los destinos afectados del norte del país ("hemos reducido las tarifas a dichos destinos"). De igual manera, comunican que se solidarizan con los afectados ("Nos solidarizamos con nuestros compatriotas y estamos comprometidos [...]") y que llevarán apoyo a las zonas afectadas (“[...] llevar apoyo en coordinación con Piura en Acción"). Vemos entonces, que esta publicación tiene como objetivo dar a conocer las acciones por parte de la empresa respecto a la emergencia del norte del país, que incluyen beneficios hacia los pasajeros, así como ayuda humanitaria hacia los damnificados. Se configura como una comunicación unilateral, que deja de lado la interacción con el receptor

El segundo comunicado, emitido el mismo día, extiende el contenido del primero y le añade información (Anexo 2). Se ofrecen exenciones a más rutas ("además de los destinos del norte, seguimos manteniendo nuestras excepciones comerciales a las siguientes rutas") y se reitera que cambios de fecha o devoluciones de pasajes se podrán hacer sin costo alguno (“[...] podrán pedir la devolución o cambiar de fecha dentro del mes sin ningún pago adicional"). Al ser una continuación del mensaje anterior, mantiene el mismo objetivo: el hacer saber a sus clientes acerca de los beneficios y el 
accionar solidario de LATAM Airlines se constituye como el principal objetivo de comunicación. La finalidad es dar a conocer el mensaje per se.

El tercer y último comunicado analizado se emitió el día 17 del mismo mes (Anexo 3). El mensaje a transmitir tenía un diferente fin con respecto a las dos publicaciones anteriores: su objetivo era desmentir la información que destilaba a través de los comentarios y respuestas de los usuarios. Observados los dos primeros comunicados, los pasajeros de LATAM Airlines sostenían que los beneficios que ofrecía la empresa eran falsos o que tenían restricciones que fueron omitidas en los mismos. De esto se desprende una serie de críticas hacia la empresa, que ya vislumbraba el nacimiento de una crisis en Facebook. Para evitar esto, se publicó este tercer comunicado, que resaltaba la veracidad de la información vertida anteriormente ("mantenemos el compromiso de reducir las tarifas"; "rechazamos haber subido los precios”). Mencionaba, además, un nuevo beneficio para los pasajeros con vuelos con conexión en Lima ("para realizar un vuelo inter-ciudades, es necesario hacer conexión por Lima [...] hemos reducido también las tarifas de dichas conexiones"). La finalidad de este nuevo comunicado, al igual que los dos anteriores, es la aprehensión de esta información por parte de los usuarios, que desmiente lo mencionado por estos tanto en el muro de la empresa como en los comentarios y respuestas de los anteriores comunicados.

Ahora bien, analizando la totalidad de las intervenciones de LATAM Airlines en las respuestas a comentarios de sus tres comuniados, podemos ver que las funciones más utilizadas por la empresa son la fática, referencial y conativa.

Partiremos diciendo que la función fática se manifiesta $a b$ initio desde la interacción de LATAM Airlines con sus usuarios en los tres comunicados. Amado y Tarullo (2015, p. 105) definieron a esta función, entre otros detalles, como "todos aquellos recursos que ratifican que el canal funciona y permite mantener la interacción". Es así, que las respuestas de la empresa a los comentarios, las contestaciones por inbox, y las derivaciones al call center y al correo electrónico (al margen de que estas dos plataformas funcionaran idóneamente o no) no hacen sino reconfirmar que la plataforma de Facebook funciona de una manera correcta, tanto para usuarios como para la empresa, cuando el objetivo es una comunicación rápida, directa 
y bidireccional (Anexo 5: respuesta 004 del comentario 1C25: "Tuvo una respuesta rápida por parte de lan. Los cambios de destino deben pagar la diferencia”).

En cuanto a la función referencial, se pone énfasis -sobre todo- en las condiciones de los pasajes comprados (Anexo 5: comentario 1C02, en su respuesta 007: "Beatriz, las devoluciones serán realizadas de acuerdo a la tarifa que adquiriste y en este caso no te permite devoluciones, si deseas acogerte a las opciones mencionadas, escribenos. Quedamos atentos"). En este tipo de respuestas, la empresa menciona implícitamente que solo se podrá endosar, postergar o cancelar los pasajes (supuestos beneficios mencionados en los comunicados) basándose en los términos por los que fue adquirido: los beneficios ofrecidos son nulos, pues son los mismos beneficios en un tiempo sin emergencia alguna. Asimismo, también esta función se manifiesta en las respuestas de LATAM Airlines al momento de "cerrar" una conversación, mencionando las respuestas de la empresa vía inbox (Anexo 7: comentario 3C14 en su respuesta 003: "Hola Daniela, hemos respondido a tu consulta por inbox. Puedes revisar la información que te enviamos. Saludos.”).

Por otro lado, la función conativa, la que está presente en la mayoría de comentarios, consta, casi en su totalidad, de solicitudes de datos e información a los pasajeros (Anexo 7: comentario 3C21 y su respuesta 001: "Hola Ysa, envíanos por Inbox el o los códigos de reserva para entregarte mayor información. Quedamos atentos). Este tipo de respuestas de LATAM Airlines incluyen -necesariamente- verbos en modo imperativo, lo que las diferencia de otro tipo de respuestas en las que se manifiestan otras funciones. Verbos como "envíanos", "escríbenos" o "revisa" instan a la acción al receptor de las respuestas, y se prioriza la interacción.

\subsection{La respuesta de los usuarios ante la crisis}

En cuanto a las respuestas de los usuarios de Facebook, en base a los criterios expuestos en la metodología antes descrita, podemos darnos cuenta de que, según la calidad de las respuestas, podemos dividir a los usuarios en tres grupos: los usuarios del diálogo, los usuarios frustrados, y los xenófobos. Los primeros son los que participan de la conversación empleando un lenguaje formal y con calificativos positivos (aproximadamente el $31 \%$ del total de usuarios). Utilizan la plataforma para una comunicación con la empresa, dirigida a absolver dudas respecto al contenido de la 
publicación o a sobre la aplicación de los comunicados a sus casos (Anexo 5: comentario 1C11: "Buenos Días yoo tengo pasajes comprados para el día 01 de abril LIMA - PUCALLPA y quisiera cambiarlos de fecha porfavor espero una respuesta [sic]").

Por otro lado, los usuarios frustrados (casi el 55\%) son los que presentaban demandas y quejas respecto del contenido de los comunicados, ya sea porque el mismo no se cumplía en su caso (Anexo 6: comentario 2C16: "Señores LATAM, que les está sucediendo que NO cumplen su palabra y las respuestas que envían contradicen las afirmaciones establecidas por ustedes mismos! [...] Cumplan su palabra y háganse respetar como una empresa seria.") o porque la respuesta de la empresa no satisfacía su pedido o se mostraba muy vaga (Anexo 6: respuesta 005 al comentario 2C17: “Gracias por su respuesta, sin embargo no me han dado claridad sobre el tema [...]"). Aquí, se dejó en evidencia el hecho de que LATAM Airlines omitió cierta información en sus comunicados: si bien mostró información "que quería que fuese aprehendida", no comunicó las muchas restricciones e impedimentos que tenían los usuarios al momento de hacer válido el apoyo ofrecido por LATAM Airlines (Anexo 1: comentario 1C10: "Sres LATAM Airlines acabo de llamar para modificar mi vuelo que sale el 25 de marzo a Talara para otro mes pero me dicen que ese aviso sólo aplica para vuelos con salida hasta el 17 marzo. [...] Pongan la información completa").

Por último, tenemos a los usuarios xenófobos (14\% del total de usuarios), que no participaban de la conversación con el fin de satisfacer dudas o presentar demandas, sino que se alimentaban de los comentarios frustrados para soltar insultos (Anexo 6: comentario 2C01 con respuesta 022: "Son unos hijos de puta malnacidos [...]"), comentarios xenófobos (Anexo 7: comentario 3C07 en su respuesta 006: "Estos chilenos culo roto hacen lo q [sic] quieren en nuestro país \#fueradelperulatam”), y hasta promover actos en contra de LATAM Airlines y también a otras empresas chilenas o peruanas (respuesta 016 del comentario 3C08, que consta de un afiche conde se incita al saqueo de los supermercados Tottus, Metro y Plaza Vea).

Respecto del léxico usado para los comentarios, si bien no podríamos sostener que todos los comentarios negativos contienen palabras soeces, sí podemos aseverar que los comentarios negativos en su totalidad contienen adjetivos peyorativos hacia la empresa por parte de los usuarios (Anexo 5: comentario 1C14: "Son unos estafadores!!! 
[...]"). Ya sea con amenazas a nivel legal-civil, migración a otras empresas, la evidencia de la ocultación de información, o -vale decirlo- insultos, se pone de manifiesto el descontento de los usuarios respecto de la comunicación de LATAM Airlines durante el contexto presentado.

Asimismo, podemos reconocer a dos tipos de comentarios: los que tienen que ver con el contenido expuesto en los comunicados, y los que no. De los primeros (alrededor del $61 \%$ del total de comentarios y respuestas) podemos decir, al margen de que sea un comentario positivo o negativo, que son los comentarios que buscan ayuda en solucionar su situación respecto a lo dicho en los comunicados (Anexo 6: comentario 2C07: “[...] cómo hago para poder coordinar la devolución o reprogramación?”), así como también están los comentarios que ponen de manifiesto el malestar de los usuarios respecto a los problemas que pudieron haber tenido al momento de aplicar a los beneficios ofrecidos (Anexo 7: comentario 3C01: "Señores, llame a su call center y me indican que no se puede cancelar y realizar la devolución de mi dinero [...]"). En cuanto al segundo grupo (alrededor del 39\%), que no tenía que ver con los comunicados en cuestión, estaba conformado por comentarios que aparecían esporádicamente haciendo consultas sobre otros ítems no mencionados en los comunicados (Anexo 6: comentario 2C04 con respuesta 004: "Hola! Yo tengo pasajes para viajar el 10 de abril a Piura, pero la situación está cada vez peor [...] Como puedo hacer?"), además de los insultos y comentarios xenófobos que escapaban totalmente del tema en cuestión y eran recursos para expresar emociones personales de cada usuario (Anexo 7: comentario 3C19: "No viajen en esta Aerolínea [...]") o, simplemente, para alimentar la creciente aversión hacia esta empresa extranjera (Anexo 7: comentario 3C10 y su respuesta 003: “Que asco \#FueradelPeruLATAM”).

\subsection{El impacto de la crisis y la repercusión en la imagen}

Analizando la encuesta realizada a 300 individuos, obtuvimos los siguientes resultados que mostraremos a continuación:

Respecto a la imagen que tenían los consumidores sobre LATAM Airlines, el $40 \%$ de encuestados respondió que manejaban una imagen regular. En cuanto al uso de canales de comunicación virtual, un $45 \%$ señala que no los ha usado, mientras que un $31 \%$ sí los ha usado, pero no satisfacen todas las necesidades e inquietudes de los 
usuarios. Por otro lado, al preguntar si estos canales de comunicación eran necesarios para la imagen de la empresa, la mayoría respondió que sí lo eran (64\%).

Figura 4.1

Percepción de la imagen de los consumidores sobre LATAM Airlines (\%)

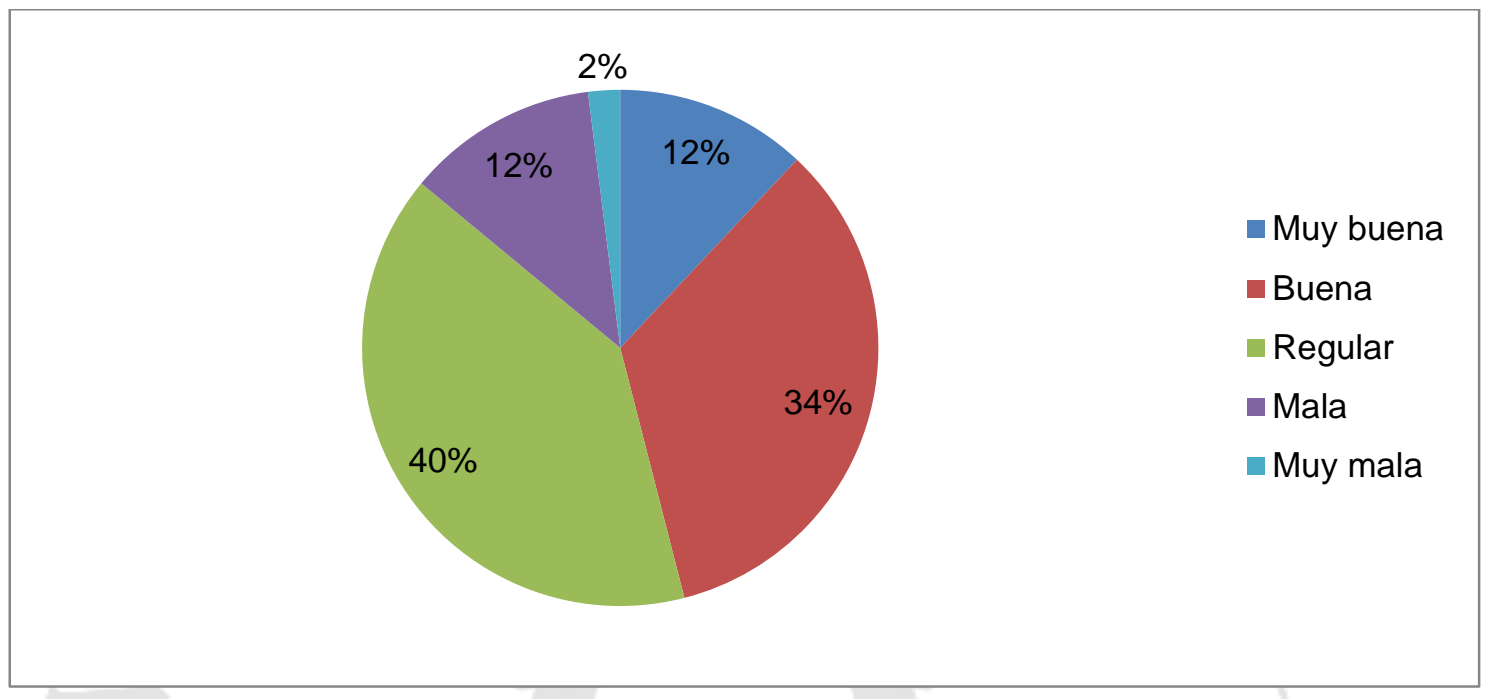

Nota: Total de encuestados (300).

Fuente: Elaboración propia. Encuesta realizada a usuarios deinternet del 9 de abril al 1 de mayo de 2018.

Figura 4.2

Uso de canales de comunicación virtual y su nivel de satisfacción (\%)

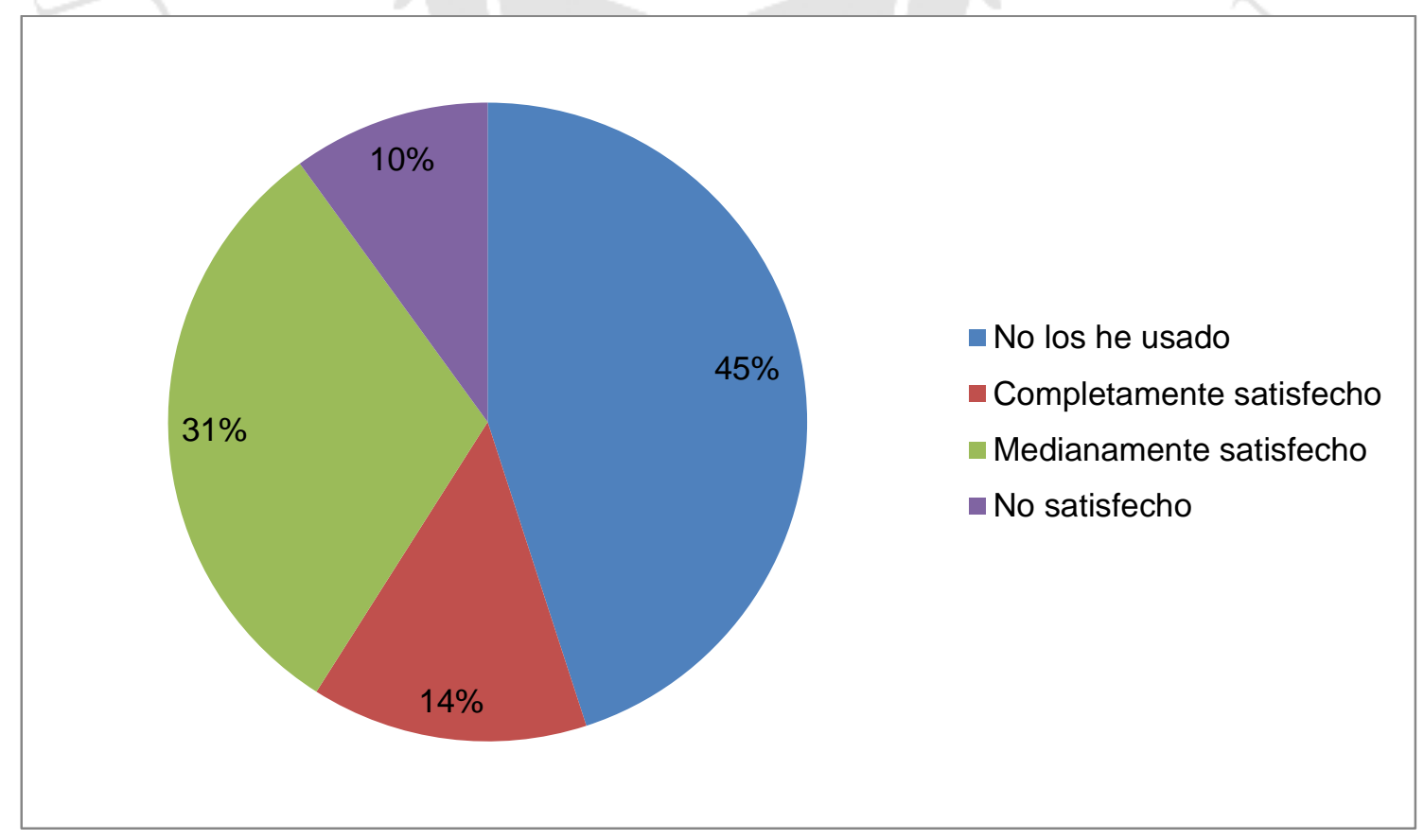

Nota: Total de encuestados (300).

Fuente: Elaboración propia. Encuesta realizada a usuarios deinternet del 9 de abril al 1 de mayo de 2018. 
Figura 4.3

Importancia de los canales de comunicación (\%).

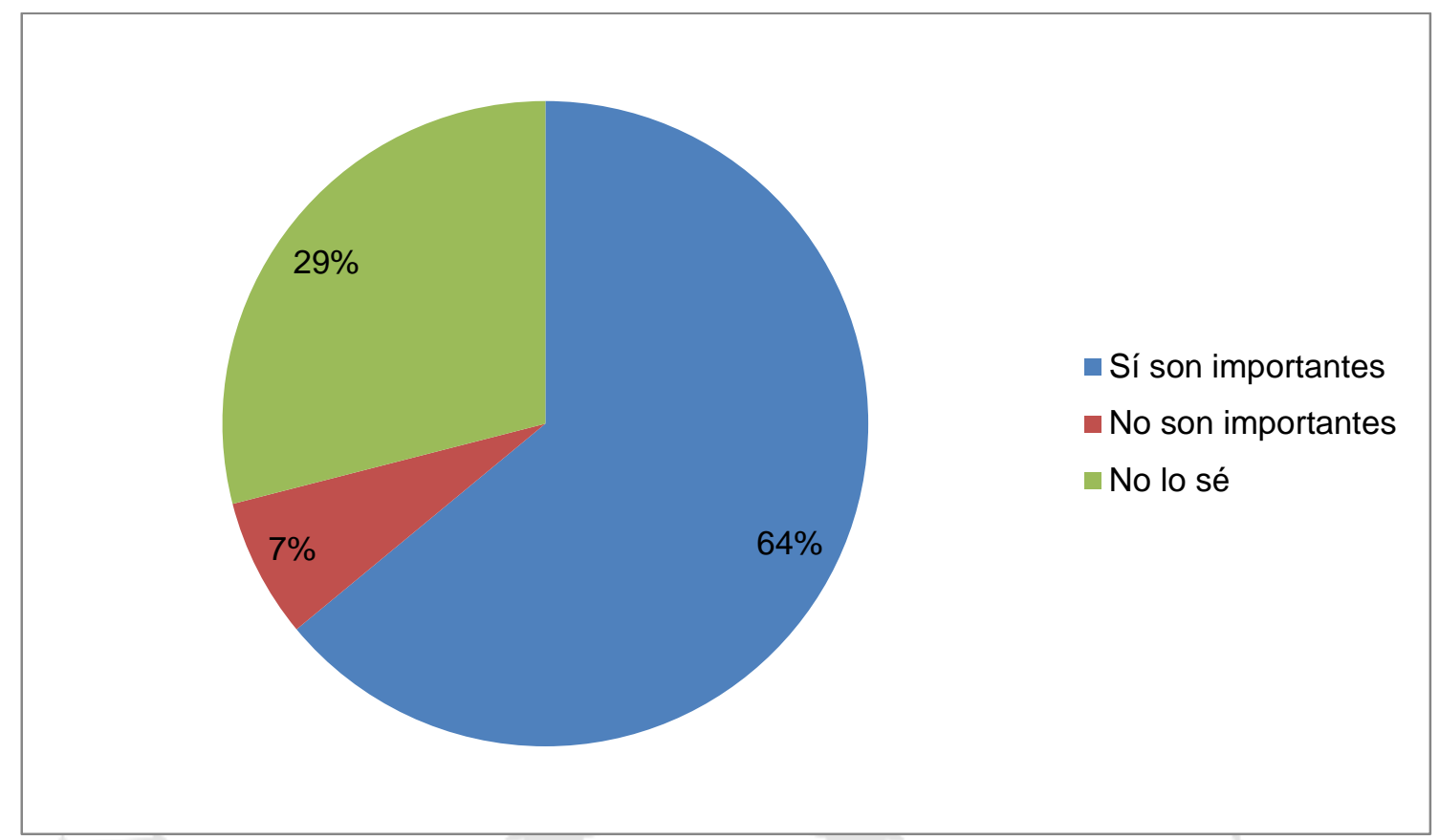

Nota: Total de encuestados (300).

Fuente: Elaboración propia. Encuesta realizada a usuarios deinternet del 9 de abril al 1 de mayo de 2018.

Al preguntar sobre el conocimiento de la crisis de marzo de 2017, quienes no se enteraron representan el $45 \%$ de la muestra. Sobre las razones del origen de la crisis (una pregunta con respuesta múltiple), la mayoría de encuestados sostenía que se debió a una falla en la comunicación entre la empresa y sus gestores virtuales (67\%), y que debido a eso hubo información faltante o errónea en los comunicados vertidos por LATAM. Respecto a la afección de la crisis sobre la imagen de LATAM, se obtuvo un resultado parejo en cuanto a las opiniones vertidas. Un $18 \%$ de la muestra aseveraba que no afectó esta crisis a la imagen de LATAM. Dentro de los que pensaron que sí lo hizo, la afección mínima representa el 16\%, la afección en poca magnitud lo hizo en $25 \%$ y la afección media, en $22 \%$. En cuanto a los que respondieron que la crisis afectó significativamente a la empresa, un $17 \%$ respondió que fue en gran magnitud, mientras que el 2\% restante sostuvo que afectó en extremo a la imagen de la empresa. 
Figura 4.4

Conocimiento sobre la crisis de lluvias de marzo de 2017 (\%).

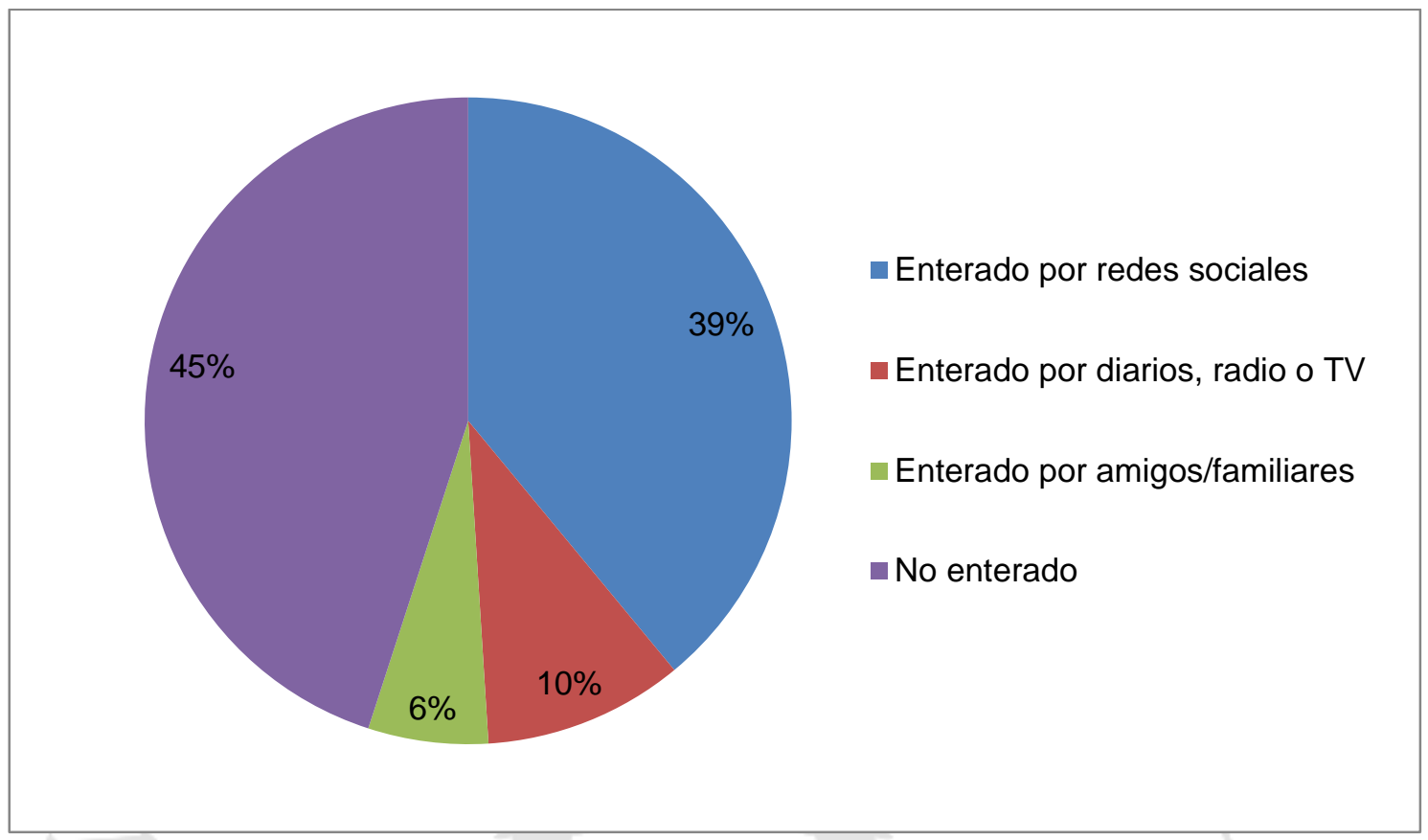

Nota: Total de encuestados (300).

Fuente: Elaboración propia. Encuesta realizada a usuarios deinternet del 9 de abril al 1 de mayo de 2018.

Figura 4.5

Factores de origen de la crisis (\%).

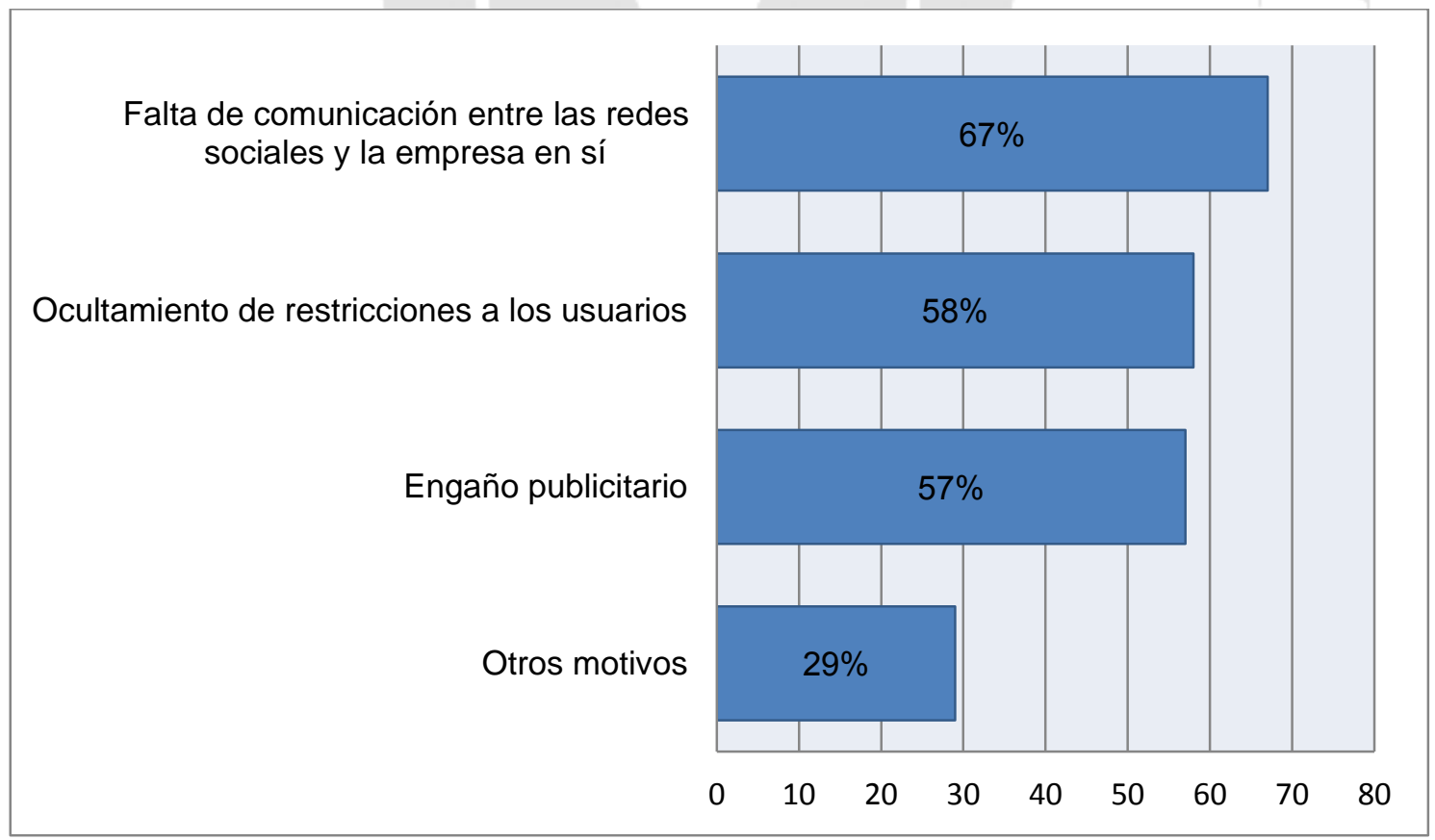

Nota: Total de encuestados (300).

Fuente: Elaboración propia. Encuesta realizada a usuarios deinternet del 9 de abril al 1 de mayo de 2018. 
Figura 4.6

Percepción de la afección de la crisis sobre LATAM Airlines (\%).

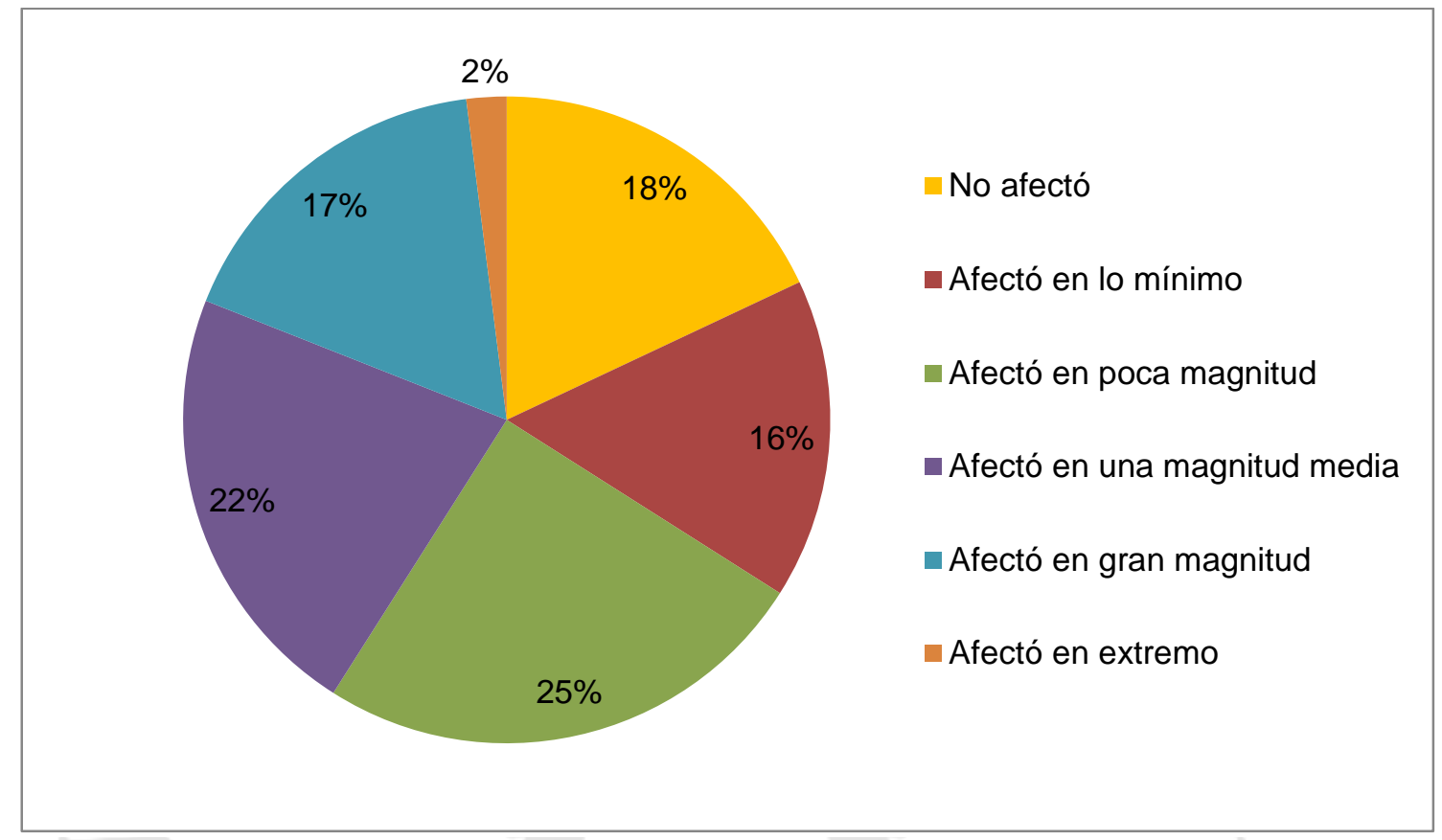

Nota: Total de encuestados (300).

Fuente: Elaboración propia. Encuesta realizada a usuarios deinternet del 9 de abril al 1 de mayo de 2018.

Al preguntar si la percepción sobre la imagen había cambiado, el 54\% de encuestados respondió que no. En la segunda pregunta de respuesta múltiple de la encuesta, sobre los motivos por los cuales los encuestados volverían a viajar en LATAM, las respuestas más atendidas fueron Precios Accesibles (64\%), Canje con Millas (59\%) y Cobertura de Destinos (56\%). 
Figura 4.7

Cambio de la percepción de la imagen de LATAM en los usuarios luego del conocimiento de la crisis $(\%)$.

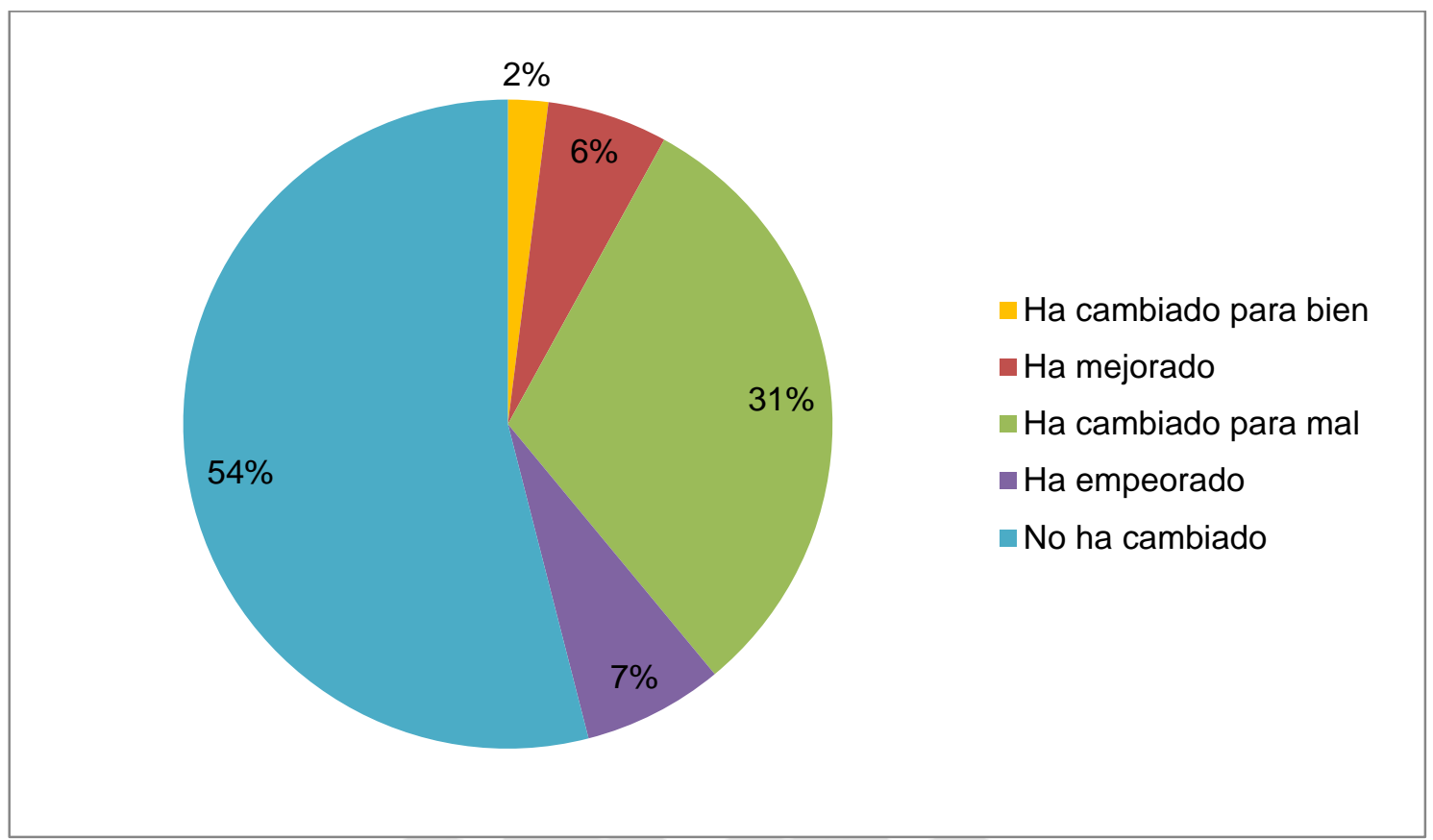

Nota: Total de encuestados (300).

Fuente: Elaboración propia. Encuesta realizada a usuarios deinternet del 9 de abril al 1 de mayo de 2018.

Figura 4.8

Razones por las cuales los usuarios volverían a viajar con LATAM Airlines (\%).

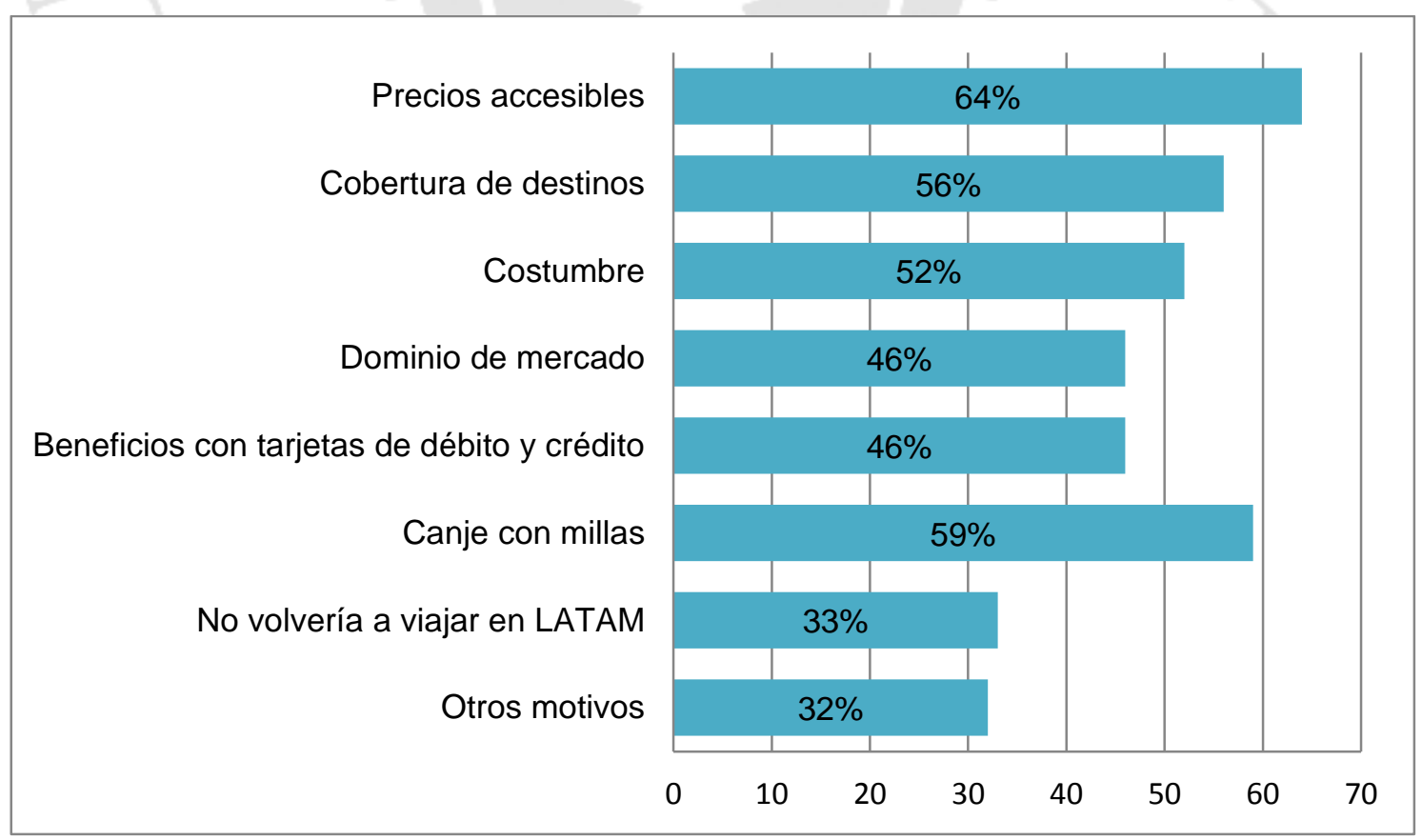

Nota: Total de encuestados (300).

Fuente: Elaboración propia. Encuesta realizada a usuarios deinternet del 9 de abril al 1 de mayo de 2018. 
Sobre si fue un fenómeno aislado, la mayoría aseveró que no era la primera vez que conocía sobre alguna crisis de LATAM Airlines (60,6\%). Sólo un 9,1\% señaló que era la primera vez que lo hacía. El resto de la muestra no supo responder. Cabe resaltar, que del total de encuestados, solamente un $3 \%$ fue afectado directamente por la crisis de LATAM Airlines.

Figura 4.9

Percepción sobre si la crisis fue un hecho aislado (\%).

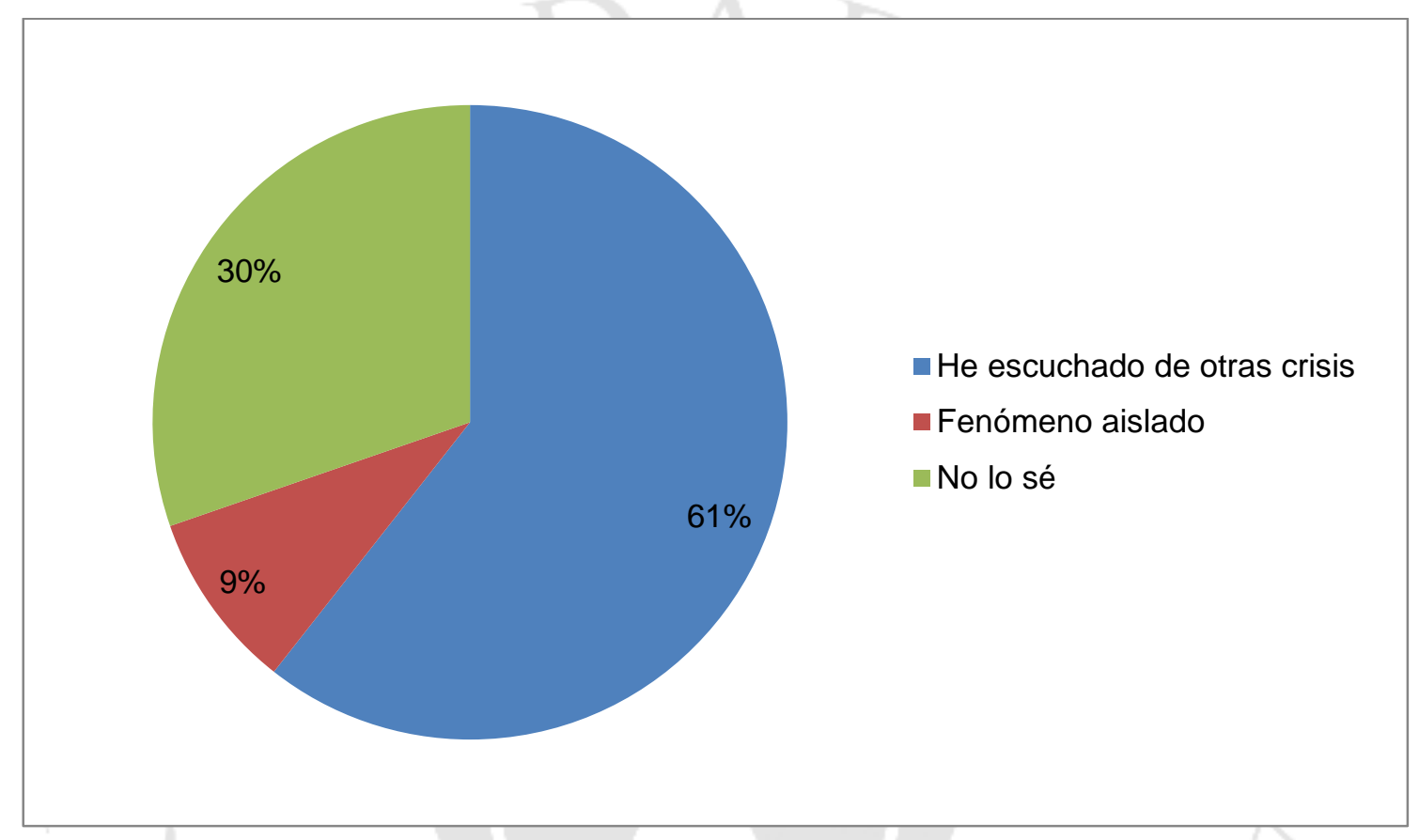

Nota: Total de encuestados (300).

Fuente: Elaboración propia. Encuesta realizada a usuarios deinternet del 9 de abril al 1 de mayo de 2018.

Al analizar estas cifras, nos damos cuenta de que la empresa, a ojos de los consumidores, no tiene problemas de imagen. Mas son estos consumidores los que consideran que una comunicación virtual idónea es vital para la salud de la empresa. Y es aquí donde LATAM comete un primer error: tanto el no estimular el uso de sus canales virtuales, como implementarlos para que den un servicio que no satisface las necesidades de los usuarios crea un vacío de confianza en el consumidor. Si aunado a esto, vemos que los propios consumidores creen que el origen de la crisis fue la no alineación entre las redes sociales y la empresa en sí, se crea un clima de desconfianza frente a las manifestaciones virtuales que la empresa muestra en su entorno. 
Asimismo, la mayoría de individuos encuestados asegura que esta crisis sí afectó (en mayor o menor medida) a la imagen de LATAM Airlines, más la propia imagen que tenía cada individuo no necesariamente cambió. Además, la razón más fuerte por la que los usuarios volverían a utilizar el servicio de LATAM es por sus precios asequibles, por sobre otros motivos. Así, nos damos cuenta que la empresa no es una empresa con una buena imagen en cuanto a comunicación online se refiere, y que los consumidores no piensan en la marca al momento de utilizar su servicio, sino precios asequibles y beneficios puntuales, lo que también podría ofrecer cualquier otra aerolínea. Vemos, entonces, que LATAM Airlines es una empresa con una marca débil en el mundo online. 


\section{CAPÍTULO IV: DISCUSIÓN Y ANÁLISIS}

¿Cuál fue la naturaleza de la crisis de comunicación online sufrida por LATAM Airlines en su plataforma de Facebook durante la emergencia de lluvias de marzo de 2017? Podríamos decir que, luego de analizar tanto las intervenciones de la empresa como de sus usuarios, la naturaleza de la presente crisis de debió tanto a factores externos (sociales) como a factores internos (intraempresarial).

En cuanto al factor externo, el no tomar en cuenta la percepción discriminatoria de los usuarios peruanos de Facebook hacia empresas foráneas, aunado a la “embriaguez” de Todorov (2013), causada por la sensibilidad de la población frente al tema de la emergencia de lluvias, crearon un ambiente hostil para el buen desarrollo de la comunicación por parte de LATAM Airlines en esta plataforma. La xenofobia manifestada por los usuarios nos dice que, al momento de plantear una estrategia, tática o-simplemente- una acción comunicativa en redes sociales virtuales, se debe conocer las características de su público receptor, tanto las positivas como las negativas, para (1) plantear medidas de comunicación en base a ellas, y (2) para reducir óptimamente el riesgo de crisis en cuanto al retorno de los mensajes.

Por otro lado, también se debió a factores internos por tres razones. Primero, porque la empresa, a su interior, no se encontraba alineada: tan solo la plataforma de Facebook manejaba los beneficios y exenciones frente a la situación dada (y manifestada en los comunicados); mas las áreas de e-mailing y central telefónica no se encontraban alineadas a la propuesta comunicacional vertida por esta primera plataforma.

La segunda razón comprende la omisión de mensajes y respuestas por parte de la empresa. Si bien se respondían numerosos comentarios, la omisión de la mayoría alimentaba el rechazo hacia la empresa y la etiquetaba como una corporación que no quería resolver el problema de sus propios clientes. Además, respecto a las respuestas a comentarios, muchas de estas eran escuetas y se podrían confundir con una respuesta "de cierre" frente a las conversaciones entabladas entre usuarios y empresa: esto es, que implícitamente cerraban la conversación en detrimento de un mayor abordamiento en las soluciones frente a los problemas que aparecían. 
Finalmente, la tercera razón que arrojó el presente estudio es la "no mención" de condiciones y restricciones por parte de LATAM Airlines. Estas condiciones (que fueron apareciendo en la conversación de los comunicados gracias a la exposición de la problemática que sufrían los usuarios) significaban límites de calendario para reprogramar/reembolsar/endosar viajes hacia los destinos afectados. Incluía también políticas restrictivas para acogerse a los beneficios mostrados, como solamente otorgarlos a pasajeros que hayan comprado boletos aéreos que, al margen de la existencia de emergencia en el norte del país, el aspecto contractual del mismo permitía cambios sin penalidades. Es decir: un boleto aéreo estándar, cuyos términos contractuales per se no permitían endose, postergaciones ni reembolso sin penalidades, no podría acogerse a los beneficios mostrados. Por otro lado, los boletos aéreos más costosos, que daban ventajas a sus clientes al margen de ninguna emergencia, podrían hacerlo sin ningún problema, gracias a los beneficios que incluía la compra de estos boletos.

En cuanto al estado del arte, Teun Van Dijk propuso que, dentro de las redes sociales, los actores moldeaban sus relaciones mediante la convivencia en un mismo entorno. Si bien los usuarios del presente caso han vivido en el entorno cultural peruano y han aprehendido sus valores, historia y demás, y han visto condicionadas sus relaciones gracias a estas; no se termina de aplicar este modelo a las redes sociales online, ya que no hay un "poder social" que ordene el comportamiento de los demás en base al propio (2009, p. 154), así como también se da la ausencia de actores que superpongan su voluntad por sobre el resto de participantes, para así condicionar su conducta (Castells, 2009). En esta crisis, todos los comentaristas han mantenido una jerarquía completamente horizontal, sin atropellar voluntades ni autoimponiendo las propias.

Por otro lado, el poder de conectar en red formulado por Castells (2009, pp. 7273) no puede ser aplicado en su integridad en este estudio. Por un lado, no podemos involucrarlo completamente en el presente estudio pues se da la ausencia de actores que superpongan su voluntad por sobre el resto de participantes, así como determinados actores que, voluntariamente, convoquen otros a esta red: ya sea que esta red se entienda como Facebook o como la red de seguidores de LATAM Airlines, ningún usuario analizado puso de manifiesto este mencionado poder de atracción hacia este 
determinado "ecosistema de relaciones". Esta definición de poder de conectar en red podríamos dejárselo, en todo caso, a los influencers que imperan hoy en día en internet, que son capaces de movilizar masas de usuarios (voluntaria o involuntariamente) para determinados fines. Aun así, este poder no está del todo ausente en este caso, pues podemos hablar de una nueva forma de poder: el de reconectar en red. Este poder lo observamos en la capacidad indirecta en involuntaria de seguir alimentando los comentarios en las publicaciones estudiadas. Si bien ningún usuario tiene $-\mathrm{O}$ no ha puesto de manifiesto- la capacidad para hacer que no conectados se aúnen a la red, sí han tenido capacidad para convocar a seguidores que ya se encontraban en la red pero que no participaban de la discusión con LATAM Airlines, ya sea mostrando su comentario o respuesta en el muro de Inicio de sus amigos o, gracias a tal participación, “destacando" la publicación dentro del muro de LATAM.

Dados los resultados, podríamos decir, respecto de la teoría de las redes sociales (Lozares, 1996) de nuestro marco teórico, que, en primer lugar, las figuras de los actores sociales corresponden tanto a LATAM Airlines como a los usuarios de Facebook que interactúan con esta empresa, mediante su Fan Page en dicha plataforma, ya que ambos tienen vínculos por la red en la que interactúan.

En segundo lugar, los lazos relacionales se configuran en la relación existente entre la empresa y los usuarios, y que esta puede entenderse como una relación de seguimiento formal o fidelidad comercial (cliente recurrente de esta empresa), seguimiento simple por parte del usuario (que se traduce en un like para la página, al margen de que el usuario sea un activo prosumer del Fan Page) o de convivencia (la coexistencia de ambos, tanto Fan Page como usuario, pero sin que estos últimos sigan o interactúen con la empresa en Facebook).

Por otro lado, la díada existente en esa relación se da entre LATAM Airlines y los seguidores que comentan en las publicaciones del presente objeto de estudio. En este caso no se presenta ninguna tríada, al no haber un tercer actor involucrado.

Finalmente, los usuarios per se se configuran como un subgrupo dentro de un grupo mayor, que es el de las personas que tienen una cuenta en Facebook, y este grupo mayor del que se desprende el subgrupo antes mencionado sería el de personas que gozan de acceso a internet y hacen uso del mismo. 


\section{CONCLUSIONES}

Luego de realizar la investigación, e indagar sobre los diversos aspectos abarcados en la misma, hemos llegado a las siguientes conclusiones:

- El origen de la crisis se debió a factores intraempresariales, que incluyen un mal manejo de crisis de comunicación online, falta de utilidad de los canales virtuales de comunicación con sus usuarios, y nula capacidad para gestionar planes de contingencia a futuro.

- El origen de la presente crisis se dio gracias a la "desviación doble" de Argenti. Primero, LATAM Airlines, al mostrar una aparente descoordinación entre el area logística y la de gestión virtual. La segunda desviación corresponde al nulo esfuerzo por parte de LATAM Airlines de resolver aquellos problemas generados por sí misma.

- Concluimos que la omisión de respuestas que resuelvan los problemas acaecidos por los usuarios, así como intervenciones monótonas e iguales para cada uno de las situaciones sin ningún trato específico llevaron a la exacerbación de los usuarios que, al ver una inacción por parte de la empresa para enmendar el error que esta misma produjo, volcaron su molestia y formaron una "vitrina" para el resto de usuarios descontentos. Esta vitrina fue la que funcionó como panel de denuncias para los usuarios descontentos, iniciando y alimentando la crisis.

- La imagen de LATAM Airlines ya se encuentra desgastada por sí misma, y crisis como la estudiada no empeorará la situación. Estos errores de la empresa tan solo representan un número más dentro de los que ya lleva consigo.

- Casos como el presente son manifestación de una reiterada falta de interés en la solución de los problemas para con sus clientes. LATAM Airlines, al eregirse como la empresa con mayor participación de mercado en el Perú con casi $60 \%$ del mercado (Diario Gestión, 2018), y al no vislumbrar rival alguno en el mercado aéreo, aleja de sus objetivos prioritarios la comunicación con sus clientes y el bienestar de la relación empresa-consumidor. La constante repetición en los comentarios de los comunicados de LATAM Airlines sobre quejas y problemas anteriores acaecidos por los usuarios dan fe de ello. 
- Para mejorar el aspecto de la comunicación entre la empresa y sus clientes, urge un cambio de protocolos en el proceso de comunicación y en manejo de crisis por parte de LATAM Airlines. El actual plan de manejo de crisis de la empresa (o defectuoso, o inexistente) no hace frente a los problemas que nacen de la interacción entre la empresa y sus clientes en el mundo online. La constante postergación de su mejora influirá de manera negativa al hacer frente a las crisis derivadas del mundo online.

- Los usuarios de LATAM Airlines no valoran ningún aspecto intrínseco de la marca, como la historia, identidad o servicio: tan solo le otorgan valor a aspectos efímeros, temporales, o que cualquier otra empresa pueda tener en cualquier otro momento o situación, como ofertas y precios bajos, beneficios con tarjeta de crédito/débito, canje con millas, etc. 


\section{LIMITACIONES DE LA INVESTIGACIÓN}

A continuación detallaremos las limitaciones de la investigación y recomendaciones:

- La presente investigación tiene como campo de estudio exclusivo el desenvolvimiento de interacciones solo en la plataforma de Facebook: las características de esta red social (tales como la perennidad de las publicaciones, la capacidad de una fácil ubicación de estas dentro del resto de contenido de una misma página, o el hecho de que el comentario de un amigo presente la publicación en el muro de Inicio de uno) son irreplicables en plataformas como Instagram, Twitter, YouTube y demás. Asimismo, el análisis no toma en cuenta la participación de otros medios de comunicación masivos como son la radio, televisión, prensa escrita y otros. Una investigación futura sobre crisis en medios masivos tradicionales ayudará a comprender aún más la conducta de los consumidores frente a determinados escenarios

- A su vez, su implicancia se reduce tan solo al estudio de crisis originadas por desastres naturales, como lo fue el Fenómeno del Niño Costero. Las cualidades de este suceso son únicas para efectos de estudiar el porqué de las reacciones y comportamientos de los usuarios. El aplicar los mismos lineamientos de este análisis podría inducir a error al tratar otro tipo de crisis originadas por causas humanas, como lanzamiento fallido de productos o escándalos de corrupción en empresas. El llevar a cabo una investigación en un escenario de crisis distinto al presente, como de lanzamiento de promociones u ofertas de vuelo -dejando de lado desastres naturales de cualquier tipo- determinará si LATAM Airlines es, efectivamente, vista como una empresa aprovechadora por sus consumidores en otros contextos.

- Por otro lado, la crisis de comunicación ahora estudiada se dio dentro de acciones corporativas de responsabilidad social, manifestando el deseo de la empresa en la mejora de la situación y su participación dentro de la solución. Es por este factor que nuestro estudio no se podría replicar fuera de este canon. El fracaso en el lanzamiento de productos o servicios, las declaraciones de carácter negativo de algunos representantes de la empresa, o los escándalos de corrupción deberán ser estudiados desde otra perspectiva, añadiéndole herramientas a la misma que puedan ayudar a esclarecer el problema que en cada caso se presente. 


\section{REFERENCIAS}

Aced, C. (2013). Relaciones públicas 2.0. Cómo gestionar la comunicación corporativa en el entorno digital. Barcelona: Editorial UOC.

Amado, A., \& Tarullo, R. (Julio-Diciembre de 2015). Las redes sociales en la comunicación política: ¿comunicación unidireccional o conversacional? Contratexto(24), 97-111.

Argenti, P. A. (2014). Comunicación estratégica y su contribución a la reputación. Madrid: LID Editorial Empresarial.

Bardin, L. (1996). Análisis de Contenido. Madrid: Akal.

Barletta, F., Pereira, M., Robert, V., \& Yoguel, G. (2013). Argentina: dinámica reciente del sector de software y servicios informáticos. Revista de la CEPAL(110), 137155.

Bruns, A. (4 de Septiembre de 2009). From Prosumer to Produser: Understanding UserLed Content Creation. Transforming Audiences Conference. Londres.

Bustamante, V. (2016). Buenas prácticas y lecciones aprendidas de la gestión comunicacional de crisis empresariales (tesis de licenciatura). Universidad de Lima.

Castells, M. (2009). Comunicación y Poder. Madrid: Alianza Editorial.

Choy, M., \& Chang, G. (2014). Medidas macroprudenciales aplicadas en el Perú. Lima: Banco Central de Reserva del Perú.

Diario Gestión. (04 de Marzo de 2018). Balance. Recuperado el 06 de Junio de 2018, de sitio web de Diario Gestión: https://gestion.pe/economia/transporte-aereonacional-pasajeros-peru-crecio-8-5-2017-228562

Enrique, A. M. (enero-abril de 2013). La gestión de comunicación de crisis en las redes sociales. Orbis. Revista Científica Electrónica de Ciencias Humanas., 8(24), 116-131.

García Nieto, J. P. (2013). Consturye tu Web comercial: de la idea al negocio. Madrid: RA-MA.

López, M. (12 de Febrero de 2017). Lluvias e inundaciones en la costa de Perú: científicos explican las causas. Recuperado el 12 de Mayo de 2017, de Mongabay: https://es.mongabay.com/2017/02/peru-lluvias-inundaciones-mar/.

Lozares, C. (1996). La teoría de las redes sociales. Papers(48), 103-126. 
Perilla, L., \& Zapata, B. (2009). Redes sociales, participación e interacción social. Trabajo Social(11), 147-158.

Rodríguez, E. (24 de Enero de 2012). El caso Nestlé: otro fracaso de relaciones públicas en redes sociales. Recuperado el 15 de Julio de 2017, de SMARTUP Agencia Digital de Marketing Online y Publicidad en Internet : https://blog.smartup.es/el-caso-nestle-otro-fracaso-de-relaciones-publicas-enredes-sociales

Schmitt, I. (Marzo de 2017). Las cifras que van dejando las lluvias en el Perú. Recuperado el 12 de Mayo de 2017, de sitio web de RPP: http://rpp.pe/peru/actualidad/mas-de-56-mil-damnificados-por-la-temporada-delluvias-a-nivel-nacional-noticia-1036219.

Todorov, T. (2013). Nosotros y los Otros. Madrid: Biblioteca Nueva.

Tripp, T., \& Grégoire, Y. (Enero de 2012). Cuando los clientes descontentos contraatacan en internet. Harvard Deusto Business Review, 40-50.

Valera, L. (2012). ¿Deliberación 2.0 o radicalización de la retórica partidista? Un análisis de las discusiones polítics en los muros de Facebook de candidatos políticos españoles. Textual \& Visual Media(5), 311-340.

Van Dijk, T. (2009). Discurso y poder. Barcelona: Gedisa Editorial.

Vaquero, A. (2012). La reputación online en el marco de la comunicación corporativa. Una visión sobre la investigación de tendencias y perspectivas profesionales. Revista Científica de Estrategias, Tendencias e Innovación en Comunicación(3), 49-63.

Wittmann, R. (2006). ¿Hubo una revolución en la lectura a finales del siglo XVIII? En G. Cavallo, \& R. Chartier, Historia de la lectura en el mundo occidental (págs. 435-472). México D.F.: Santillana.

Zavala, V., \& Zariquiey, R. (2007). 'Yo te segrego a ti porque tu falta de educación me ofende': una aproximación al discruso racista en el Perú contemporáneo. En T. Van Dijk, Racismo y discurso en América Latina (págs. 333-369). Barcelona: Editorial Gedisa. 


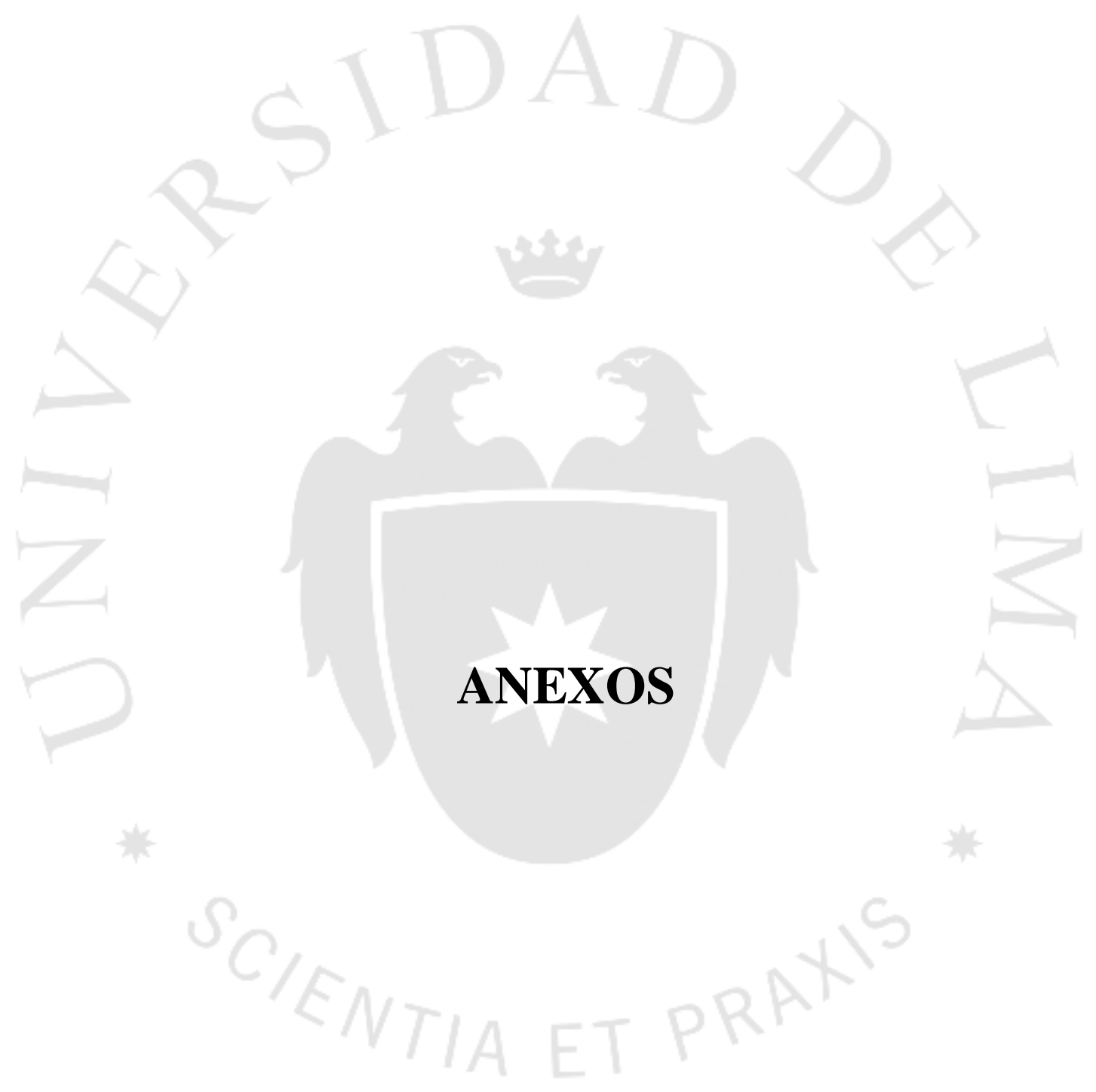




\section{ANEXO 1: COMUNICADO \#1 DE LATAM AIRLINES}

Este fue el primer comunicado publicado por LATAM Airlines en su página de Facebook, con fecha 15 de marzo de 2017.

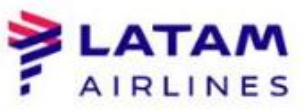

COMUNICADO

Estamos brindando excepciones comerciales a los pasajeros que no deseen viajar o prefieran cambiar de fecha a los siguientes destinos desde Lima o viceversa: Chiclayo, Trujillo, Piura,

Talara y Tumbes, lo cual podrán realizar sin pagar penalidad. Asimismo, debido a la coyuntura hemos reducido las tarifas a dichos destinos a través de todos nuestros canales de venta.

Nos solidarizamos con nuestros compatriotas y estamos comprometidos para brindar todo el apoyo necesario.

Con la finalidad de llevar apoyo en coordinación con Piura en Acción (www.facebook.com/piura-en-accion) se ha coordinado para trasladar donaciones que serán distribuidas a los afectados por las lluvias.

Fuente: Página de Facebook de LATAM Airlines. Link: goo.gl/1Gxga1 


\section{ANEXO 2: COMUNICADO \#2 DE LATAM AIRLINES}

Este fue el segundo comunicado publicado por LATAM Airlines, con fecha 16 de marzo de 2017.

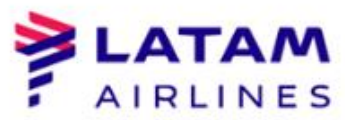

COMUNICADO

Informamos que además de los destinos del norte, seguimos manteniendo nuestras excepciones comerciales en las siguientes rutas: Chiclayo, Trujillo, Piura, Talara, Tumbes,

Cajamarca, Ayacucho, Iquitos, Jaén, Pucallpa y Tarapoto.

En tal sentido, las personas que tengan tickets a dichas ciudades para volar durante el mes de marzo, podrán pedir la devolución o cambiar de fecha dentro del mes sin ningún pago adicional.

Fuente: Página de Facebook de LATAM Airlines. Link: goo.gl/6y1Sri 


\section{ANEXO 3: COMUNICADO \#3 DE LATAM AIRLINES}

Este fue el tercer comunicado publicado por LATAM Airlines, con fecha 16 de marzo de 2017, publicado horas despúes del segundo.

\section{$\geqslant$ LATAM \\ A I RLINES}

Mantenemos el compromiso de reducir las tarifas en los destinos desde Lima o viceversa para: Chiclayo, Trujillo, Piura, Talara y Tumbes. Asimismo, rechazamos haber subido los precios o querer tomar provecho de un momento tan dificil como el que pasa el país.

Queremos comentarles que para realizar un vuelo inter-ciudades (ej. Piura-Trujillo), es necesario hacer conexión por Lima. Por ello, hemos reducido también las tarifas de dichas conexiones.

Finalmente, hemos puesto a disposición dos (2) vuelos de ayuda humanitaria gratuita en la ruta Lima-Piura para este viernes 17 y el sábado 18, llevando voluntarios y carga a la zona afectada. Además, hemos coordinado con Cáritas de Perú y la asociación Piura en Acción a fin de atender sus requerimientos de apoyo.

Lima, 16 de marzo del 2017

Fuente: Pàgina de Facebook de LATAM Airlines. Link: goo.gl/TtYU0G 


\section{ANEXO 4: LEYENDA PARA LA LECTURA DE TABLAS}

Las siguientes será la presentación de las Tablas de Excel de todos los comentarios y respuestas analizados en la presente investigación, en las cuales se codifica cada uno de estos, brindados tanto por los usuarios de Facebook como de LATAM Airlines.

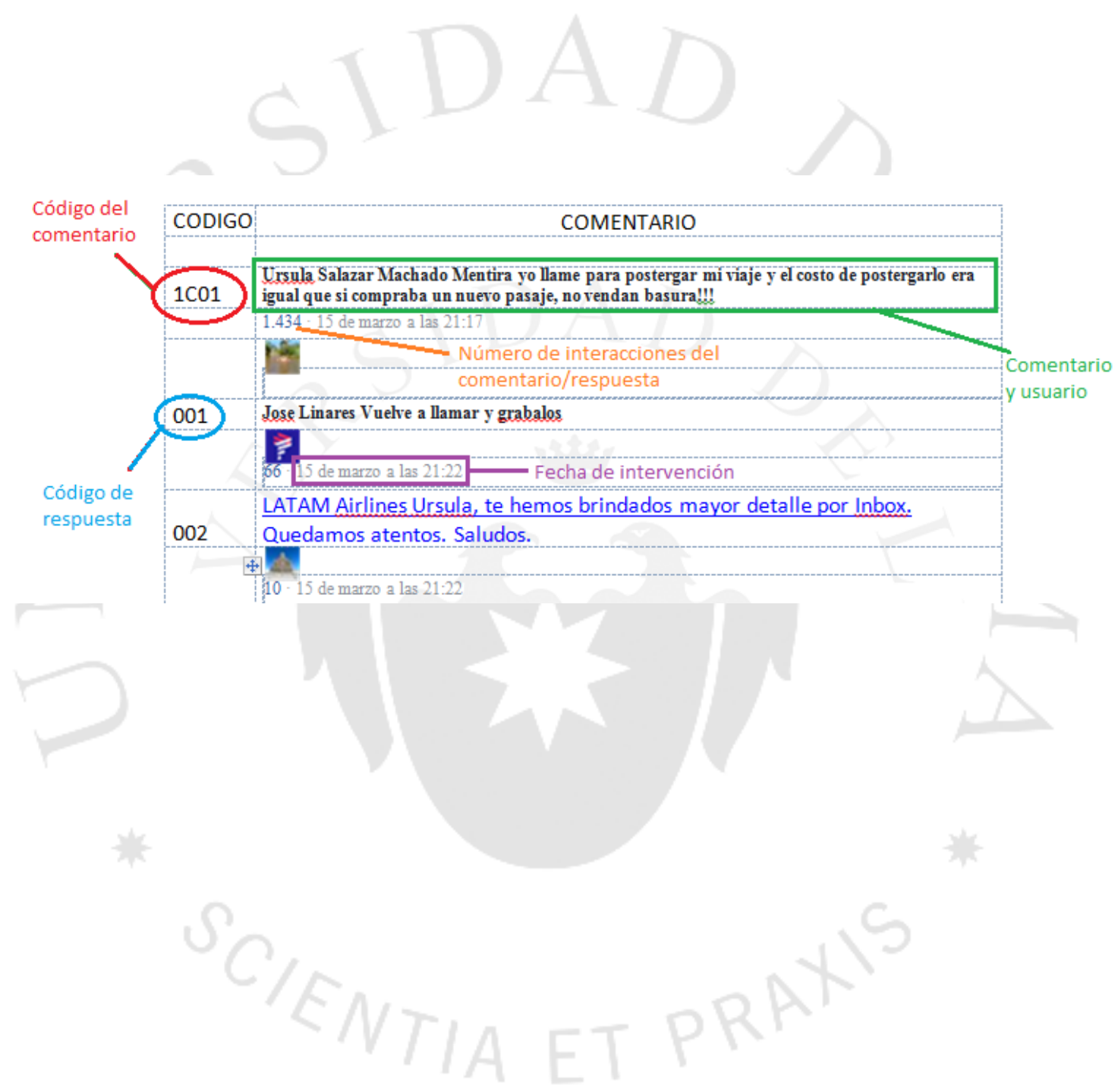




\section{ANEXO 5: TABLAS DE COMENTARIOS Y RESPUESTAS DEL COMUNICADO 1}

Ursula Salazar Machado Mentira yo llame para postergar mi viaje y el costo de postergarlo era igual que si compraba un nuevo pasaje, no vendan basura!!!

$1.434 \cdot 15$ de marzo a las 21:17

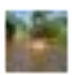

$001 \quad$ Jose Linares Vuelve a llamar y grabalos

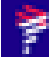

$66 \cdot 15$ de marzo a las 21:22

LATAM Airlines Ursula, te hemos brindados mayor detalle por Inbox.

002 Quedamos atentos. Saludos.

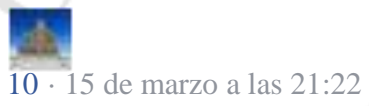

003 Marko Benitez Vende humos si la gente no sale a desmentir, cualquiera les cree

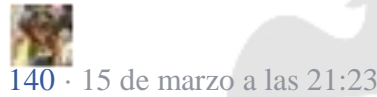

$004 \quad$ Liza Melissa Porquerias de lucradores!!!! LATAM Airlines

$107 \cdot 15$ de marzo a las 21:23

005 Christian Aylas Zelayaran Jajajajjaa. Si no se hacía publico ésto no "\$e comprometian con el País "

006 Raúl Paredes Arismendiz Que feo roche CM... El jefe de mk está en break o qué pasa? Apuuuuura que se desata el terro :V

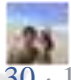

30. 15 de marzo a las 21:24

007 Yare Nicho Rivadeneyra Busca una app para grabae llamadas

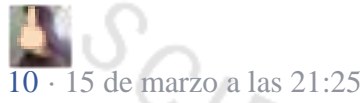

008 Sou De Piérola LATAM Airlines

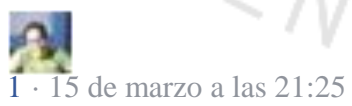

009 Manuel Bernal Loro LATAM Airlines bajen los precios perros!

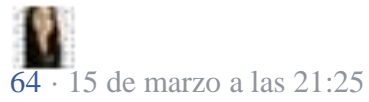

010 Isabel Puma Graba, denuncialos

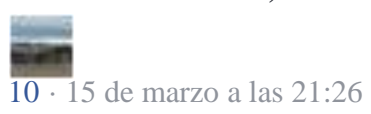

Ceci J Vilela QUÉ HORRIBLE LO QUE HACEN LATAM, ESPERO QUE LA GENTE DEJE LOS PRECIOS A MONTOS INACCESIBLES 
59. 15 de marzo a las 21:26

Meli Soto ¿Se solidarizan? ¿Subiendo los precios lo más alto posible? Sinvergüenzas, es lo que son. Oportunistas. Recién cambiaron sus precios. No olvidemos esto! Hagamos que quiebren : https://www.facebook.com/events/1850065928582387/?ti=cl

mar-20

\section{Qué Latam Quiebre!!!}

Lun 22:00 UTC-05

121 personas interesadas

$103 \cdot 15$ de marzo a las 21:42 Editado

015 Jherson Gutierrez Galvez Inbox inbox fuera csm 25. 15 de marzo a las 21:27

016 Diana Granados Que esperabas esta aerolínea siempre se aprovecha de las desgracias!<smiles>C1=[As]=[As]=[As]1</smiles>

13. 15 de marzo a las 21:27

$017 \quad$ Ursula Salazar Machado

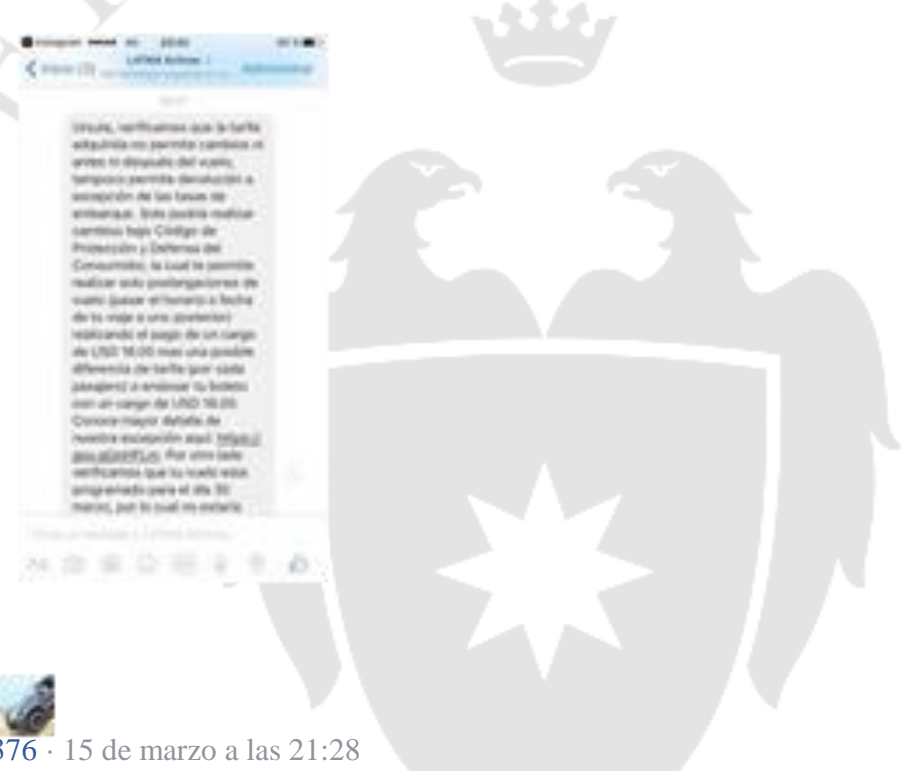

018

Mauricio Villarreal Igual un compañero de trabajo, quiso postergar su vuelo y le salía mas caro. Es MENTIRA, o brinden las condiciones exactas en su comunicado.

\section{(it:}

29. 15 de marzo a las 21:28

019 dicen que bajaron las tarifas, no se escondan, no son ratas, respondan al pueblo peruano.

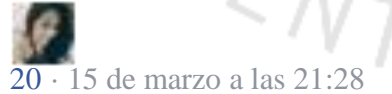

020 Belen Montes De Oca Orellana Denúncialos!! Porque sino, nos toman de tontos.

9. 15 de marzo a las 21:29

021

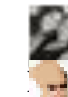

n Sánchez Jajajaa.inbox.diceee.... les deberia dar verguenza por postear algo asi..... desgraciados 10. 15 de marzo a las 21:29

$022 \quad$ Pedrin Güere LATAM Airlines que tal empresa no ?? 


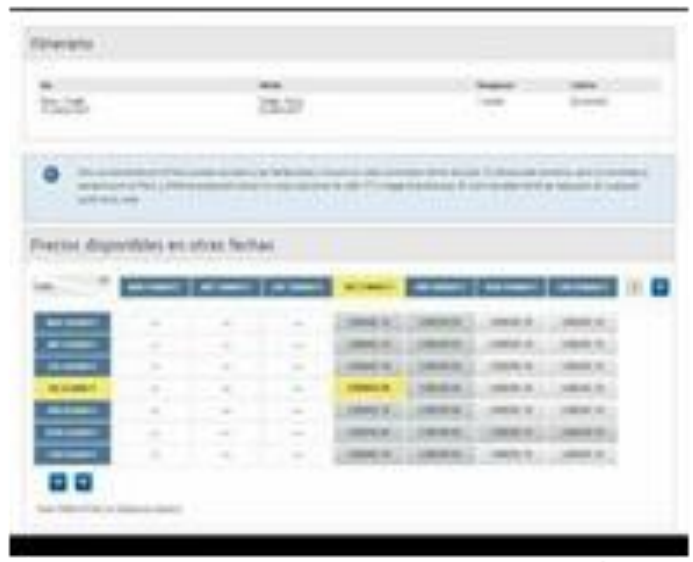

96. 15 de marzo a las 21:29

023 William Huayta Málaga URSULA, PUEDES DESMENTIR O AFIRMARLO NUEVAMENTE? (2z)

9. 15 de marzo a las 21:29

024 Su Tou Son unos oportunistas ....

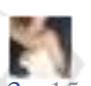

3. 15 de marzo a las 21:29

025 Jimena Guevara son una mierda

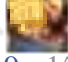

9. 15 de marzo a las 21:29

026 Karen Rojas Paqui Después del roche que se les ha hecho, recién bajan pasajes, es el colmo que se aprovechen del dolor ajeno

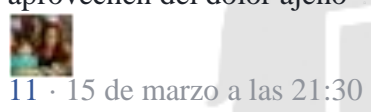

027 Irene Caparo ACR graba las llamadas

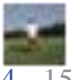

4. 15 de marzo a las 21:30

028

Javier Saravia Que descaro ... Tomen screamshot de esta foto y corresponde una denuncia por publicidad engañosa..

$10 \cdot 15$ de marzo a las 21:31

029

Michaell's Blount Hijos de puta!

$4 \cdot 15$ de marzo a las 21:31

Ceci J Vilela MENTIROSOS, DEJEMOS DE PAGAR POR SU SERVICIO. UN BOLETO NO DEBE 030 COSTAR TANTO EN MOMENTOS DE DESGRACIA NI EN MOMENTOS DE BIENESTAR. ENCIMA MIENTEN. TE QUIEREN COBRAR MÁS. QUÉ HORROR

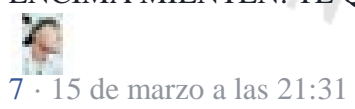

$031 \quad$ Michaell's Blount Hijos de puta!

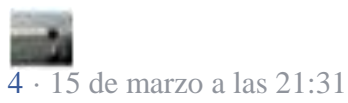

032 Jhimmii Sarango Estafadores se aprovechan de las desgracias para subir sus pasajes<smiles>C1C[C@H]2CC[C@H]1C2</smiles>

$2 \cdot 15$ de marzo a las 21:31

033

Ingrid Ve Gr Y asi dicen que quieren ayudar osea porq la tarifa es menor a 500 dolares la ayuda no va!!!??? Ahi esta la generosidad de la empresa 
Beatriz Galarza Perez Acabo de comunicarme con su call center

Tengo dos pasajes con destino a Piura con fecha 16 de abril pero las circunstancias no son seguras.

Las lluvias continúan y no es que en 15 días se va a recuperar toda la ciudad

La señorita me indica que no puedo modificar de destino, que sería lo más recomendable en este caso.

$1 \mathrm{CO2}$ Que el pasaje no me lo permite.

Nosotros no podemos postergan para otra fecha el pasaje .

Prácticamente nos están obligando a viajar a la ciudad de Piura sin ninguna seguridad de infecciones o plagas que se puedan presentar.

No me están dando ninguna solución

Que mal por LAN porque no se pone en nuestra situación solo ven su beneficio

La página respondió en privado $\cdot 23$ de marzo a las 14:16

Ocultar 15 respuestas

\section{F}

001 LATAM Airlines Hola Beatriz, hemos respondido por inbox. de marzo a las 14:26

002 Beatriz Galarza Perez Señores de Lan solicito cambio de destino

Es muy riesgoso viajar a la ciudad de piura

Y no me salgan que las condiciones del pasaje no lo permite

Acaso no ven noticias? De cómo está la ciudad de piura en estos momentos y que las lluvias continuarán por todo el mes de abril?

Necesitamos una respuesta y una solución lógica.

27 de marzo a las 13:39

LATAM Airlines Beatriz, el Código de Protección y Defensa del Consumidor solo te permite endosar y poder postergar por un plazo máximo de 30 días siguientes de la fecha original de salida del primer tramo. Para los siguientes tramos, la postergación será de acuerdo a la validez de la tarifa. Puedes verificar mayor información en siguiente

003 enlace: https://goo.gl/HGfXym. Saludos.

Endosos y Postergaciones

En cumplimiento del Código de Protección y Defensa del Consumidor informamos las condiciones para Endosos y Postergaciones de

\section{LATAM.COM}

27 de marzo a las $14: 38$

Fernando Tupia Osea ninguna solucion, que clase de empresa que no le interesa lo que pase en el pais, que lo unico que le interesa es lucrar, asi siga lloviendo en piura, no se puede cambiar el pasaje 004 pues, asi son seňores de latham, una pena.

\section{7 de marzo a las 17:13}

LATAM Airlines Fernando, para revisar lo que nos mencionas, indícanos mediante inbox el código de tu reserva o número de ticket. Estaremos a la espera. 
27 de marzo a las 18:23

006 Beatriz Galarza Perez Que mal señores, yo exijo la devolución de mis dos pasajes

No solo los impuestos, como quieren hacer, exijo la devolución total de mis pasajes

Llegaremos hasta el final, hasta las máximas autoridades.

Esto no lo dejaré pasar

Que se creen que pueden lucrar y no importarles lo que le suceda a las personas

Solo piensan en su beneficio y no en lo que sucede en mi Perú

Haber pues envíen a sus padres, hijos, hermanos, a la ciudad de Piura donde ya se está dando los casos de dengue, haber háganlo

Serían capaces de hacerlo??????

O no tienen familia ni corazón

Claro como son una empresa extranjera, siempre quiere hacer lo que quieran con nuestro pueblo. Indolentes

29 de marzo a las 7:43

LATAM Airlines Beatriz, las devoluciones serán realizadas de acuerdo a la tarifa que adquiriste y en este caso no te permite devoluciones, si deseas acogerte a las opciones mencionadas, escríbenos. Quedamos atentos.

\section{9 de marzo a las 9:20}

008

Vivi Rivas Yo tb compre 2 pasajes para 17 de abril y retorno 22.no deseo viajar y ustedesno m.dan solucion.tengan concideracion yo no perdere los pasajes.

\section{30 de marzo a las 8:07}

Beatriz Galarza Perez Señores, yo adquirí esos pasaje porque me estaba yendo de vacaciones, y por lo tanto no puedo postergar ese viaje para ninguna fecha. NO ES CULPA DEL PASAJERO QUE SE PRESENTE ESTA SITUACION CLIMATOLOGICA.

En estos casos debe haber alguna salvedad, no pueden ser tan cerrados. USTEDES SON INHUMANOS.

Al final sólo lo ven dinero.

\section{QUIEREN QUEDARSE CON EL DINERO PORQUE LES HACE FALTA?}

SON UNA VERGUENZA PARA NUESTRO PAIS Y LAS AUTORIDADES DEBEN HACER ALGO PARA DEFENDERNOS, PRACTICAMENTE TENEMOS QUE ACEPTAR SUS CONDICIONES.

$1 \cdot 30$ de marzo a las $8: 36 \cdot$ Editado

LATAM Airlines Beatriz, reiteramos la respuesta anterior. De confirmar la devolución ahora será bajo la condiciones de tu pasaje. Quedamos atentos

010 a tus comentarios.

\section{0 de marzo a las 10:45}

Yosselyn de la Cruz yo igual llamé y me dijeron que me respondería na mi correo en $48 \mathrm{hrs}$. y me respondieron mientras hablaba con la Srta .del call center y me dijeron que no me podían cambiar de vuelo, son unos inhumanos yo compre 5 boletos

1 de abril a las 11:30 
Arantza FS LATAM Airlines Señores LATAM, Tengo dos pasajes a piura para la próxima semana pero debido a las condiciones de la ciudad, con riesgo a las lluvias que continuan, las enfermedades y plagas existentes deseo aplazar mi viaje ya que no es un destino seguro en estos momentos aún. POR FAVOR espero su respuesta a la brevedad ya que en el call center no me han sabido brindar una

012 solución efectiva a mi problema.

GRACIAS

\section{9 de abril a las 5:36}

LATAM Airlines Hola Arantza, te hemos respondido a través de un Inbox.

013 Esperamos lo solicitado. Saludos.

9 de abril a las 6:20

Judith Fiorella Garcia Chinchay Acabo de llamar al call center para hacer el cambio de mi reserva ya que viajó el 20 de abril y me dicen que no aplica y q tengo q pagar la penalidad !!! Que clase de apoyo a Piura es eso y que garantía dan al consumidor

$2 \cdot 11$ de abril a las 7:04

LATAM Airlines Hola Judith, envíanos un inbox con tu código de reserva o 015 número de ticket para poder asistirte. Quedamos atentos.

11 de abril a las 7:10

CODIGO

1C03

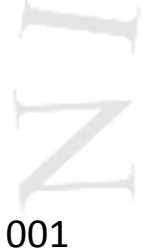

001

002

003

004

005

006

\section{COMENTARIO}

Denisse Sulca Urquizo En mi caso tengo un pasaje a Jaen porque tengo que tomar buss a Bagua y la carretera está cerrada...puedo cambiar de fecha?

5. 16 de marzo a las 9:53

Ocultar 17 respuestas

LATAM Airlines Denisse, envíanos tu código de reserva por inbox.

$1 \cdot 16$ de marzo a las 10:02

Michel Latorre López Pobechita, ni viajes amiga la cosa ta fea en amazonas buuu

$1 \cdot 16$ de marzo a las 10:03

Denisse Sulca Urquizo Michelin por eso quiero ver qué solución me podrían dar

$1 \cdot 16$ de marzo a las 10:10

LATAM Airlines Denisse, te hemos brindado una respuesta a través de inbox. Quedamos atentos a tus comentarios.

$1 \cdot 16$ de marzo a las 10:38

Sandy Marcelo Yo he enviado un mensaje, estoy esperando que me respondan pero hasta ahora nada 16 de marzo a las 11:22

Denisse Sulca Urquizo A mi ya me respondieron. Me acerqué a su agencia en plaza san miguel y me dieron un número 2138200 opc 3-2 pero ESTA OCUPADO y seguirá así por el resto del día. Tengo que avisar que no viajare y deseo la devolución antes del sábado. Que fastidio

$1 \cdot 16$ de marzo a las 11:40

Vico Velásquez Machuca te van a devolver solo los impuestos, el pasaje comprado no, si quieres mover de fecha aparte del cargo adicional, hay una diferencia que debes asumir entre lo que compraste y lo que tienen en diponibilidad...en impuestos solo te devuelven 86.50 soles, ya me paso eso la semana pasa.

$1 \cdot 16$ de marzo a las 22:49

Denisse Sulca Urquizo En serio Vico? 
"Hola Denisse, estamos brindando excepciones comerciales para los vuelos hacia Jaén y otros destinos para las fechas entre el 15 y 31 de marzo. Posponerlo 15 días o caso contrario solicitar la devolución del pasaje."

17 de marzo a las 4:16 · Editado

LATAM Airlines Denisse, notamos que ya solicitaste la devolución. Te confirmamos que la devolución será en su totalidad no solo de impuestos.

009 iSaludos!

$1 \cdot 17$ de marzo a las 4:35

$010 \quad \begin{aligned} & \text { Denisse } \\ & \text { rápido }\end{aligned}$

17 de marzo a las 4:43

LATAM Airlines Ante cualquier inconveniente, no dudes en escribirnos.

011 Saludos.

17 de marzo a las 4:55

012 Vico Velásquez Machuca Así latam...Debo esperar dos días más a cancelarlo entonces ...

17 de marzo a las 6:10

LATAM Airlines Sandy, te hemos brindado información vía inbox, te

013 solicitamos verificarlo. Saludos.

18 de marzo a las 4:29

Marle Lu Dennise Denisse Sulca Urquizo solo te daran máximo a 10 días para que cambies después

014 de los 10 días tienes que agregar 45 dólares, así son los de LATAM.

18 de marzo a las 16:50

Denisse Sulca Urquizo Gracias Marle.me dijeron que podía postergar mi vuelo 15 días pero preferí la

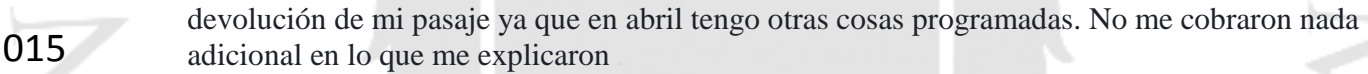

$1 \cdot 18$ de marzo a las $17: 31$

016 Vico Velásquez Machuca Suertuda ...

$1 \cdot 18$ de marzo a las 17:34

017 K.m. Trelles Cuanto está piura lima piura favor

4 de abril a las 10:18

Vanessa Cardenas Miyashiro Hola, hoy pedí cancelar mi vuelo a Trujillo y me indicaron que si cobran penalidad, como hago? Donde me quejo??

9. 16 de marzo a las 11:34

Ocultar 12 respuestas

LATAM Airlines Hola Vanessa, estamos ofreciendo protecciones para vuelos programados hasta el 31 de marzo hacia o desde Trujillo. Para verificar tu caso envíanos tu código de reserva a través de inbox por seguridad.

$001 \quad$ Estaremos a la espera de tu respuesta.

16 de marzo a las 11:42 
Vanessa Cardenas Miyashiro LATAM Airlines mi vuelo estaba programado para este sabado 18 de marzo, hoy llamé para cancelarlo y me indicaron el cobro. Acabo de llamar al contact center y despues de 26 minutos me dicen que se tiene que ingresar un reclamo porque ellos no tenían conocimiento de la no penalidad.. que hermoso no?.. les dejo por inbox la reserva y código de reclamo.

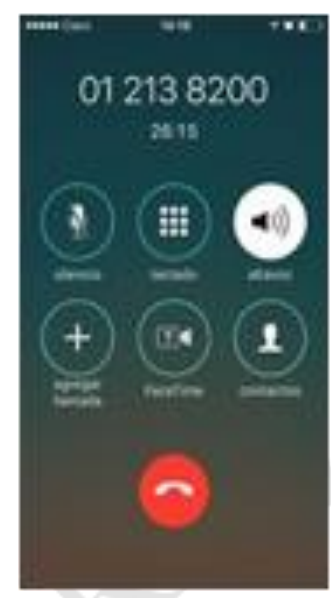

\section{$2 \cdot 16$ de marzo a las $12: 26$}

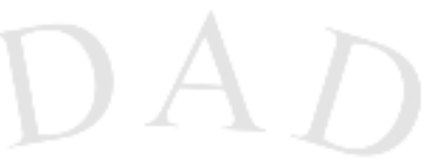

LATAM Airlines Hola, te hemos respondido a través de inbox. Saludos.

16 de marzo a las 13:05

$004 \quad$ Magno Alves Kowalski Vanessa presidente !

$1 \cdot 16$ de marzo a las 17:29

005

Vanessa Cardenas Miyashiro Jajaja estos son unos estafadores solo para que la gente que no sabe les regale un like

$5 \cdot 16$ de marzo a las 17:50

006

Vanessa Cardenas Miyashiro Sigo esperando una respuesta, me dijeron en 48 horas y nada, encima la penalidad es más alta de lo que me indicaron.

$1 \cdot 20$ de marzo a las 19:55

LATAM Airlines Vanessa, estamos trabajando en tu caso y nos

007 contactaremos con una respuesta en el menor tiempo posible.

20 de marzo a las 20:07

008

Carolina Flores Ardiles Vanessa Vane, no sabia que estabas entrampada con LAN, continua con tu proceso, solo asi estas empresas entenderan que no es una broma lo que dicen y/o hacen.

20 de marzo a las 20:52

009

Vanessa Cardenas Miyashiro Estafa total! Así termina el caso? No interesa lo que publican acá, no me devolvieron ni los kilómetros ni el pago de impuestos. \#latam \#estafatotal

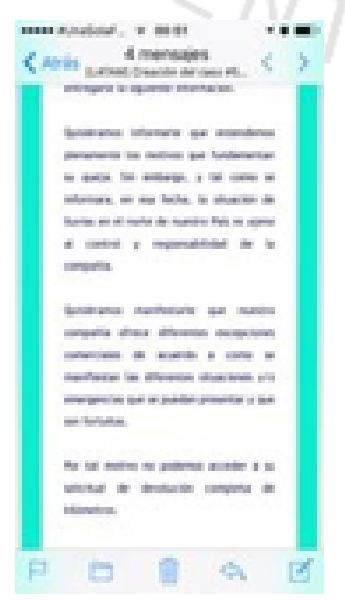




\section{$1 \cdot 2$ de abril a las 22:56}

010 Carolina Flores Ardiles Vanessa Vane postéalo en modo público en tu perfil

3 de abril a las 6:09

011 respuesta.

3 de abril a las 10:39

Vanessa Cardenas Miyashiro Y finalmente luego de otro reclamo me devolvieron los kilómetros, el dinero aún no, mantengo la esperanza . Lamentablemente generaron mucho malestar y tuve que reclamar repetidas veces. Cuantos habrán pasado lo mismo, desistieron y no les devolvieron nada. Mal \#latam así no se trata a los clientes

$1 \cdot 6$ de abril a las $16: 53$

CODIGO

$1 \mathrm{C05}$

\section{COMENTARIO}

Claudia Llerena Cruz Hola tengo un vuelo para mañana a tumbes, cual es el procedimiento que debo hacer para el cambio de fecha. Llamo a la central y la red esta ocupada.

$3 \cdot 16$ de marzo a las $8: 58$

LATAM Airlines Hola Claudia, para asistirte envíanos por inbox tu código de reserva o número de ticket, nombres y apellidos completos, DNI, teléfono y

001 correo. Quedamos atentos.

16 de marzo a las 9:04

002 Jessica Pamela Nuñez Nadie contesta cuando llamo, esta congestionada la linea y se cuelga 16 de marzo a las 9:25

LATAM Airlines Hola, acabamos de enviarte un inbox. Te sugerimos verificar

003 la información. Saludos.

16 de marzo a las 9:47

004 Paty Mayta Debe estar congestionada, hay muchos pasajeros que llaman

16 de marzo a las 13:31

005 Claudia Llerena Cruz Mandé el inbox a las 3pm y hasta ahora no tengo respuesta

16 de marzo a las 18:14

006 LATAM Airlines Claudia, te hemos enviado un inbox con mayor información. 18 de marzo a la 1:29

Diana Uribe Señores de LATAM , El día de ayer mis suegros tenían un vuelo a las 13:35 pm con destino a Chiclayo, a causa de el estado en el que se encuentra la ciudad ellos deseaban cambiar sus pasajes por lo que nos acercamos al centro de atención de San Miguel, llamamos al contact Center e incluso fuimos al aeropuerto 2 horas antes a intentar cambiar los pasajes y LA NEGATIVA FUE ROTUNDA, incluso ofrecimos pagar una penalidad y sus colaboradores en todo momento nos negaron la ayuda que pedíamos... Como puede ser que sean tan insensibles, considerando el estado en el que esta Chiclayo, no hay movilidad en las calles, no hay pase, todo está inundado y las calles 
cerradas! mis suegros (personas de la 3ra edad) pasando por el barro, caminando cuadras de cuadras, cargando sus maletas, PORQUE NO HAY TRANSPORTE, que PÉSIMO SERVICIO, y a las 11 de la noche se les pega la gala de emitir este "comunicado" ... QUE DECEPCIÓN! INDOLENTES !

Ah ! Y como si fuera poco! Hace 3 dias se encontraban en Ayacucho y el día domingo les postergaron el vuelo por las lluvias al día lunes, el día lunes los hicieron esperar 1 HORA sentados en el avión ! Tuvieron que hospedarse 1 noche más en Ayacucho, gastar más dinero , pagar el hotel y comida por 1 noche mas y salir de su presupuesto, y Uds bien gracias, ni siquiera les reconocieron un chicle ! Uds pueden hacer los cambios que deseen y sin embargo cuando uno quiere modificar su pasaje le ponen mil y un trabas ! ! PÉSIMO!

$49 \cdot 16$ de marzo a las 8:27 - Editado

Ocultar 12 respuestas

LATAM Airlines Hola Diana, para asistirte y ayudarte con el cambio o formalizar tu reclamo envíanos por inbox el código de reserva o número de ticket, nombres y apellidos completos, DNI, teléfono y correo. Quedamos

001 atentos.

$1 \cdot 16$ de marzo a las 12:26

002

Vale Ventas Jajaja, para que?, si los dejaras en el inbox.... en el baúl del olvidó.... propongo firmas para que las autoridades sancionen cualquier abuso.... son muchas quejas!!!

$8 \cdot 16$ de marzo a las 18:58

003

Stephanie Biandie Malditos.

16 de marzo a las 19:10

004 Jose Fernando Allemant Chero Una porquería de empresa!

$1 \cdot 16$ de marzo a las 19:15

005 Oscar Moreno Hurtado Todos los peruanos marchemos xq se vaya esta empresa de porkeria!!

$1 \cdot 16$ de marzo a las 19:46

006 Christian Christopher Alegría Delgado hdp

16 de marzo a las 19:49

007 Iris Durand Mercado Se aprovechan de la situación de la gente son unos malditos

17 de marzo a las 4:51

008 Miriam Veronica Coloma Sondor Putoss

17 de marzo a las 15:53

009 Mireya Eya Garcia Que mal lan muy mal!! Ese tipo de situaciones solo les da una pésima imagen , lo que tienen que pasar las persona por no tomar acciones antes .... Por ultimo ni disculpas de su parte.

$1 \cdot 17$ de marzo a las 23:11

Marco Antonio Carpio Valdez Utilicen el LIBRO DE RECLAMACIONES, ahi ponen su queja y si $010 \quad$ no los

1. 23 de marzo a las 15:26

Marco Antonio Carpio Valdez Utilicen el LIBRO DE RECLAMACIONES, ahi ponen su queja y si $011 \quad$ nubes

$1 \cdot 23$ de marzo a las 15:26

Oscar Llatas Soraluz Amiga éstos son unos MISERABLES, SINVERGÜENZAS, NUNCA TE APOYAN NO LES INTERESA NADA SOLO EL BILLETE Y PEOR TE LO ROBAN

012 CAMBIAN. SE HAN QUEDADO CON MI DINERO ESTOS SINVERGÜENZAS.

29 de marzo a las 21:27 
CODIGO COMENTARIO

Pia Filomeno Buenas noches LATAM Airlines, una consulta el día lunes hice el cambio de fecha de un vuelo Talara- Lima. Tenía que volar el día 20 de marzo pero dada la situación preferí viajar el día 17 de marzo (mañana) por dicho cambio tuve que pagar una penalidad y además diferencia tarifa.

$1 \mathrm{C07}$ Ahora ustedes sacan este comunicado, ahora quiero solicitar que me reembolsen lo que me hicieron pagar por mi cambio de fecha.

$3 \cdot 15$ de marzo a las $21: 41 \cdot$ Editado

$001 \quad$ Pia Filomeno LATAM Airlines podrán responder a mi consulta???

15 de marzo a las 23:00

LATAM Airlines Hola Pia, con la finalidad de asistirte, envíanos tus datos de contacto, código de reserva o número de ticket por inbox. Quedamos

002 atentos a tus comentarios.

$1 \cdot 17$ de marzo a las 7:56

003

Mabhell Pinto Estimados .. Ya necesito postergar mi viaje a Iguazu .. Por motivos de mal clima no puedo viajar a Lima . Cual seria el costo ???

18 de marzo a las 19:33

LATAM Airlines Hola Mabhell, envíanos un inbox con tu código de reserva

004 para asistirte. Gracias.

19 de marzo a las 0:36

005 Oscar Llatas Soraluz Con la estupidez del inbox te engañan. MISERABLES.

29 de marzo a las 21:28

Veronica Martinez Sr. de LATAM tenemos vuelo programados para fines de abril a Piura por lo acontecido queremos cambiar nuestros pasajes para fines de junio? estando a su comunicado, nos permitirán dicha modificación? a que área debo llamar parar averiguar eso?

$1 \mathrm{C08}$

26 de marzo a las 12:50

LATAM Airlines Hola Veronica, nuestras excepciones comerciales se están brindando a pasajero cuyos vuelos operen hasta el día 31 de marzo. Ante tu situación, te sugerimos permanecer atenta a futuras excepciones que estarían siendo publicadas a través de nuestra web o redes sociales oficiales. Recuerda que es nuestra prioridad el velar por la integridad de nuestros pasajeros y comprendemos la situación que nos describes; sin embargo, apelamos a tu comprensión ante esta situación con lo antes

001 expuesto. Saludos.

$1 \cdot 26$ de marzo a las 13:40 002 Veronica Martinez Gracias por la respuesta, esperemos que efectivamente se preocupen por nuestra

26 de marzo a las 15:03

003 LATAM Airlines Agradecemos tu gentil comprensión, Veronica. Saludos. 26 de marzo a las 16:09 
Sandra AR Mentirosos!!!? Yo vine a Piura y tengo que esperar que sea Domingo para poder regresarme porque mi pasaje no permite cambios, entonces que miercoles publican este anuncio si al final es la misma web..

$3 \cdot 16$ de marzo a las $22: 22$

LATAM Airlines Sandra, envíanos por inbox el código de reserva y tu

001 teléfono.

17 de marzo a las 5:36

002 Ray Amaru Ya no viajen en esta empresa que se aprovecha de la desgracia del pais.

\section{7 de marzo a las 6:03}

Sandra AR Encima vuelvo a llamar para adelantar y la que me atiende me dice q tengo q pagar diferencia tarifaria xq solo puedo adelantar con 7 dias antes d vuelo, osea como voy a saber que las lluevias van a seguir, yo he estado en mancora y recien hoy he podido pasar a Piura y quiero adelantarlo y no me dejan saben que Latam nunca mas vuelvo a viajar cn uds!!

La página respondió en privado $\cdot 18$ de marzo a las 11:57

LATAM Airlines Sandra, para asistirte y por cuestiones de seguridad, hemos solicitado algunos datos por inbox. Estaremos atentos a tu respuesta.

18 de marzo a las 14:25

005 Oscar Llatas Soraluz MISERABLES.

29 de marzo a las 21:29

Jaqueline Ovalle Sres LATAM Airlines acabo de llamar para modificar mi vuelo que sale el 25 de marzo a talara para otro mes pero me dicen que ese aviso sólo aplica para vuelos con salida hasta el 17 marzo. Entonces como quedamos? El fenómeno del niño va continuar hasta más adelante no sólo hasta el 17/03 así que no mientan con sus avisos. Pongan la información completa

$7 \cdot 15$ de marzo a las 22:02

001 Jaqueline Ovalle LATAM Airlines sigo esperando su respuesta a mi inbox. Gracias 15 de marzo a las 22:26

Yolita Parra yo tengo una reserva para el 17 de marzo pero igual están cobrando penalidades por 002 cobran si viajas en los siguientes 15 días.

\section{5 de marzo a las 22:31}

Jaqueline Ovalle A ti te dicen una cosa y a mi otra. Ese comunicado miente

$003 \quad$ cambien de fecha es tanto pedir??

15 de marzo a las 22:36

$004 \quad$ James Azeic $\mathrm{Si}$

16 de marzo a las 9:23

LATAM Airlines Jaqueline, vía inbox te hemos brindado detalle y solicitado

005 datos. Saludos.

16 de marzo a las 19:16

LATAM Airlines Hola Yolita, si aún necesitas asistencia, envíanos un inbox con tu código de reserva. Gracias. 
1C11 Johanna Lizbeth Nagarro Placido Buenos Días yoo tengo pasajes comprados para el día 01 de abril LIMA - PUCALLPA y quisiera cambiarlos de fecha porfavor espero una respuesta

29 de marzo a las 6:58

001 LATAM Airlines Johanna, te hemos respondido a través de inbox. Saludos.

29 de marzo a las 7:18

Johanna Lizbeth Nagarro Placido Estoy queriendo comunicarme y los teléfonos están ocupados ase

2 días llamo y nada que entra la llamada, porfabor devolver la llamada a los números que figuran en la reserva gracias..

Espero Tener Una respuesta

29 de marzo a las 17:10

003 LATAM Airlines Hola Johanna, hemos respondido via inbox. Saludos

29 de marzo a las 17:44

004 Wilmer B. Matta Tururú.. .tururú..tururú deje su mensaje en la casilla de vos jijiji

29 de marzo a las 19:32

005 Johanna Lizbeth Nagarro Placido Malulo Chinito >:)

1. 29 de marzo a las 19:33

Priscilla Valdiviezo Hola, tengo 3 pasajes Lima - Piura - Lima saliendo el 03 de abril, que se puede hacer? Necesito otra fecha para viajar. Gracias

\section{$\geqslant$ de marzo a las 9:53}

LATAM Airlines Hola Priscilla, confírmanos el nombre y apellidos de los pasajeros, fechas exactas de viaje y ruta por inbox. Quedamos atentos a tus

001 comentarios.

\section{7 de marzo a las 7:14}

Priscilla Valdiviezo Señores necesito cancelar mis vuelos ya que es imposible estar en Piura! 002 de criterio y comprension por favor!

Zágina respondió en privado $\cdot 28$ de marzo a las 13:30 $\cdot$ Editado

LATAM Airlines Hola Priscilla, te hemos enviado un Inbox, esperamos tu

003 respuesta para ayudarte.

29 de marzo a las 4:56 
Lu Dominguez Hay otras empresas que lo hacen gratis !!! Y no te cobran como si fuera a comprar un 1C13 pasaje nuevo porque son abusivos? Hay mucha gente que trabaja afuera por motivo de trabajo y quiere retornar y no puede porque cobran demasiado

La página respondió en privado $\cdot 12 \cdot 16$ de marzo a las 9:46

LATAM Airlines Hola Lu, envíanos lo solicitado por Inbox para asistirte.

001 Saludos.

16 de marzo a las 10:42

$1 C 14$

Leslie Bardalez Del Giudice Son unos estafadores!!! Me quieren cobrar 500 dolares x camviar un vuelo de piura a Talara!!!! Donde M esta su compromiso con ayudar a la gente??!?;?!

27 de marzo a las 14:57

LATAM Airlines Hola Leslie, por favor envíanos tu código de reserva o número de ticket vía inbox. Quedamos atentos a ello para tu pronta

$001 \quad$ asistencia.

27 de marzo a las 15:05

002 Leslie Bardalez Del Giudice Les he escrito hace dias y no me respondieron

27 de marzo a las 18:04

LATAM Airlines Hola Leslie, te hemos brindado mayor detalle vía inbox. Por otro lado, procederemos a ocultar tu comentario ya que nos brindas

003 información privada como lo es tu código de reserva. Saludos.

27 de marzo a las 18:37

$004 \quad$ Leslie Bardalez Del Giudice Siguen sin responderme

28 de marzo a las 6:19

Leslie Bardalez Del Giudice La unica solucion que me dan para cambiar destino es comprar la

005 diferencia de millas, que son mas de 500 dolares por pasaje!!!! Eso es ayudar a la gente???? Eso es apoyar al Pais???? Malditos raterossssss

28 de marzo a las 9:19

Dan Rz Estoy llamndo para cambiar la fecha de viaje y hora .. y me indican que debo pagar penalidad !.. su personal no leyó su comunicado ?....

Por favor Es urgente !

$11 \cdot 15$ de marzo a las 22:14 $\cdot$ Editado 
LATAM Airlines Hola Dan, para asistirte envíanos por inbox tu código de reserva (6 letras) o número de ticket (13 dígitos), nombres y apellidos completos, DNI, teléfono y correo. Quedamos atentos.

16 de marzo a las 10:12

002

Joe Mario Cabrera Pimentel Por q no hace todo esto su personal. Sr tiene que denunciar para aplicar su comunicado. ??

16 de marzo a las 12:52

Joss V. Ore A ver compre mi pasaje a piura pero por problemas que conocemos a nivel nacional no podré viajar y no me parece que la aerolínea viendo los problemas climáticos, la única solución que nos dan para no perder la totalidad de la compra, es la devolución de los impuestos cuando esto es un evento fortuito e involuntario que vive ahora nuestro país. No es un tema del pasajero deberían dar una solución de reserva al boleto comprado sin tiempo limitado porque viendo las circunstancias no sabemos hasta cuando seguiremos así o devolver la totalidad de la compra y no deberían dar un plazo de 30 días o pagar las tasas que es la cuarta parte de lo que costo el pasaje y eso.... me parece un robo total y en vez de bajar sus precios deberían preocuparse por los pasajeros que confiaron en uds. Y darle la solución más adecuada

$3 \cdot 16$ de marzo a las 10:40

LATAM Airlines Hola Joss, para verificar tu caso envíanos a través de inbox tu código de reserva, ya que son datos privados. Estaremos atentos a tu

001 respuesta.

$1 \cdot 16$ de marzo a las 10:54

002 Daniela Jiménez Calderón Hay vuelos gratis a piura informate

\section{6 de marzo a las 17:56}

Joss V. Ore Daniela Jiménez Calderón si has leído bien mi comentario lo que no quiero es viajar ...estaba yendo de vacaciones. Mi queja iba a que solo dan opción para postergar 15 días (lo más

003 probable es que siga igual la situación) o a devolver solo los impuestos del pasaje.

16 de marzo a las 18:04

004 Johanna Peña Joss V. Ore amiga esto esta como la cagada de plus ultra.

16 de marzo a las 20:10

Toño Guardia Tengo pasajes para Piura para el dia jueves y como saben Piura esta un desastre y e pedido cambiarlos para Talara puesto que mi destino final es Mancora me dicen que por hacer ese cambio me cobran 220 dolares por cada pasaje OSEA QUE ESTARIA PAGANDO 300 DOLARES POR IR AL NORTE eso es un abuso!

\section{$2 \cdot 27$ de marzo a las 12:27}

27 de marzo a las 13:26 
LATAM Airlines Hola Toño, dentro de las excepciones te permitimos el cambio de ruta el cual se encuentra exento de penalidad pero se deberán cubrir las posibles diferencias tarifarias que podrían existir. Quedamos atentos a tus futuras consultas. Saludos.

27 de marzo a las 15:38

Elizabeth Herrera Pero las" posibles" diferencias tarifarias equivalen a 3 pasajes mas? Es el norte sres ; no es un cambio de pasaje a otro país. Criterio por favor.

27 de marzo a las 15:48

Grise CH Y con se tiene que contactar, Xk el vuelo que tenía para Trujillo lo he querido postergar y ahora me dicen que tengo que pagar 35 dólares, o todo es una farsa como siempre. Les escribo al inbox y hasta ahora no responden.

\section{$1 \cdot 16$ de marzo a las 18:57}

$001 \quad$ Grise CH LATAM Airlines respondan

16 de marzo a las 19:02

LATAM Airlines Hola Grise, queremos ayudarte, por ello hemos solicitado mayor información por inbox. Estaremos atentos a tu respuesta por ese

002 medio.

16 de marzo a las 19:06

003 Olga Mucho Castillo ps todo es mentira de latam

16 de marzo a las 21:32

Olga Mucho Castillo es una farsa lo que publica esa comunicacion señores de latam nuetros compatriotas estan pasando por una emergencia por los desastres pero la empresa LATAM aprovecha en elevar sus pasajes

16 de marzo a las 21:37

005 Jorge Hernan Lagos Huaman oigan chilenos bajen los pasajes o nos pasaremos a la competencia 17 de marzo a las 9:49

César Ramos Sres LATAM Airlines acabo de llamar a su Call Center y me dicen que no puedo reprogramar la fecha de mi vuelo porque solo esta reprogramando los vuelos del 15 al 30 de marzo??? Ya han salido en las noticias que las lluvias en Piura seguiran por todo abril!! No es posible que no nos permitan realizar el cambio de vuelo cuando ya se sabe que esa region seguira afectada todo el mes!! Es una estafa!!! Dicen que brindan facilidades para vuelos en zonas afectadas, pero cuando

1 1lamo no dan ninguna facilidad!!!

\section{$1 \cdot 20$ de marzo a las 10:22 $\cdot$ Editado}

LATAM Airlines Hola Cesar, hasta el momento estamos ofreciendo excepciones comerciales para pasajeros viajando hasta el 31 de marzo de 2017. Sin embargo, es importante que permanezcas atento a nuestras

001 redes sociales ante novedades. Si deseas envíanos el código de tu reserva 
por Inbox para más detalles. Saludos.

20 de marzo a las 11:39

CODIGO COMENTARIO

Para variar dan las soluciones q a uds les convienen sin tener en cuenta al pasajero y ponen a gente sin

$1 C 20$ educacion en el call center q no dan solucion alguna, dejan esperando y cortan las llamadas

$4 \cdot 2$ de abril a las 9:17 - Editado

Brenda Pongo Valderas Exacto Pamela a Paola la tienen así hace días!!! Y no le quieren poner en un 001 mismo vuelo con sus hijos que son menores de edad pretenden q ella viaje en una fecha y sus hijos en otro indignante!!! Realmente

\section{$1 \cdot 2$ de abril a las 9:37}

Pamela Díaz Pongo Son de lo peor.. tengo un problema parecido y quieren hacerme pagar encima por darme solucion. Ya es hora de q le pongan un alto a esta aerolinea. No es posible que pretendan q 2

002 niños viajen solos, estan locos

$1 \cdot 2$ de abril a las 9:41

LATAM Airlines Hola Pamela, envíanos mayor detalle de lo que nos 003 comentas por inbox para poder asistirte. Quedamos atentos.

3 de abril a las 4:34

CODIGO

COMENTARIO

Juan De la Cruz Buen día, estoy tratando de comunicarme por teléfono para las gestiones de cambio y no logro ser atendido, agradeceré el apoyo por este medio o la indicación de un canal de atención $1 C 21 \quad$ eficiente... gracias

17 de marzo a las 12:48

LATAM Airlines Hola Juan, para poder asistirte por este medio por favor brindanos por inbox el código de reserva o número de ticket electrónico y el nombre y apellido del pasajero. Quedamos atentos a los datos

001 solicitados.

17 de marzo a las 12:51

Andrea Julliana Yenque Cherres Señores latam. De acuerdo a su comunicado,nos indican que se pueden hacer cambios en los vuelos del mes de marzo. Mi vuelo es el 24 a las 9:30 pm. Podria cambiarlo ese mismo día pero salir en la tarde. Espero su pronta respuesta

1. 21 de marzo a las 9:30

LATAM Airlines Andrea, te hemos enviado un inbox con mayor información. 
Gracias.

21 de marzo a las 23:05

CODIGO

COMENTARIO

Maria Elena Campaña Señores, les agradeceré precisar su comunicado, en qué consisten las excepciones comerciales? A qué vuelos aplican? Cuál es el rango de fechas? Qué ocurre si los pasajes fueron canjeados y ya venció el plazo para el canje? Las excepciones también aplican a ese supuesto?

$1 \mathrm{C} 23$ Recordemos que estamos ante un evento de caso fortuito y legalmente no debe existir perjuicio para el consumidor. Por otro lado, de lo leído en ls comentarios advierto que la fecha de corte que habrían considerado es el 31 de marzo; sin embargo, habemos clientes que hemos adquirido pasajes para los primeros días de abril y no estamos dispuestos a asumir riesgos innecesarios. En mi caso, tengo tres pasajes Lima-Tumbes-Lima por lo que apreciaré me indiquen cuál es el procedimiento a seguir para devolver esos pasajes o cambiarlos por otro destino.

16 de marzo a las 16:49

LATAM Airlines Hola Maria, queremos ayudarte, por favor indícanos vía inbox tu código de reserva o número de ticket. Quedamos atentos tus

001 comentarios. Buen día.

18 de marzo a las 6:27

Giosianna Huby Deza Señores LATAM tengo un problema compre un pasaje con los km de mi esposo. Y como ustedes llenan los datos de manera automática al colocar el nombre de mi mama ( que es la que va a viajar) el pasaje salió a nombre de mi esposo y con el DNI de mi hija de 5 años, al parecer su sistema se confundió. Al llamar al call 5 minutos después de la compra ( cuando me di cuenta) me dicen que tengo q pagar una multa de 25 dólares por un error de ustedes. Pedí la devolución del pasaje pero También me descuentan 4 mil millas. Le dije a la señorita que por favor no tenía 48 horas para esperar a q me devuelvan los km porque mi mamá necesita viajar urgente a trujillo a ver a sus papás que ya son súper viejitos ( mis abuelos) porque están en zonas de desborde de ríos. Por favor ojalá me puedan responder y ayudar mil gracias.

$1 \cdot 16$ de marzo a las 7:01

LATAM Airlines Te hemos enviado un inbox solicitando información.

001 Gracias.

17 de marzo a las 0:09

Ricardo Sanchez Tengo un vuelo para mañana destino Chiclayo, puedo cambiarlo de destino por ejemplo a la selva, favor, a la espera de su respuesta

$5 \cdot 16$ de marzo a las 6:07 
LATAM Airlines Ricardo, hemos derivado los detalles de tu solicitud bajo el número de caso: 5180333 . Serás contactado tan pronto como sea posible. Saludos.

Evalúa nuestro servicio en el siguiente enlace: http://bit.ly/1CU3zvI. Saludos.

001

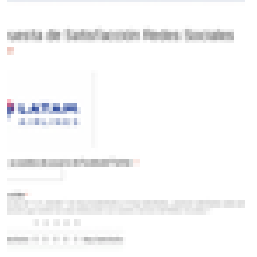

Encuesta de Satisfacción Redes Sociales

DOCS.GOOGLE.COM

$2 \cdot 16$ de marzo a las 6:54

Julio Bernabe

002

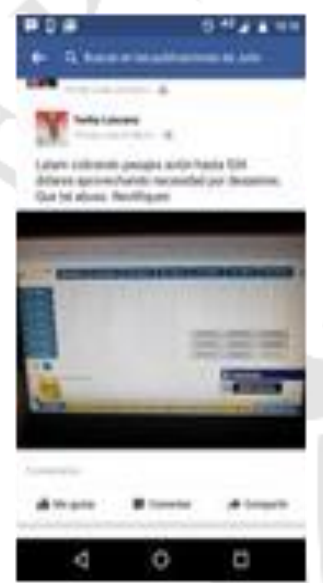

16 de marzo a las 8:12

003

Jair Gómez Sánchez Gonzales La selva está peor viejo

16 de marzo a las 8:43

004

Ricardo Sanchez Tuvo una respuesta rápida por parte de lan. Los cambios de destino deben pagar la diferencia ( obviamente $\$ \$ \$$ no conviene)

17 de marzo a las 7:23

Magali Maita Cruz Buenos dias ..yo tengo un pasaje para el 23 de marzo de este año..para asistir a un curso en la ciudad de trujillo ..por el estado de emergencia se ha postergado dicho curso...solicito a uds por favor tenga a bien postergar mis pasajes. Atenta a su atencion.

La página respondió en privado $\cdot 16$ de marzo a las 6:03

001 LATAM Airlines Magali. te hemos respondido a través de inbox. Saludos. 16 de marzo a las 12:47 
$1 C 27$ Em Ocaña @LATAM el callcenter no está informado!!! Y necesito cancelar mi pasaje !!!

$14 \cdot 16$ de marzo a las 5:31 Editado

LATAM Airlines Hola Emily, queremos asistirte por este medio, para ello por favor brindanos por inbox tu código de reserva o número de ticket electrónico y el nombre y apellido del pasajero. Quedamos atentos a los

001 datos solicitados.

16 de marzo a las 5:34

002 Em Ocaña Listo ya los envié, atenta a su respuesta

16 de marzo a las 5:40

Gabriela Grados Guevara Yo tbm llame anoche, tengo viaje previsto un viaje a chiclayo con mis mellizas de dos años de edad, no puedo exponer a mis niñas a tan duro desastre natural, no m parece justo que tenga que pagar penalidad es un robo!!! No se aprovechen de la situación!

$1 \cdot 16$ de marzo a las 5:24

LATAM Airlines Hola Gabriela, envíanos un inbox con tu código de reserva 001 para asistirte. Gracias.

16 de marzo a las 23:45

CODIGO

\section{COMENTARIO}

Esther Prieto Buenos días mi mamá tuvo k viajar por problemas familiares ,pero llamamos y nos dijeron que no se podía adelantar su vuelo y que tenía k pagar una penalidad, ahora ella se encuentra aislada por los carros tampoco están saliendo ,por serían tan amables en considerar y darme una

$1 C 29$ respuesta señores de LATAM.

16 de marzo a las 5:09

LATAM Airlines Esther, por favor envíanos por inbox el código de reserva y el 001 nombre de tu madre.

17 de marzo a las 7:45

Luis Alonso Chiok Es mentira. Ayer llamé y solo puede cancelsrse, como dicen ellos, "por única vez" gratuitamente y solo se podrá reprogramar el viaje dentro de los siguientes 15 días. Osea 
planifican que en una semana dejará llover a tal magnitud.

$2 \cdot 16$ de marzo a las 5:08

LATAM Airlines Hola Luis, nos puedes enviar un inbox con tu código de 001 reserva para revisar lo que nos comentas. Gracias.

16 de marzo a las 23:43 


\section{ANEXO 6: TABLAS DE COMENTARIOS Y RESPUESTAS DEL COMUNICADO 2}

\section{CODIGO COMENTARIO}

2C01

Carolina Pizarro Anaya MENTIRA! Nos acaban de decir que solo son para vuelos hasta el 22 y para cambiar el nuestro del 24 tenemos que pagar penalidad para postergarla por un max de 30 días Fabiola $217 \cdot 16$ de marzo a las 10:17

Ocultar 81 respuestas

001

Fabiola Carballo Portocarrero Sinceramente no se cuales son las excepciones comerciales cuando de todas maneras quieren realizar penalidades y manifiestan una y mil restricciones para el tema de las devoluciones. Bonita manera de empatizar, lo único que hacen y muy bien es lucrar con la desgracia ajena disparando todos sus precios.

$29 \cdot 16$ de marzo a las 10:55

LATAM Airlines Hola Carolina, para poder evaluar tu consulta por favor brindanos por inbox tu código de reserva o número de ticket electrónico y

002 el nombre y apellido del pasajero. Quedamos atentos.

$4 \cdot 16$ de marzo a las 11:04

003

Andrea Salazar Flores Yo tenía un vuelo para el 22/03 a Chiclayo y me dijeron que tenía que pagar pq sólo es para los vuelos de hoy y mañana LATAM Airlines

$7 \cdot 16$ de marzo a las 11:13 - Editado

004 UN PUTO SOL

$17 \cdot 16$ de marzo a las 11:17

Erika Katherine Rosas Aguirre Latam es una estafa por a mi mamá la estafaron con los pasajes y me dijeron que me hiba a devolver el dinero y hasta hora ni una llamada y ni siquiera un mensaje esa empresa es una estafa y lucra con las desgracias ajenas y más que todo son chilenos.

$33 \cdot 16$ de marzo a las 11:25

006 Em Ocaña Latam! Les escribí y no me han respondido de vuelta !!

$4 \cdot 16$ de marzo a las 11:37

007 Em Ocaña A mí también me han dicho lo mismo!!!

$3 \cdot 16$ de marzo a las 11:37

008 Lizbeth Terceros de Canedo Ahhhjjjj..........la gente solo sabe quejarse

$2 \cdot 16$ de marzo a las 11:38

$009 \quad$ Nefi James Ladrones!

$11 \cdot 16$ de marzo a las 11:41

Carolina Pizarro Anaya Lizbeth Terceros de Canedo "la gente" no está pidiendo nada regalado te contaré! Las quejas cuando tienen fundamento son válidas, así que muy fuera de lugar tu comentario. $60 \cdot 16$ de marzo a las 11:45 $\cdot$ Editado

011 Jefferson J Alvarez igual me paso a mi, ve a denunciar en indecopi

$8 \cdot 16$ de marzo a las 11:49

012

Erick F. Buendia Meza OJALA VIVA AIR SE LOS CHIFE A LATAM....PURO LADRONES

$13 \cdot 16$ de marzo a las 11:53 


\section{6 de marzo a las 11:55}

014 Diana Acorahua Si! Lo mismo me dijeron a mi que viajo a Talara la siguiente semana

$2 \cdot 16$ de marzo a las 12:08

015 Luis Goycochea Navarro Inhumanos desalmados solo piensan en el dinero

$3 \cdot 16$ de marzo a las 12:14

016 Milushka Gn En vez de solucionar los problemas. Lo complican más \#LATAMAirlines

$2 \cdot 16$ de marzo a las 12:15

017 Carlos Eduardo San Roman estafadores aprendan de la FAP

$4 \cdot 16$ de marzo a las 12:21

018

Majo Castro

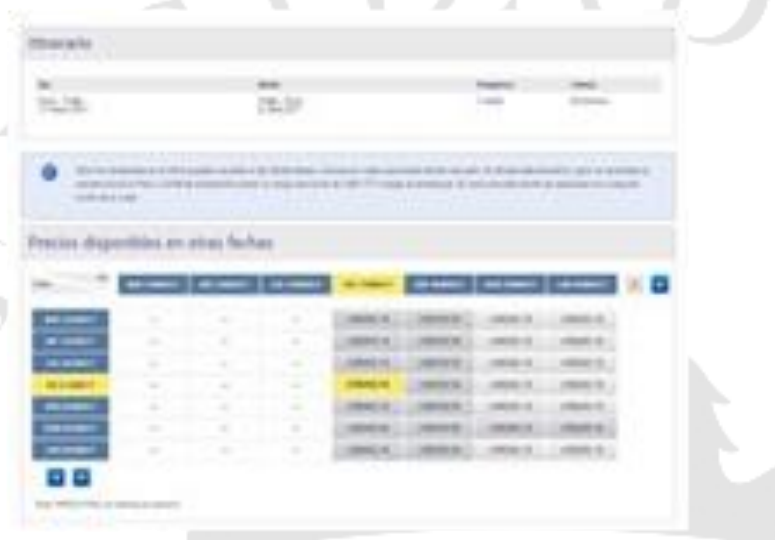

$5 \cdot 16$ de marzo a las $12: 21$

019 Luis Goycochea Navarro

$1 \cdot 16$ de marzo a las 12:21

Anitta Tantalean No DEBERÍAN NI COBRAR!!! la gente en estos momentos está necesitando más el ahorro q gastar X un pasaje, Todo cobran CARAJO!!! X eso ESTAMOS CÓMO ESTAMOS!!! nadie se solidariza !!!

Ya es hora de darse la mano y ayudarnos!

$3 \cdot 16$ de marzo a las $12: 54 \cdot$ Editado

$021 \quad$ Kelly Enriquez Baygorrea Rateros!!

$4 \cdot 16$ de marzo a las 12:27

022

Will Wills Son unos hijos de puta malnacidos como mierda pueden set tan inhumanos ...chilenos tenian q ser..

$8 \cdot 16$ de marzo a las 12:28

023 Mily Rivera Alvarez Falsos, mentirosos!!!!!

$3 \cdot 16$ de marzo a las 12:29

024 Helen Mabel Rateros solucionen su problema es lo mínimo q deben hacer

$6 \cdot 16$ de marzo a las 12:31

Sarak Cotarma Carolina Pizarro Anaya no le prestes atención creo que el ajjj se le salió cuando miraba su espejo!!

$3 \cdot 16$ de marzo a las $12: 31$

026 Johanna Cachique Grabalos y denuncialos por publicidad engañosa al consumidor!

$6 \cdot 16$ de marzo a las 12:36

Ruben Yonathan Eguizabal Matos Esto es momentáneo, que pase todo y que nadie de los peruanos use esa línea así, se morirán y quebrara esa aerolínea 
$2 \cdot 16$ de marzo a las 12:39

028 Yancito Cadenillas Fernandez Es una total burla, hace rato cotice lima jaen lima no hay disponibilidad hasta el 22. Y ya esa fecha el pasaje me sale USD 241.

$1 \cdot 16$ de marzo a las $12: 47$

029 LATAM Airlines Hola Andrea, te brindamos respuesta por inbox. Buen día. 16 de marzo a las 13:00

Ma Cristina Uceda de Brivio Ayer mi hno viajo pago la penalidad y el pasaje le costó 185 dólares más la penalidad, aprovechando su desesperación pago!

La página respondió en privado $\cdot 4 \cdot 16$ de marzo a las 13:11

\section{CODIGO COMENTARIO}

2C02 Freddy Aguilar Deben trasladar a pasajeros varados en de los pueblos mas lejanos gratuitamente...

$25 \cdot 16$ de marzo a las 11:39

Ocultar 17 respuestas

LATAM Airlines Hola Freddy, hemos dispuesto 2 vuelos de ayuda humanitaria en la ruta Lima-Piura para este viernes 17 y el sábado 18 , llevando voluntarios y carga a la zona afectada. Si quieres ser parte de este equipo de voluntarios por favor escríbenos a voluntariado.corporativolp@latam.com o si deseas hacer donaciones lo puedes hacer a través de Caritas del

001 Perú https://www.facebook.com/caritasdelperu/. Saludos. Cáritas del Perú

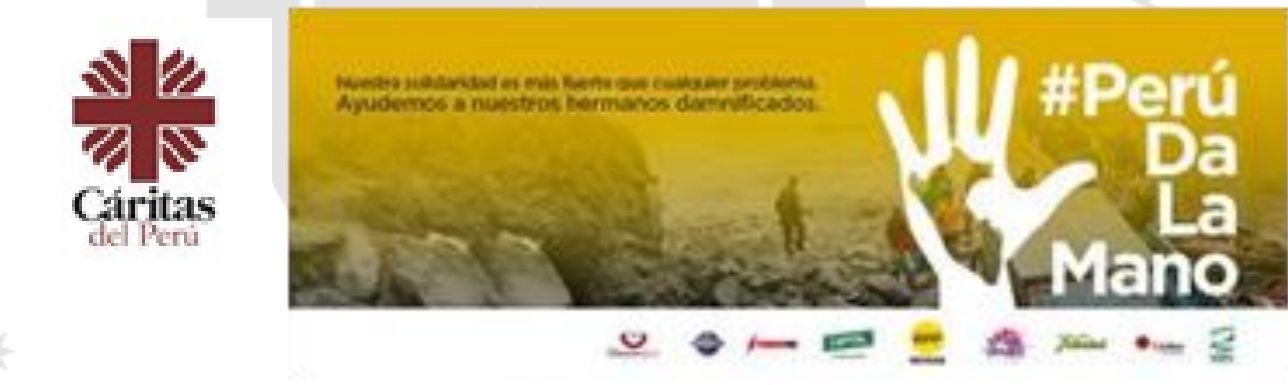

39.390 Me gusta

483 personas están hablando de esto

$43 \cdot 16$ de marzo a las 11:42

002

Fatima Salazar Yo soy de piura tengo un bebe y necesito regresar a mi ciudad apesar que esta este callendo en pedazos

Mi vida entera esta alla ,mi familia ,mis estudios

$2 \cdot 16$ de marzo a las 12:04

003 Freddy Aguilar Que bueno que la empresa tengan tiempo para responder los comentarios

$2 \cdot 16$ de marzo a las 12:13

004 Angel Gonzales te cago

$3 \cdot 16$ de marzo a las $12: 41$

Renato Daniel Daniel VOLUNTARIADO NI MIERDA ! CHILENOS HDP lo unico q quieren es 
lucrar con la desgracia !!!

9. 16 de marzo a las 13:11

006

Ma Cristina Uceda de Brivio Yo vivo en mancora no hay como pasar, somos 4 dos adultos dos niños,LATAM Airlines

16 de marzo a las 13:21

007 Ericka De Los Rios LATAM Responde a quienes les conviene!!!

$2 \cdot 16$ de marzo a las 13:59 que es de trujillo y queremos regresar a nuestros hogares pero los pasajes estan demasiados elevados! $2 \cdot 16$ de marzo a las 15:21

Yessica Yuliana Rios Narcizo Porque no hacen vuelos de lima a trujillo, hay gente varada en lima que es de trujillo y queremos regresar a nuestros hogares pero los pasajes estan demasiados elevados! 16 de marzo a las 15:21

010 Lizet González Respondannnnnnnnn.

16 de marzo a las 15:22

Maria Liliana Montenegro Quisiera saber si hay vuelo de retorno a Chiclayo para el sabado .por favor responder, gracias

16 de marzo a las 20:09

Talitha Qumi Hola LATAM Airlines a mi me gustaría ayudar en el voluntariado por favor me indican que pasos seguir.

17 de marzo a la 1:38

LATAM Airlines Hola Jill, gracias por tu interés en apoyar la emergencia en Piura. Los cupos para voluntarios en Caritas del Perú ya están tomados. Sin embargo, si estás listo para viajar y tienes una institución a la que puedas sumarte escríbenos a voluntariado.corporativolp@latam.com para incluirte en alguno de nuestros vuelos de ayuda humanitaria.

\section{7 de marzo a las 2:10}

LATAM Airlines Jackeline, si aún necesitas asistencia, envíanos un inbox con más detalles.

18 de marzo a las 4:35

Vilma Ramos Hoyos Buenas tardes tengo.cuatro pasajes comprados para mañana a las $10 \mathrm{y}$ am con

015 destino a jaen de aqui de Lima

18 de marzo a las 14:26

LATAM Airlines Hola Vilma, hemos enviado mayor detalle de tu

016 requerimiento por inbox. Saludos.

18 de marzo a las 14:56

017 Cristian Gremy Cuanto está el pasaje de Lima a jaen alguien me puede desie

\section{7 de marzo a las 21:57}

\section{CODIGO COMENTARIO}

Nilda Molero Estoy indignada ante la actitud de esta empresa, les comento mi caso, compramos pasajes para mis padres para que vengan a vacacionar a Lima del 25 al 30 pero por todo lo que esta pasando en la capital, se pusieron nerviosos y ahora no quieren viajar, son ancianos y es comprensible su actitud, tampoco podemos arriesgarlos o exportarlos a

2C03 algún peligro llame a la empresa pidiendo un poco de consideración después de atenerme de una manera nada agradable, me dijeron que podían devolverme solo los impuestos de los pasajes que no era mas que 30 dolares en total compramos 5 pasajes osea la devolución no seria ni siquiera el 50\%, es una vergüenza que no exista un poco de consideración ante la situación que todos estamos viviendo, realmente me siento indignada ante la actitud de ustedes. 
$129 \cdot 16$ de marzo a las 11:58

Ocultar 23 respuestas

$\geqslant$

LATAM Airlines Hola Nilda, estamos ofreciendo protecciones a los pasajeros con vuelos programados hasta el 31 de marzo del 2017 desde/hacia Lima (LIM). Para brindarte más detalles y verificar tu caso envíanos a través de inbox, por seguridad, el código de la reserva de los pasajeros y nombres

001 completos. Estaremos a la espera de tu respuesta.

$1 \cdot 16$ de marzo a las 12:08

Nelly Villalta Yo tenia que viajar el diez de marzo el dia 9 se desbordó nuevamente la quebrada la manuela en Piura y nadie podia pasar porque venia de talara, Llame a latam y no me quisieron cambiar los pasajes, me dieron una disculpa tonta. Para cambiar de fecha para mayo o junio porque para Abril si tengo. me cobraban $\$ .153 .00$ de penalidad A pesar que soy una viajero frecuente. Yo no quiero devolución de dinero solo quería me canbien de fecha porque no viaje porque no queria sino porque no podia.

16 de marzo a las 12:25 - Editado

003

Will Wills Es mentira estos hijos de puta quieren ganar como sea malditos de mierda como indigna ...@CanalN ..ponganle su multa

$6 \cdot 16$ de marzo a las 12:29

\section{4}

Manu Albrt Que se larguen estas empresas chilenas oportunistas que se aprovechan de la desesperación y la desgracia ajena

$5 \cdot 16$ de marzo a las 12:41

Laura Astovilca Son unos desconsiderados y malcriados sin educacion perdi 6 pasajes y ni los impuestos hasta ahora de mandan de un 17 gar a otro y nada pero si para vender todos miel perdi como

$005 \$ 700$ bueno a veces no hay otras empresas que sola sta.

$1 \cdot 16$ de marzo a las $12: 48$

AbadLoyola Pedro LATAM Airlines He sacado pasajes para el 25-Marzo para el Campeonato Nacional de Taekwondo en Arequipa. La federación lo ha suspendido por las emergencias que están ocurriendo. Pueden poner nuestros pasajes en stand by hasta que se reprograme el

006 torneo?? https://www.facebook.com/Federaci\%C3\%B3n-Deportiva.../...

Federación Deportiva Peruana de Taekwondo

16.060 Me gusta

348 personas están hablando de esto

$3 \cdot 16$ de marzo a las 14:03 $\cdot$ Editado

007 Nilda Molero LATAM Airlines Ya les envie los datos solicitados .. espero por su respuesta.

16 de marzo a las 14:14

Jessica VR LATAM Airlines no es hasta el 31/03 porque a mi me estan pidiendo reprogramaas hasta $31 / 03$,creo que las operadoras estan mal i nformadas necesito reprogramar para 19-22 me mayo y no se puede

16 de marzo a las 14:46

009 horas de anticipación y ahora es gratis para todos!!!!!!!!!

16 de marzo a las 14:51

$010 \quad$ Rolando Castro Hijos de puta

$2 \cdot 16$ de marzo a las 14:54

LATAM Airlines Hola, te hemos solicitado información vía inbox. Quedamos atentos a ello. 
16 de marzo a las 15:23

012 Jhordan MP La culpa la tenemos nosotros que consumimos esta marca.

$7 \cdot 16$ de marzo a las 15:31

013 Nilda Molero Si ya envie la informacion pero no me responden

$1 \cdot 16$ de marzo a las 15:42

014 Cut Guille Esa marca caerá cuando llegue Viva Air Perú

$6 \cdot 16$ de marzo a las 15:56

015 Liss Zuñiga q abuso!!!, lucrarse con la desgracia ajena

$1 \cdot 16$ de marzo a las 16:12

V16 Vane Armijo Señores de Latam dejen de responder con mensajes tan generales y den respuestas específicas a la quejas de sus clientes, son de lo peor

$4 \cdot 16$ de marzo a las 16:25

Nilda Molero Parecd que responde una maquina he enviado la informacion que me solicitaron y nada no me responden. No me dan ninguna solucion no quiero seguir pensando que se estan burlando de

017 nosotros

$2 \cdot 16$ de marzo a las 17:51

Nilda Molero Parecd que responde una maquina .he enviado la informacion que me solicitaron y nada no me responden. No me dan ninguna solucion no quiero seguir pensando que se estan burlando de

$018 \quad$ nosotros

16 de marzo a las 17:51

019 Florencio Tineo No consumir este marca punto

$2 \cdot 16$ de marzo a las 17:53

020 Waldir Cardoza No les compren a estas mierdas

$2 \cdot 16$ de marzo a las 19:00

$021 \quad$ Luis Lizonde Ya fuiste latam

18 de marzo a las 8:26

022

Hernán Zevallos Y que está pasando en la capital? Ahhh el corte de agua? Si pues es de ponerse muy nervioso

\section{0 de marzo a las 5:38}

Maria Rosa Ortiz Argomedo En Avianca por cancelar un vuelo, solo se quedan con máximo el 10\% de lo que pagó, según me explicaron son impuestos que no son reembolsables, cancelé 24 horas antes, y en 4 días ya estaba el dinero reembolsado en mi cuenta. En cambio LAN es malísima, un robo para

023 los peruanos. No compren ahí!

\section{CODIGO COMENTARIO}

Zulema Fernandez Buenos días quería saber si había alguna novedad con respecto a los pasajeros que queremos cambiar nuestros pasajes a Piura este mes de abril sin penalidad. Aún no tenemos respuesta de parte de ustedes y como sabrán Piura sigue cada vez peor, en estado de emergencia y con serios problemas de sanidad como para viajar orita en abril. Mi pasaje es para el 7 ósea la próxima semana y necesito saber qué hacer ya por favor . Espero su pronta respuesta y comprensión sobretodo. Gracias saludos.

$5 \cdot 28$ de marzo a las 6:26

Ocultar 13 respuestas

\section{F}

LATAM Airlines Hola Zulema, contamos con excepciones para pasajeros viajando hasta el 7/Abr/2017, envíanos por inbox tu código de reserva o número de ticket y nombre de los pasajeros para entregarte asistencia. 
$1 \cdot 28$ de marzo a las 7:49

002 gracias!

\section{8 de marzo a las 8:25}

003 LATAM Airlines Te hemos enviado un inbox.

$1 \cdot 28$ de marzo a las 8:49

Estefanía Desulovich Hola! Yo tengo pasajes para viajar el 10 de abril a piura, pero la situación está $004 \quad$ cada vez peor. Veo en los comentarios que las excepciones son solo marzo o hasta el 7 de abril. Como
puedo hacer?

$1 \cdot 28$ de marzo a las 17:44

Katherine Domínguez Hola LATAM Airlines. Yo también tengo pasaje para viajar a Piura pero el 14 de abril; sin embargo las excepciones son solo hasta el 7 de abril. Claramente en 2 semanas no se va a arreglar el pase por carretera ni la situación de todos los pasajes que vienen postergando por lluvias y reparaciones de la pista de aterrizaje. Cómo puedo hacer? Deberían ampliar las fechas de las excepciones.

$4 \cdot 30$ de marzo a las 10:03

LATAM Airlines Hola Katherine, te sugerimos estar atenta a nuestra web y redes sociales ante futuras noticias sobre las excepciones debido a las lluvias en Perú. Si deseas confirmar un cambio ahora será bajo las

006 condiciones de la tarifa. Quedamos atentos a tus comentarios.

30 de marzo a las 10:52

Ximena Cano Artadi A mi me.pasa igual yo viajo supuestamente el 14 de abril y Latam no me da una solución al.contrario me.quieren cobrar más por cambio de fecha

Ximena, debido a lo sucedido en el Norte del país, estamos ofreciendo protecciones para vuelos programados hasta el 7 de abril a las ciudades de Piura, Talara, Tumbes, Trujillo y Chiclayo. Por el momento no contamos con extensión de fechas. En el caso de tu reserva, puedes hacer solo el cambio de fecha sujeta al Código de Consumo, la cual implica una multa de USD 16 por pasajero sujeta a diferencia de tarifa y máximo de postergación de 30 días. Lo puedes solicitar como mínimo hasta 24 hrs antes del vuelo. Conoce más detalles aquí: https://goo.gl/wkTjZG. Por otro lado, podrás solicitar la devolución solo de tasas aeroportuarias. Quedamos atentos a tus consultas.

Te invitamos a evaluar la calidad de nuestro servicio aquí: http://bit.ly/1CU3zvI. Gracias.

\section{Endosos y Postergaciones}

En cumplimiento del Código de Protección y Defensa del Consumidor informamos las condiciones para Endosos y Postergaciones de

LATAM.COM

30 de marzo a las 11:37

LATAM Airlines Ximena, comprendemos tu situación. Tal como te indicamos vía inbox, te sugerimos permanecer atenta a nuestras páginas oficiales.

\section{0 de marzo a las 19:51}

Lpp Lili Zziitaa Señores de latam los q compramos anticipadamente con intención de turismo pedimos porfavor haya una opción de cambio de destino imposible q en unas semanas se arregle y se recupere la ciudad mi viaje es el 24 de abril a Piura compré para mi madre mi tía y una prima...

009 Deberían tener consideración o por lo menos postergarnos la fecha para cuando pase todo esto sin ningun recargo... Lo q ustedes hacen es aprovechar la desgracia de nuestro país ... No podemos estar a la espera necesitamos organizarnos para dejar todo nuestras responsabilidades bien.. porfavor consideración a sus consumidores. 
Ana Gonzales Señores yo también me encuentro en la misma situación, con mi familia hemos comprado pasajes con anticipación para viajar el 21 de abril para pasar unas vacaciones en la playa, somos tres personas y de acuerdo a lo que indican solo podrán cambiar pasajes los que tengan boletos hasta el 07/04. Cómo voy a poder ir a la playa con todo este problema de los huayco. Tengan en cuenta esta situación y bríndenos una solución que no genere que prácticamente paguemos por penalidad el mismo costo que pagamos por él pasajes.Irma Consuelo y Armando

$2 \cdot 1$ de abril a las 5:15

LATAM Airlines Hola Ana, por el momento contamos con excepciones para vuelo programados hasta el día 7 de abril. Sin embargo, debido a la situación del país estaremos evaluando la información constantemente y en

011 caso de novedades para extender las fechas entregaremos la información a través de nuestras redes sociales y página web. Así mismo, para verificar tu reserva, indícanos las rutas y apellidos de los pasajeros, vía inbox.

Quedamos atentos. Saludos.

$1 \cdot 1$ de abril a las 5:51

Lpp Lili Zziitaa Ana Gonzales Maria Julia Falcon Cespedes deberíamos buscar dónde quejarnos la ciudad está siendo declarada en emergencia y los señores de LATAM no tienen consideración con muchos que adquirimos los pasajes...A todos mandan los mismos mensajes y los mismos links

012 ticketemos a los demás y formemos una cadena de protesta ante las negativas de esta empresa.

$1 \cdot 1$ de abril a las 8:07 $\cdot$ Editado

013

Katherine Domínguez LATAM Airlines su último comunicado publicado en facebook es del 16 de marzo, no hay ninguno donde indiquen nada sobre abril.

\section{CODIGO COMENTARIO}

Sissy Del Rosario Bueno dias, tengo un vuelo para Piura el día 11 de abril, me iba de vacaciones.. pero veo que Piura sigue terrible con muchas lluvias y en estado de emergencia.. Deseo cancelar ese viaje por obvias razones, Piura aun no es seguro, llamo al Call Center de Latam me hacen esperar 40 min para que me conteste un español que no sabe lo que pasa y me dicen que me cobraran por cancelar o cambiar mi vuelo, Por favor nos podrían comunicar si también podremos cambiar o cancelar sin penalidad ya que en abril todavía esa area aun se encontrará con problemas de lluvias tal como lo han pronósticado en Senami??? Quedo a la espera de su pronta respuesta notar que estoy a 2 semanas del viaje y me parece una irresponsabilidad de parte de Latam sabiendo la problematica del pais en este momento que hasta ahora no se pronuncie sobre como se resolvera los vuelos de las personas que viajamos en abril. Muchas gracias. Yolanda Del Rosario

$2 \cdot 26$ de marzo a las 11:50 - Editado

Ocultar 17 respuestas

\section{每}

LATAM Airlines Hola Yolanda, contamos con protecciones para vuelos programados hasta el 31 de marzo. Para verificar tu caso envíanos el código de reserva a través de inbox, por seguridad, caso contrario indícanos la ciudad de origen así como la fecha de vuelta y nombre de los pasajeros.

$001 \quad$ Quedamos a la espera.

26 de marzo a las 12:04 
Sissy Del Rosario Ya mande mi caso y me dicen lo mismo que van a cobrar por un viaje que no realizaré por que Piura esta en estado de emergencia... Que vergüenza que para nada les importe el bienestar de sus clientes e indican que tengo que pagar una PENALIDAD por cancelación o cambio. Sres mi motivo de cancelación es por que Piura esta inundado no porque me da la gana.

\section{$2 \cdot 26$ de marzo a las $14: 35$}

Carla Gutiérrez Meza Estoy en las mismas. Si quiero cambiar de destino (Cusco), me cobran el doble, si cambio de fecha igual. Encima, todavía siguen evaluando si ampliar las excepciones

003 comerciales o no para los vuelos de abril. Se aprovechan de la situación. De lo peor con esta empresa.

\section{8 de marzo a las 11:26}

Sissy Del Rosario Lo peor es que me acaban de mandar un mensaje por inbox indicando que se ha extendido pero hasta el 7 de abril... Me parece una burla ya que en mi queja claramente indico que mi boleto esta para el 11 de abril. La verdad que esta situación de parte de Latam cada dia indigna mas

\section{La página respondió en privado $\cdot 28$ de marzo a las 11:47}

\section{LATAM Airlines Sissy, hemos respondido vía inbox. Quedamos atentos a tus} 005 comentarios.

\section{8 de marzo a las 16:09}

Sissy Del Rosario Sres. LATAM Uds. Responden para decirme que pague... Porque no contemplan devolución o cambio sin PENALIDAD en abril... Yo ni nadie tiene que pagar penalidad puesto que no es culpa de nosotros que los desastres naturales hayan puesto en emergencia distintos lugares del Perú... Pero si es su responsabilidad de Uds. Velar por la seguridad de sus clientes y brindar

006 facilidades de cambios o cancelación de los pasajes de sus clientes. Pero son tan usureros que llaman para practicante condicionar al cliente diciendo que pague para cambiar porque para Uds. Las inundaciones en Piura no es nada y si quiere que tome el cambio o no, pero de tomarlo que pague sino no procede, que horror... Ni siquiera realmente toman los casos por cliente sino como robots actúan con negativa.

$1 \cdot 30$ de marzo a las 8:53 Editado

007 LATAM Airlines Sissy, te hemos brindado respuesta vía inbox. Saludos. 30 de marzo a las 11:10 extender las fechas entregaremos la información a través de nuestras redes sociales y página web. Saludos.

\section{0 de marzo a las 14:16}

Lpp Lili Zziitaa Organicemos un plantón en un canal para ser escuchados.. esperamos con tanta ilusión nuestro viaje de vacaciones y está empresa no nos da solución justa ... Podría. Darnos opción de cambio de destino sin recargo, devolución del dinero, postergar la fecha.. etc. Sin embargo aprovechan de la desgracia de los peruanos este fenómeno afecta a todos incluyendonos.. pasen la voz y etiqueten si LATAM no nos escucha los medios de TV influenciaran en su decisión. Sissy Del Rosario Carla Gutiérrez Meza

$1 \cdot 30$ de marzo a las 22:54

Sissy Del Rosario Si estoy de acuerdo hay que mandar al Whatsapp de los noticieros lo que estan haciendo si somos cada vez mas los que denuncian este abuso Latam hara algo al respecto ya que por 011 ahora al tener la sarten por el mando le importa un pepino las quejas de sus clientes.

\section{$3 \cdot 30$ de marzo a las 23:01}

Alvaro Torres Buenas noches! yo también tengo reservados para el 21 de abril dos pasajes LIMA TALARA LIMA, y la respuesta de los sres. de Latam es la misma, pagar por concepto de reemision de 16 USD, UNA VERGUENZA, nada les cuesta darnos las facilidades para reprogramar, cambiar o 
$2 \cdot 1$ de abril a las $18: 42$

Sissy Del Rosario Hay que denunciar esto al Whatsapp de Latina... Si somos varios así saldrá en el

013 noticiero y mas gente podrá exponer su molestia y asi Latam realmente entenderá... 989090909 . Por favor hay que difundir esta situación.

$5 \cdot 1$ de abril a las 21:24

$014 \quad$ Lpp Lili Zziitaa Yo ya lo hice

$1 \cdot 3$ de abril a las 4:58

$015 \quad$ Lpp Lili Zziitaa Hagan lo mismo

$1 \cdot 3$ de abril a las 4:58

Carolina Núñez Gloria Sissy Del Rosario duda, además de queja en los medios te quejaste con

016 Indecopi? ya que veo que estamos muchos en las mismas y no dan mayor solución. Gracias por tu respuesta!

3 de abril a las 14:57

Sissy Del Rosario Ya presente mi reclamo a Indecopi... Por la página... Háganlo para que de este modo Latam realmente se preocupe realmente por el cliente... Empatia seres de Latam.. Mucha gente esta en una situación preocupante por culpa de Uds.

3 de abril a las 23:04

\section{CODIGO COMENTARIO}

Jose Andre Compre pasajes para 3 personas para viajar a Piura durante la semana santa. Queremos cambiar la fecha de viaje o el destino y no nos lo permiten. Solo quieren postergar el viaje hasta 30 días pagando una penalidad.

Realmente son de lo mas miserables sabiendo todo lo que esta pasando en el norte y el brote de dengue y enfermedades.

$1 \cdot 8$ de abril a las 9:43

Ocultar 13 respuestas

\section{F}

LATAM Airlines Jose, las excepciones hacia la ruta de Piura se han extendido, por lo tanto queremos verificar tu reserva y ayudarte, para ello es necesario que nos brindes tu código de reserva o número de ticket vía

001 inbox. Quedamos atentos a tus comentarios. Buen día.

8 de abril a las 11:03

002

Jose Andre Ya mande los datos solicitados, esperó ni recibir la misma respuesta que le han dado a todos.

8 de abril a las 11:40

003 LATAM Airlines Jose, te hemos respondido a través de inbox. Saludos.

8 de abril a las 11:50

Jose Andre Son la peor basura. Solí me han respondido lo mismo que me dijeron por teléfono que no

$004 \quad$ epidemias.

8 de abril a las 11:55 - Editado

Jose Andre Como saben que tienen muchos pasajes vendidos para el feriado largo, prefieren hacer que la gente solo pierda sus pasajes sabiendo que no se van a exponer yendo a Piura en estos momentos.

$1 \cdot 8$ de abril a las 11:56 
requerimiento.

8 de abril a las 14:10

Isabel MV Tengo el mismo caso que todos. Tengo 6 pasajes y me ponen la misma restricción de viaje, encima esperan que pague una millonada por el cambio. El país está en emergencia no sean vivos

$3 \cdot 8$ de abril a las $15: 26$

008 Jose Andre Su respuesta nuevamente. No nos importa lo que te pasa y pierde tus pasajes. 10 de abril a las 10:59

009 Jose Andre Su respuesta nuevamente. No nos importa lo que te pasa y pierde tus pasajes.

10 de abril a las 11:00

Luis Montero Hola Jose Andre, veo que llevas varios días con este tema, te han atendido y han accedido con excepciones a este caso fortuito? Estoy en un caso similar, no contestan el call, y es claro que Piura está en emergencia, hasta el mismo Latam está sintiendo esa dificultad en el aeropuerto de

010 Piura...

$1 \cdot 11$ de abril a las 9:44

Jose Andre Me han solicitado algunos documentos. Lo ultimo que se es que ayer se declaró emergencia sanitaria a varios departamentos incluidos Piura, debido a epidemia de dengue y zika. 11 de abril a las 10:06

012 Jose Andre Me han solicitado algunos documentos. Lo ultimo que se es que ayer se declaró emergencia sanitaria a varios departamentos incluidos Piura, debido a epidemia de dengue y zika. 11 de abril a las 10:06

LATAM Airlines Hola Jose, para proseguir con tu caso deberás enviar los 013 datos solicitados. Quedamos atentos.

CODIGO COMENTARIO

$2 C 07$

Marisol Cuadros Tengo 2 pasajes, para Arequipa y Cusco... cómo hago para poder coordinar la devolución o reprogramación? no entran las llamadas por teléfono!! Por favor ayuda! gracias!

La página respondió en privado $\cdot 4 \cdot 16$ de marzo a las 14:49 $\cdot$ Editado

LATAM Airlines Hola Marisol, para asistirte, hemos solicitado algunos datos

001 por inbox. Estaremos atentos a tu respuesta.

16 de marzo a las 14:51

Roberto Merino Hola, yo tengo el mismo problema y les he dejado los datos de mi vuelo desde la

002 mañana y no me responden ni los comentarios, ni mensajes y al telefono.... que hago? Mi vuelo deberia ser en dos horas!!!

16 de marzo a las 15:46

003 tu seguridad.

16 de marzo a las 16:50

004 para Arequipa por fa.

16 de marzo a las 18:16

005 Marisol Cuadros envié lo que me solicitaron por inbox hace dias... aun no tengo respuesta....

20 de marzo a las 12:26

LATAM Airlines Hola Marisol, para asistirte te brindamos respuesta por

006 inbox. Buen día.

20 de marzo a las 12:37

Vilma Alcarraz Flores Buenas noches quisiera saber si hay alguna promoción para viajar a Arequipa para el mes de mayo o junio por favor de antemano muchas gracias 
La página respondió en privado $\cdot 9$ de abril a las 19:17

CODIGO COMENTARIO

2C08 Fernando Tupia Mi viaje era para el 16 a piura, pero es imposible.viajar en estos momentos, necesito la devolucion del dinero, piensen en sus clientes, sin clientes no existen las empresas.

1 de abril a las 6:30

LATAM Airlines Fernando, para poder brindarte mayor información, necesitamos que nos indiques tu código de reserva vía inbox. Quedamos

001 atentos.

1 de abril a las 7:17

002 Fernando Tupia Ya se los envie

5 de abril a las 20:17

LATAM Airlines Fernando es necesario que nos indiques tu numero de documento de identidad y nombres de las personas que se encuentran en

003 tu reserva. No olvides validarnos los datos por inbox. Quedamos atentos.

5 de abril a las 22:43

$004 \quad$ Fernando Tupia Ya les envie los datos

La página respondió en privado $\cdot 8$ de abril a las $14: 12$

LATAM Airlines No hemos recibido tu inbox, Fernando. Envíalo

005 nuevamente.

$1 \cdot 8$ de abril a las $14: 31$

006 Fernando Tupia Volvi a.enviarlo

8 de abril a las 20:25

CODIGO COMENTARIO

2C09

Jer Robles Cas Saludos.. tengo dos boletos a Piura 8 abril y retorno 10abril, que posibilidad de cambiarlos al destino Tumbes. A esperas de sus comentarios

30 de marzo a las 15:53

LATAM Airlines Hola Jer, por favor envíanos tu código de reserva o número

001 de ticket vía inbox. Quedamos atentos.

30 de marzo a las 16:08

002 Jer Robles Cas Son dos boletos gracias y a esperas de su respuesta

31 de marzo a las 6:55

LATAM Airlines Jercy, verificamos que tu vuelo de Piura hacia Lima se encuentra reprogramado, por lo tanto te brindamos la siguiente protección: puedes adelantar 7 días o postergar 15 días de manera gratuita por única vez. Caso contrario solicitar la devolución del pasaje. De acuerdo a tu consulta, si deseas modificar la ruta o modificar la fecha de tu viaje a mas allá del plazo indicado, se te cobrará una posible diferencia tarifaría. Así 
mismo, ocultaremos tu publicación por motivos de seguridad, ya que contiene información privada. Saludos.

Te invitamos a evaluar la calidad de nuestro servicio aquí: http://bit.ly/1CU3zvI. Gracias.

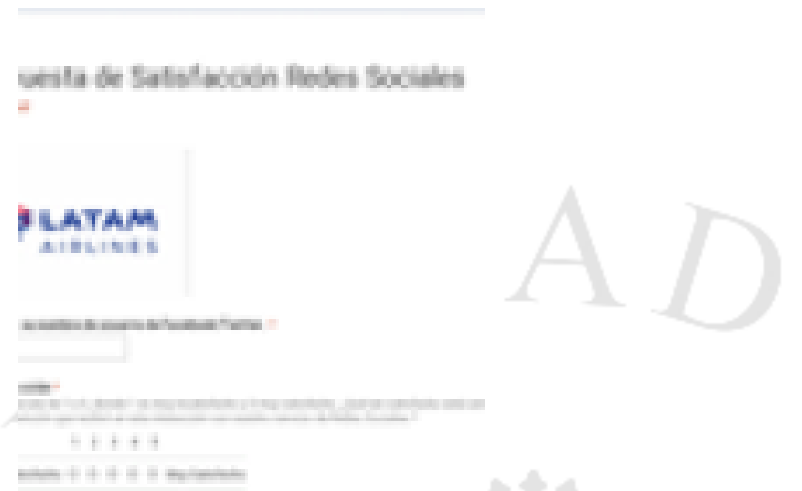

Encuesta de Satisfacción Redes Sociales

DOCS.GOOGLE.COM

31 de marzo a las 6:59

004 Jer Robles Cas Gracias por la información estaré confirmado directamente este 01 de abril 31 de marzo a las 7:19

005 LATAM Airlines Gracias a ti. Quedamos atentos a tus comentarios. Saludos. 31 de marzo a las 8:00

\section{CODIGO COMENTARIO}

Lorena Hurtado Velarde LATAM Airlines tengo dos pasajes a Piura para el 1 de Abril a las 7 am, sin embargo no me dejan realizar el cambio sin cobrarme penalidad, en su comunicado dice que es para los pasajes del mes de Marzo, pero sean conscientes que el problema persiste y que no hay

2C10 $\quad \begin{aligned} & \text { diferencia en el problema que atraviesa } \\ & \text { respuesta comprensiva de parte de uds. }\end{aligned}$

$1 \cdot 26$ de marzo a las 13:36

LATAM Airlines Hola Lorena, nuestras excepciones comerciales se están brindando a pasajero cuyos vuelos operen hasta el día 31 de marzo. Ante tu situación, te sugerimos permanecer atenta a futuras excepciones que estarían siendo publicadas a través de nuestra web o redes sociales oficiales. Recuerda que es nuestra prioridad el velar por la integridad de nuestros pasajeros y comprendemos la situación que nos describes; sin embargo, apelamos a tu comprensión ante esta situación con lo antes expuesto. Saludos.

26 de marzo a las 13:52

Karla Rejas Si por favor. Abril ya esta a 4 dias. Yo tengo un pasaje en semana Santa. Seria terrible viajar a Piura. Hagan esa excepcion en esas fechas que son muy concurridas. Gracias.

$2 \cdot 27$ de marzo a las 6:25 
Paola Relayze Porras Hola LATAM Airlines, aún las condiciones climáticas son desfavorables por el norte del país. Ya extendieron las excepciones comerciales hacia el mes de abril? Todos merecemos salvaguardar nuestras vidas. Es una cuestión de seguridad, salud y tranquilidad.

$3 \cdot 27$ de marzo a las $6: 57$

LATAM Airlines Paola, te hemos enviado una respuesta a través del muro de Facebook. Estaremos a la espera de tu respuesta a través de inbox, ya 004 que son datos privados.

27 de marzo a las 7:35

Lorena Hurtado Velarde LATAM Airlines LATAM Airlines deben estar enterados de la situación de Piura en este momento, el río se ha desbordado y estando a 4 días del 1a de Abril les pido que amplíen el plazo para poder cambiar la fecha de mi viaje, si ustedes dicen que es " su...Ver 005 más

La página respondió en privado $\cdot 27$ de marzo a las 11:00

006 LATAM Airlines Lorena, te hemos enviado respuesta por inbox. Saludos. 28 de marzo a las 13:17 007 Katy Sv LATAM Airlines yo tengo un pasaje para el 1 con mi bebé y madre es.imposible.viajar

29 de marzo a las 6:25

Lpp Lili Zziitaa A todos nos tiene igual son de lo peor esta empresa solo tiene una máquina o un sistema q envía los mismos mensajes a todos.. hagamos algo esto les.escribi Inbox y vaya respuesta..La misma

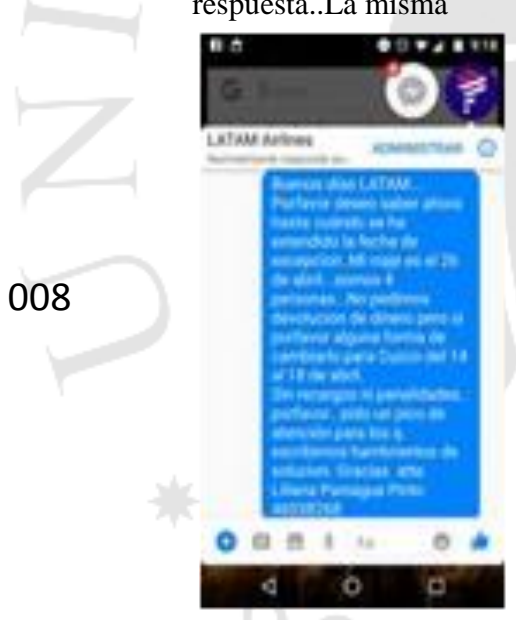

3 de abril a las 7:27

Lpp Lili Zziitaa

009

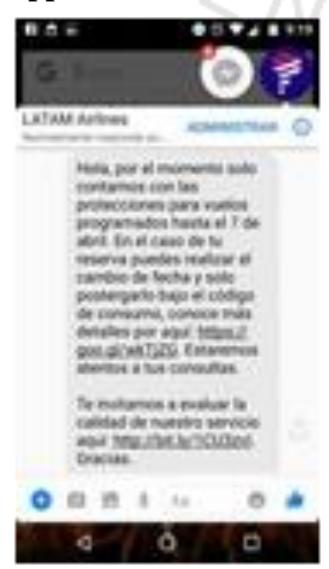




\section{CODIGO COMENTARIO}

Grupo Gumisa Mentira!!!!!!!!!!!!

Fui a un módulo y me dijeron que llame a la operadora (me contesto una chilena que no sabía nada de la excepción y menos de lo que pasa en Perú) y me dijo que fui yo quien decidió no subir y que era mi problema) que el vuelo se realizó (con un gran retraso) y ya no hay nada que hacer.

2C11 La empresa, por seguridad de los colaboradores, no envió por medidas de precaución.

Ni siquiera pedimos devolución, pero si cambio de fecha y nada. Es su problema, eso fue lo que me dijo.

Por ahora es Latam, ya viene la real competencia.

$2 \cdot 17$ de marzo a las 5:39

LATAM Airlines Hola, para verificar tu caso envíanos a través de inbox tu

001 código de reserva, por seguridad. Estaremos atentos a tu respuesta.

17 de marzo a las 5:45

002 Sara Manayay Yo envíe mi información el día de ayer y aún sigo en espera.

$1 \cdot 17$ de marzo a las 6:15

003 Grupo Gumisa Ya se envió el inbox.

Saludos,

\section{7 de marzo a las 6:35}

LATAM Airlines Hola, hemos respondido a tu mensaje vía Inbox con

004 respecto a tu requerimiento. Saludos.

17 de marzo a las 6:46

Grupo Gumisa Típico: dicen por inbox, responden lo que les conviene, no hay solución y después

005 solo silencio.

18 de marzo a las 17:47

006 Gracias.

LATAM Airlines Te hemos enviado un inbox con mayor información.

18 de marzo a las 23:10

\section{CODIGO COMENTARIO}

Rosario Escudero Muy mal su trato del personal de Pucallpa, mi tía acaba de llegar a Lima , siendo una adulta mayor, llegó a las 5:30 am y la de atención comenzó a reñirla que porque llega tan tarde, ese es el trato preferente que dan al adulto mayor ahora? El avión partía 7:00 am y partió a las 8:00 , de eso no me quejo es del maltrato de su personal que siguió dentro del counter.

$2 \cdot 30$ de marzo a las 7:58 
LATAM Airlines Hola Rosario, lo sucedido escapa de nuestro ideal. Para poder asistirte por favor brindanos por inbox el código de reserva o número

001 de ticket electrónico, nombre y apellido del pasajero, número de documento y tus datos de contacto (e-mail y número telefónico). Quedamos atentos a tus comentarios. Saludos.

$1 \cdot 30$ de marzo a las 8:06

002 Evi Alvarado Deverian saber a que tipo de personal contratan

$2 \cdot 30$ de marzo a las 14:27

Rosario Escudero Tengan la seguridad que en breve se los envío, de la misma forma quiero que me 003 respondan que sanción tomarán con ese mal personal esa srta que maltrata a una persona adulto mayor no teniendo respeto a nada

30 de marzo a las 15:01 · Editado

LATAM Airlines Rosario, sabemos tu molestia. Estaremos a la espera de los 004 datos solicitados.

1. 30 de marzo a las 15:04

005 Rosario Escudero Ya les envíe los datos

30 de marzo a las 18:26

006 Evi Alvarado Veremos qe respuesta dan y que acciones toman asi esa señorita

30 de marzo a las 18:27

LATAM Airlines Rosario, también te hemos enviado una respuesta vía inbox.

$007 \quad$ Gracias.

30 de marzo a las 23:41

\section{CODIGO COMENTARIO}

$2 \mathrm{C} 13$

Ximena Cano Artadi Ahora cuando sabremos los wue viajamos en Abril si hay más fechas para las devoluciones?

9 de abril a las 17:51

Andrea Pastor LATAM Airlines mencionan que esperemos a alguna actualización pero no 001 y oportuna..

10 de abril a las 13:40

002 LATAM Airlines Hola Andrea, hemos respondido vía inbox. Saludos. 10 de abril a las 13:47

003 Ximena Cano Artadi Dicen que hasta el 10 de Abril esto es una burla a cada rato aumentan 3 dias de cambio y no llegan a las fechas de semana santa

$1 \cdot 10$ de abril a las 17:38

LATAM Airlines Ximena, mediante inbox hemos brindado una opción a la

004 que podrías acogerte. Quedamos atentos.

10 de abril a las 19:47

$005 \quad$ Ximena Cano Artadi Enviame un número donde poder llamar

11 de abril a las 8:31

LATAM Airlines Hola, acabamos de enviarte un inbox. Por favor, verifica la

006 información. Saludos.

11 de abril a las 8:38 
2C14 Vanessa Livia Estimados he enviado un inbox para devolución de pasajes ayacucho el día de ayer, espero su repuesta

17 de marzo a las 16:41

001 LATAM Airlines Hola Vanessa, hemos respondido a tu solicitud por inbox.

17 de marzo a las 16:45

002 Vanessa Livia Estimado he mandado la información solicitada, pero no tengo respuesta

$1 \cdot 18$ de marzo a las 8:17

LATAM Airlines Vanessa, para proseguir con la devolución te hemos

003 solicitado algunos datos por inbox. Quedamos a la espera.

18 de marzo a las 10:56

004 Vanessa Livia Estimado hasta ahora no me confirman si procede o no mi devolución.

20 de marzo a las 21:01

005 LATAM Airlines Te hemos escrito vía inbox, Vanessa.

20 de marzo a las 21:31

\section{CODIGO COMENTARIO}

2C15 Karina Suárez Buenos días, se trata de los vuelos que parten sólo de lima? O viceversa? Yo tengo vuelo de tru-lim el 28/03 y de lim-tru el 02/04. También tendría que postergar???

17 de marzo a las 7:33 - Editado

\section{F}

LATAM Airlines Hola Karina, sí aplica protecciones. Para poder verificar tu reserva envíanos tu nombre completo o el código de la reserva a través de

001 inbox, por seguridad. Estaremos a la espera de tu respuesta.

17 de marzo a las 7:38

002 Karina Suárez Ya les escribí, pero no responden, estoy esperando.

17 de marzo a las 16:20

LATAM Airlines Karina, hemos respondido a tu consulta a través de inbox.

003 Sentimos la demora.

$1 \cdot 17$ de marzo a las 16:28 Silvia Villar Estrada Por favor LATAM Airlines tengo el mismo problema pero desde Piura a Lima,
contestar inbox.

1 23 de marzo a las 7:03

005 iSaludos!

23 de marzo a las 7:16 
Alexandra Sparks Pinillos Señores LATAM, que les está sucediendo que NO cumplen su palabra y las respuestas que envían contradicen las afirmaciones establecidas por Ustedes mismos! Sigo esperando la devolución de los kilómetros que faltan. Por favor los clientes les pedimos mayor 2C16 seriedad y profesionalismo. No podemos seguir lidiando con un tema tanto tiempo. Cumplan su palabra y háganse respetar como una empresa seria.

$3 \cdot 11$ de abril a las 11:07

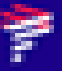

001 LATAM Airlines Hola, te hemos respondido a través de inbox. Saludos.

11 de abril a las 12:06

002 Jayme Da Cunha es la unica manera al parecer

$1 \cdot 11$ de abril a las 12:42 devolución correspondiente asap.

11 de abril a las 13:45

LATAM Airlines Alexandra, hemos enviado mayor detalle por inbox.

004 Saludos.

11 de abril a las 14:02

\section{CODIGO COMENTARIO}

\section{Andrea Pastor}

Estimados, ustedes cuentan con excepciones hasta el 7 de Abril, sin embargo la ciudad en 1 semana no se recupera. Los casos de dengue han aumentado, la ciudad está llena de polvo, me han cancelado mi hospedaje y no ofrecen ningún tipo de novedad al respecto. Cuando van a comunicar sobre alguna extensión?

Basta con mirar las noticias para saber que sus clientes requieren de cancelación o cambio de fechas, este es un tema de contingencia que otras aerolineas han solucionado casi inmediatamente, a diferencia de su servicio.

http://elcomercio.pe/.../piura-confirman-tercera-muerte...

http://rpp.pe/.../enfermedades-diarreicas-y-respiratorias..

Por favor se agredecerá su pronta solución a los pasajeros que no pueden realizar viajes a la zona.

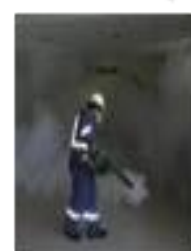

Piura: confirman la tercera muerte por dengue

Se trata de un adulto mayor de 80 años, procedente...

ELCOMERCIO.PE

$2 \cdot 10$ de abril a las 10:09

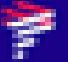


LATAM Airlines Hola Andrea, para brindarte una información detallada por favor indícanos por inbox el código de reserva o número de ticket electrónico y el nombre y apellido del pasajero. Quedamos atentos a los 001 datos solicitados.

10 de abril a las 10:31

Andrea Pastor Les he enviado mi información por inbox. Agradeceré su respuesta. Dicen que van a "evaluar" la situación, a pesar de que muy claramente esta no se ha solucionado ni se solucionará en los próximos días. Están haciendo algo al respecto?

10 de abril a las 11:48

Andrea Pastor Otras aerolíneas son más consideradas a una situación de emergencia en el país, pero ustedes no pueden dar información clara ni actualizada. Porfavor dar una solución, hay muchos pasajeros teniendo los mismos problemas.

10 de abril a las 11:50

$004 \quad$ LATAM Airlines Andrea, te hemos respondido a través del inbox.

10 de abril a las 11:56

Andrea Pastor Gracias por su respuesta, sin embargo no me han dado claridad sobre el tema.

Mencionan, así como al resto de personas, que permanezca atenta "a futuras excepciones que estarían siendo publicadas" en su web o redes sociales. Estas notificaciones no están ni siendo publicadas, solo las mencionan por interno. La última vez que pregunté fue el $7 \mathrm{y}$ me dijeron que se habian extendido hasta el 7. Hoy 10 pregunto y me dicen que se han extendido hasta el 10. Mi vuelo es en los próximos días y si no comunican con tiempo no podré hacer ningún reembolso. Es ese el objetivo? Que pierda el vuelo?

005

Me piden comprensión pero no parecen querer darle solución a los problemas.

$1 \cdot 10$ de abril a las $13: 37$

CODIGO COMENTARIO

Nathalie Valencia Rodriguez Hola LATAM Airlines tengo dos pasajes para Trujillo con fecha de salida 10 de abril, por obvias razones no puedo realizar el viaje. He ido a más de un counter / agencia y me dicen q debo hacer el cambio a través del contact Center, sin embargo no tengo respuesta cuando 2C18 llamo. Por favor su ayuda urgente.

6 de abril a las 18:28

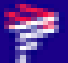

LATAM Airlines Hola Nathalie, para poder asistirte, envíanos tu código de

001 reserva o número de ticket. Quedamos atentos.

6 de abril a las 19:11

002 Walter Sánchez Nathalie, más rápido ayudan por Twitter!

$1 \cdot 7$ de abril a las 12:54

003 ayuden

7 de abril a las 12:59

004 LATAM Airlines Nathalie, te hemos respondido por Inbox. Saludos.

7 de abril a las 13:12 
Mily De la Fuente Yo necesito cambiar pasajes para abril y me dicen que tengo q pagar penalidad ademas del adicional para cambiar de destino de Piura a Arequipa malazo! No creo que en pocos dias se arregle todo el problema del norte y lamentable que LATAM Airlines no es conciente de eso.

$2 C 19$ Deben ampliar esta medida todo el mes de abril.

$1 \cdot 29$ de marzo a las $12: 44 \cdot$ Editado

LATAM Airlines Hola Mily, en estos momentos debido a la emergencia presentada estamos brindando como excepciones poder postergar los pasajes sin costo alguno a todos los vuelos programados hasta el 7 de Abril. Recomendamos que puedas estar al pendiente de nuestros medios de comunicación ya que las excepciones posiblemente puedan extenderse en

001 caso la emergencia climática continue. Si tienes dudas o consultas escríbenos. Saludos

\section{9 de marzo a las 13:22}

Mily De la Fuente Mi vuelo esta programado para el 13 de abril; cuando tendran confirmacion de 002 ampliacion de esta medida? Ya que tengo q esperar esto de parte de ustedes para modificar reservas de hotel para otra ciudad etc..

29 de marzo a las 14:47

LATAM Airlines Hola Mily, por el momento no tenemos una información específica sobre nuestras expeciones. Recomendamos que puedas estar al

003 pendiente de nuestros medios de comunicación. Saludos 29 de marzo a las 18:58

\section{CODIGO COMENTARIO}

Anabel Bohorquez Tengo viaje programado para el 07 Abril a Iquitos, como va la situación he pedido cambio para en unos meses pero me han dicho que solo puedo aplazarlo hasta 15 días??? Y que vuelva a llamar el 31 marzo...no entiendo su procedimiento pero si quieren ayudar háganlo bien!

2C20 No creo que en 15 días Iquitos salga de estado de emergencia $1 \cdot 27$ de marzo a las 10:40

001 número de ticket y datos completos del pasajero. Saludos.

27 de marzo a las 11:57

LATAM Airlines Anabel, tenemos en cuenta tus comentarios, por lo tanto te solicitamos verificar tu inbox, ya que te hemos otorgado información.

002 Saludos.

5 de abril a las 4:39 
Vilma Loayza Deberían extender el tiempo hasta abril para los cambios sin cobro de penalidad, las lluvias continúan y todo está un desastre en el norte como creen q se va poder viajar así un poco de consideración deberían tener al final lo importante es el pasajero y el bienestar del mismo pero al parecer eso poco les interesa.....

La página respondió en privado $\cdot 2 \cdot 24$ de marzo a las 8:06

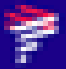

001 LATAM Airlines Hola, te hemos respondido a través de inbox. Saludos.

24 de marzo a las 10:10

Vilma Loayza Si claro LATAM Airlines pero su respuesta no ayuda, al final ubstedes no pierden cobran igual y perjudican al pasajero....que parte no comprenden q las lluvias continúan y las cosas en el norte siguen igual......deben extender el cambio de psaje sin penalidad hasta los q viajan en abril. ...que pierden si ya ganaron con la venta del pasaje sólo es un cambio de fecha no una devolución de dinero aunque ni siquiera eso pierden xq sólo devuelven los impuestos...... Ojalá pronto llegue la otra

002 línea aérea y se queden sin clientes x ser tan usureros.

$1 \cdot 24$ de marzo a las $12: 56 \cdot$ Editado

003 LATAM Airlines Hola Vila, hemos respondido via inbox. Saludos

24 de marzo a las 17:41

Karla Rejas Yo tambien quiero mi devolucion de pasaje de Abril. Es imposible viajar a Piura. Deberian comprender la.situacion.

$3 \cdot 27$ de marzo a las 6:17

Vilma Loayza Si pues ya no se q mas esperan si x las noticias claramente se ve q todo el norte está

005 inundado a donde se va ir, si esa misma gente está evacuando q inhumanos q son en LATAM Airlines 27 de marzo a las 8:40

Lpp Lili Zziitaa Hagamos un planton en un canal por aprovechados a nadie nos da respuesta de alguna manera quieren salir beneficiados.. cobrar penalidad?? Si está desgracia nos afecta a todos... Mi viaje es el 26 de abril voy por turismo.. y en esas condiciones climáticas solo nos arriesgamos si

006 vamos.. no conozco nada ni nadie consideración por favor LATAM

30 de marzo a las 22:58

\section{CODIGO COMENTARIO}

Lily Goñas Galoc Es una mentira tengo un inconveniente en la compra de un pasaje que compre por desesperación en tener que viajar cambien la ruta que iba a tomar llame a pedir por favor me cambien y me dicen que es imposible que compre un nuevo pasaje. A eso Uds le llaman apoyo $6 \cdot 23$ de marzo a las 11:32 . Editado

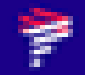

LATAM Airlines Hola Lily, para poder asistirte, envíanos via inbox tu código

001 de reserva o número de ticket. Quedamos atentos. 23 de marzo a las 13:06

002 Lily Goñas Galoc Ya les envié espero que me respondan antes de la fecha del vuelo. 23 de marzo a las 13:45

003 LATAM Airlines Lily, hemos respondido via inbox. Saludos 23 de marzo a las 14:07 
Zulema Fernandez Bueno dias, tengo un vuelo para Talara el día 7 de abril, me iba de vacaciones... pero veo que Piura sigue terrible con muchas lluvias y en estado de emergencia.. quisiera saber si puedo cambiar mi fecha de vuelo para mayo ??? Por favor nos podrían comunicar si también podremos cambiarlo sin penalidad??? A la espera de su pronta respuesta. Muchas gracias Zulema Fernandez

$1 \cdot 22$ de marzo a las 7:08

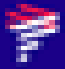

LATAM Airlines Hola Zulema, por el momento contamos con excepciones comerciales para vuelos hasta el 31 de marzo. De igual manera, la situación sigue siendo evaluada, y ante cualquier modificación, lo haremos público

001 mediante nuestra página web o redes sociales. Saludos.

22 de marzo a las 7:42

Zulema Fernandez Estaré atenta entonces porque Piura sigue grave y mi viaje es en dos semanas y la verdad no creo que sea responsable de mi parte, ni de parte de ustedes que se viaje para allá todavía..

002 todo está muy peligroso aún. Por favor consideren que viajar el 7 de abril o todo el mes

23 de marzo a las 18:19

LATAM Airlines Zulema, recuerda que ante cualquier excepción o información, lo estaremos indicando mediante nuestras redes sociales y 003 página web. Saludos.

$1 \cdot 23$ de marzo a las 18:49

Jaqueline Vg Me pasa lo mismo, pero mi caso mi vuelo es a Trujillo que está declarada en emergencia, por favor considérenlo, gracias

24 de marzo a las 10:11

\section{CODIGO COMENTARIO}

Francis Saldaña Vilela Tengo un vuelo programa para Pucallpa el 30 de marzo. No quiero hacer cambio confirmando la fecha exacta porque el tema climatológico aún es demasiado incierto, lo que quiero es poder poner mi pasaje con fecha abierta. Espero respuesta. Gracias.

La página respondió en privado 19 de marzo a las 19:47

001 Carla B Vásquez ¡Hágannos caso por favor! Les he escrito desde hace 5 días y no responden!

$1 \cdot 19$ de marzo a las 19:54

002 Francis Saldaña Vilela @LATAM Airlines respóndame el inbox. Gracias

19 de marzo a las 20:08

LATAM Airlines Francis, hemos brindado respuesta a tu requerimiento vía

003 inbox. Saludos.

19 de marzo a las 23:05

LATAM Airlines Hola Carla, te hemos solicitado mayor información vía

004 inbox. Quedamos atentos.

19 de marzo a las 23:43 
2C25 Stf La Cruz Es mentira, llame y me dijeron que solo aplica para vuelos desde el 13/03 al 22/03

$29 \cdot 16$ de marzo a las 11:57

LATAM Airlines Hola, como el comunicado especifica hemos extendido nuestras excepciones de cambio, para poder verificar lo que nos informas, por favor indícanos por inbox los datos de tu viaje como código de reserva y

001 nombre de los pasajeros. Quedamos a la espera de tu respuesta.

16 de marzo a las 12:29

002 Stf La Cruz Ya envié la información que solicitan

16 de marzo a las 12:37

LATAM Airlines Hemos respondido a tu requerimiento por inbox, puedes

003 revisar la información que te enviamos.

$1 \cdot 16$ de marzo a las 12:45

$004 \quad$ Stf La Cruz Gracias

16 de marzo a las 12:53

005 Cristhian Hinostroza Ventura Te ayudaron?

$1 \cdot 16$ de marzo a las 13:49

Stf La Cruz Me respondieron indicando que revisaron mi reserva y si procede la devolución del dinero y solicitaban mi número de Dni, envié la información que pidieron y hace 1 hora ya no tengo

006 respuesta

$1 \cdot 16$ de marzo a las 13:56 $\cdot$ Editado

$007 \quad$ Alexis Voc No te van a dar respuesta, solitos se están jodiendo.

16 de marzo a las 14:01

008 Marita Mary Ojalá resuelvan tu problema. Mantenemos al tanto y pública las comunicaciones.

16 de marzo a las 14:01

009 AbadLoyola Pedro Favor responder a mi consulta acerca de los vuelos a Arequipa

16 de marzo a las 14:36

010 Larry Alexander Tello Vela Aplica todo el mes. A mi me lo modificaron

16 de marzo a las 15:53

011 Irma Chavez Cueva

16 de marzo a las 16:07

\section{CODIGO COMENTARIO}

Cynthia Ramos Ya llamé y sólo aplica para vuelos del 15 al 17 de Marzo, ayer cancelé 2 vuelos para el día 18/03 y me cobraron penalidad de $12,000 \mathrm{kms}$. Su comunicado debería incluir las fechas a las 2C26 que aplica.

La página respondió en privado $\cdot 12 \cdot 16$ de marzo a las 10:04

Rick Prieto El comunicado dice que es para personas que vuelen durante el mes de marzo. Si te han cobrado una penalidad puedes reclamar con la empresa o incluso con Indecopi

$1 \cdot 16$ de marzo a las 10:06 
16 de marzo a las 10:10

003

Gian Fernandez Paz No entiendo? Para cuando era tu vuelo amiga. Y cuanto te cobraron el pasaje aéreo y a que destino?

16 de marzo a las 10:11

004 Cynthia Ramos Joul Benlly Asto Ruiz https://www.latam.com/es_pe/centro-de-ayuda/contacto/

\section{Contacto}

Resuelve todas las dudas relacionadas con tu viaje utilizando nuestro buscador temático, navegando por nuestras preguntas frecuentes o consultándonos por redes sociales.

LATAM.COM

\section{6 de marzo a las 10:12}

005 Héctor Plasencia González Claro, reclama para que te devuelvan tus km. Debería proceder.

16 de marzo a las 10:15

LATAM Airlines Hola, nuestro contact center es el 012138200 . Si tienes

006 alguna consulta adicional escríbenos.

18 de marzo a las 4:03

007

Cynthia Ramos LATAM Airlines, gracias por atender mi reclamo ZD- 5190146 y devolver los KMS penalizados. Cumplieron con lo indicado.

$1 \cdot 21$ de marzo a las 14:48

LATAM Airlines Cynthia, recuerda que ante futuras dudas o consultas,

008 puedes escribirnos. Saludos.

21 de marzo a las 15:28

009 Karla Rejas Quiero mi devolucion de dos pasajes para Piura en abril (sema

27 de marzo a las 6:20

\section{CODIGO COMENTARIO}

Jenny Perales Bejar Gracias por el apoyo, he solicitado la devolución de mis pasajes por teléfono y lo han hecho de manera rápida y sin mucho trámite...la atención fue muy amable, creo que es importante que nosotros tambien al comunicarnos tengamos un trato adecuado con las personas que

2C27 nos atienden, en mi caso he sentido disposición en toda mi llamada.

$15 \cdot 16$ de marzo a las $12: 38 \cdot$ Editado

\section{F}

001 LATAM Airlines Jenny, te hemos respondido a través de inbox. Saludos.

$2 \cdot 16$ de marzo a las 12:55

002 Toño Beltran De lo peor siempre hay una patera!

$6 \cdot 16$ de marzo a las 13:14

003 Alicia Zafra Siccha Jajajaj oe deja de bullear a la gente XD.

16 de marzo a las 13:26

004 Toño Beltran Me llega los(as) parteras estos csm se han aprovechado de la desgracia de nuestro país para cobrar de más

$1 \cdot 16$ de marzo a las 13:27

005 Toño Beltran Ni el sniker me calmara de decirle sus verdades a estos hdp

16 de marzo a las 13:30

Jenny Perales Bejar Lamento que tengas esa impresión, pero al igual que escribimos para quejarnos, considero que también hay que escribir para reconocer cuando recibes ayuda...que tengas un buen día 
$2 \cdot 16$ de marzo a las 13:40

007 AbadLoyola

$1 \cdot 16$ de marzo a las 14:34

008 Manuel Ac Seguramente trabaja ahí

16 de marzo a las 14:44

009 Diana Patricia Jenny Perales Bejar como hiciste para que te devuelvan tu dinero?

$1 \cdot 16$ de marzo a las 14:56

Jenny Perales Bejar Hola Diana, solo llamé e indique que queria acogerme a su excepcion comercial, que tenía pasajes comprados a Chiclayo para la próxima semana y que por la situación prefería que me devuelvan lo pagado. Me pidieron mi codigo de reserva, validaron la información y listo. De acuerdo

010 al medio de pago usado me indicaron que se procedió con mi solicitud. Me enviaron un correo confirmando lo que me indicaron por teléfono

\section{6 de marzo a las 15:37}

Gabriela Rios Eso mismo hice yo , tengo un viaje de Lima a Arequipa , pero dadas las circunstancias no se puede pasar y pedí que me hagan el cambio de Chiclayo a Arequipa y la única solución que me dieron es comprar mi vuelo de Chiclayo a Lima y el exceso en el costó es demasiado. Deberían de

011 haber soluciones

\section{6 de marzo a las 22:02}

Gleymang Yubert Jaramillo Abad Esto es falsoooo en su totalidad, porque dicen que se dara excepcionalidad y todo eso, si de antemano saben que no tienen disponible vuelos para cambiar hora o fecha... viajaba mañana en la noche y llame para adelantar o postergar el vuelo a fin de viajar en la mañana o tarde, y la respuesta fue que no habia disponibilidad de cambios hasta la otra semana...

\section{7 de marzo a las 8:15}

013 Lpp Lili Zziitaa Seguramente fue antes de fin de marzo... Solución para los q viajamos en abril... Felicidades si te devolvieron tu dinero... Pero hay muchos q aún no reciben respuesta alguna...

30 de marzo a las 23:01

\section{CODIGO COMENTARIO}

Jaqueline Ovalle Sres ILATAM Airlines yo quiero cambiar para el mes de octubre o noviembre pero no me permiten Porque? Responder urgente mi vuelo está para Talara el 25 marzo y por obvias razones

2C28 ya no podré ir

La página respondió en privado $\cdot 16$ de marzo a las 12:26

LATAM Airlines Hola Jaqueline. te hemos solicitado mayores datos por inbox

001 por tu seguridad. Esperamos tu respuesta.

$3 \cdot 16$ de marzo a las 19:14

002 Jaqueline Ovalle Gracias ya les respondí espero su ayuda

16 de marzo a las 19:53

LATAM Airlines Jaqueline, hemos respondido a tu requerimiento vía inbox.

16 de marzo a las 20:28 
Renzo García LATAM Airlines estoy al teléfono más de 2 horas y hasta ahora no puedo postergar mi $2 C 29$ pasaje de Tarapoto a Lima, que debido a las lluvias no he podido llegar a tiempo al aeropuerto. El servicio de su call centre es pésimo.

La página respondió en privado $\cdot 2 \cdot 31$ de marzo a las 18:19

LATAM Airlines Hola, te hemos solicitado mayores datos vía inbox para 001 poder asistirte. Esperamos lo solicitado.

31 de marzo a las 18:47

CODIGO COMENTARIO

Adriana Cáceres Es mentira acabo de llamar para adelantar un pasaje dentro del mes como indican ustedes y me dijeron que debia pagar una penalidad..que esto solo aplica a postergaciones y ustedes dicen claramente CAMBIAR DE FECHA, segun lo que se entiende un cambio puede ser adelantar o postergar indiferentemente

$7 \cdot 21$ de marzo a las 8:41

LATAM Airlines Hola Adriana, para brindarte una información detallada por favor indícanos por inbox el código de reserva o número de ticket electrónico y el nombre y apellido del pasajero. Quedamos atentos a los datos solicitados.

21 de marzo a las 10:05 


\section{ANEXO 7: TABLAS DE COMENTARIOS Y RESPUESTAS DEL COMUNICADO 3}

\section{CODIGO COMENTARIO}

Fernando Osorio Saravia Señores, llame a su call center y me indican que no se puede cancelar y realizar la devolución de mi dinero, porque mi vuelo del 23 de lima a piura está activo y que no puedo acogerme a este servicio hasta que se cancele y ustedes dieron las órdenes tan solo de cancelar los vuelos hasta el 22 de marzo, si el Perú está en esta de emergencia porque xuxa no nos devuelven

$3 \mathrm{CO} 1$ nuestro dinero de un servicio que no ha sido realizado, me enviaron un mensaje al inbox y hasta ahora no tengo respuesta...

Este nuevo comunicado es una mentira al igual que sus demás comunicados

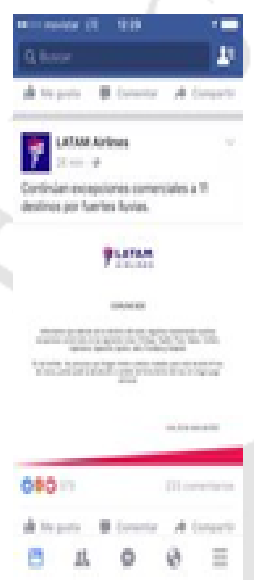

$380 \cdot 16$ de marzo a las $16: 44$

Kimberling Lino Garcia Podrías darme el número del call. Yo también viajó el 23 a piura

16 de marzo a las 17:00

LATAM Airlines Fernando, con la finalidad de asistirte hemos solicitado mayor información por inbox.

$6 \cdot 16$ de marzo a las 17:01

Cristian Salazar Reyna Jajaja...dejate de,comunicados LATAM Airlines....

Actúa....actua....Pdta.::paga tu deuda si tanto dices solidarizarte con nuestro país.. Así servirá para reconstruir algo...

$69 \cdot 17$ de marzo a las 10:38 $\cdot$ Editado

004 Liliana Soledad Vilchez Vidalòn Todo por inbox desde ayer y el problema sigue con sus pasajeros.

$19 \cdot 16$ de marzo a las 17:05

005 Alessandro Gomez Mitma Chilenos agarrando de cojudos a los Peruanos

$6 \cdot 16$ de marzo a las 17:07

006 Jose Christian Bardales Peña Una marcha mas ... por lucrar con la desgracia gogogo

$11 \cdot 16$ de marzo a las 17:07 
$6 \cdot 16$ de marzo a las 17:08

$008 \quad$ Patricia Flor Chilenos hijos de puta

$10 \cdot 16$ de marzo a las 17:10

009 Christian Martinez Y por si fuera poco deben millones a la sunat

$38 \cdot 16$ de marzo a las 17:16

010 Maravi Miguel Angel Empresa de mierda nose,porque chucha no interviene indecopi o el,estado

$26 \cdot 16$ de marzo a las 17:18

Fernando Osorio Saravia Señores de LATAM ya les envié los datos proporcinados, como me indican estaré esperando la devolución de mi dinero a mi numero de cuenta que di y espero que no

011 pase los 45 días que indican, caso contrario procede a otra instancia, saludos

$19 \cdot 16$ de marzo a las 17:19

012 Fernando Osorio Saravia Es 01-213 8200

$4 \cdot 16$ de marzo a las 17:20

Laly R. Alcantara Yo Tbm Tengo mi pasaje a Trujillo para del $25^{*}$ al 28 recién modificado y estoy a

013 al espera de mi devolución de la penalidad. Manifiestense

7. 16 de marzo a las 17:20

014

Shirley Cano-Michael Siempre lo mismo y cuando se les envia todo lo que piden dicen hemos leido y estudiado su caso pero lamentablemente no podemos hacer nada. Siempre la misma porqueria

$14 \cdot 16$ de marzo a las 17:22

$015 \quad$ Analia Pretell Calderon Indecopi

13. 16 de marzo a las 17:26

Fernando Osorio Saravia Shirley Cano-Michael si eso pasa me voy al INDECOPI y los denuncio porque tengo las pruebas necesarias, así se demore en largo tiempo no pienso dejarlo así porque son buenos y rápidos para separar y cobrar pero ahora que es imposible viajar es tan facil devolver el dinero y yap

Igual esperare tranquilo sino ya nos veremos con los señores de LATAM en el INDECOPI

$41 \cdot 16$ de marzo a las 17:36

017 Cinthya Ces Un llamado a indecopi publican que van a bajar y al final el. Call te dice otra cosa

$6 \cdot 16$ de marzo a las 17:42

018 Solcito Ca Ba Indecopi de oficio pongan en sus muros cía de mierda

$2 \cdot 16$ de marzo a las 17:44

019 Carola Chung Tonterías no se conduelen con nada

$1 \cdot 16$ de marzo a las 17:45

020

Luciana Martinez Aprendannnnnn

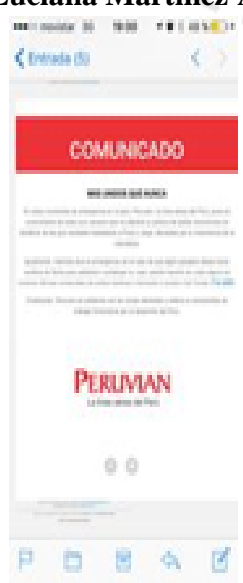


$118 \cdot 16$ de marzo a las 17:45

$021 \quad$ Iveth Lo Basuras!!!

$3 \cdot 16$ de marzo a las 17:50

$022 \quad$ Yasmile

$46 \cdot 16$ de marzo a las 17:53

023 Eddù NC Metele tu denuncia a. Indecopi piensa en. Todos. Los peruanos. Afectados y esta. Empresa chilena sin. Ningún tipo de. Pena ni nada no lo dudes ands indecopi

$6 \cdot 16$ de marzo a las 18:00

024 Gerald Helfer La verdad que desde que son LATAM sus tarifas son más altas y la atención más mala. Aparte el trato para categorias Premium no es lo mismo, igual que el trato de se personal.

$2 \cdot 16$ de marzo a las 18:07

025 Milton Santillan Jamás te responderán, así es LATAM

$3 \cdot 16$ de marzo a las $18: 12$

026 Micaela Bulnes A denunciar este abuso !

$2 \cdot 16$ de marzo a las 18:18

027 Jose Miguel Alcantara Jajaajaj pobres envidiosos

$1 \cdot 16$ de marzo a las 18:18 028 Kathia Vari Señores de LATAM lo mismo me dice su call center, como puedo comunicarme con

La página respondió en privado $\cdot 16$ de marzo a las 18:26

029 Omar Zubiate NO OLVIDEMOS JAMAS ESTE ABUSO Y DE LA FORMA COMO QUISIERON APROVECHARSE DE NUESTRA DESGRACIA HDP

$13 \cdot 16$ de marzo a las 18:41

030 Hans Breña Pastor Martin Azrom

16 de marzo a las 18:47

CODIGO COMENTARIO

Graciela Ugaz Señores son una total estafa , acabo de llamar y me informan que no puedo cambiar mi vuelo porque está programado para Abril , yo tenía planeado ir en abril a Piura pero como sabrán ustedes las lluvias para ese destino todavía se prolongan hasta Mayo, como creen que voy a ir a arriesgarme solo porque ustedes no pueden cambiar mi pasaje, ah claro si lo cambian cobrándome el costo de casi un pasaje más, que estafa . A la próxima cuando hagan anuncios así, pongan todas su restricciones.

$13 \cdot 20$ de marzo a las 12:50

Ocultar 24 respuestas

LATAM Airlines Hola Graciela, en estos momentos debido a la emergencia presentada estamos brindando como excepciones poder postergar los pasajes sin costo alguno para todos los vuelos que

001 tengan como programación hasta el 31 de Marzo, hasta un máximo de 15 días, para...Ver más

\section{0 de marzo a las 13:07}

Graciela Ugaz Acabo de llamar para gestionar la devolución intengra de mi dinero, y no me dan solución mi viaje estaba programado para el 10-19 de abril, que hago si no pienso viajar a Piura y arriesgarme 
de ticket para poder asistirte. Quedamos atentos.

20 de marzo a las 13:29

Stefanie UI Estimados, tengo el mismo problema que graciela pero con cajamarca. Mande msje interno con codigo de reserva y aun no responden ( ya ha pasado mas d 4 días sin respuesta) cuanto tiempo mas tengo que esperar para tener una respuesta por parte de ustedes?

$1 \cdot 22$ de marzo a las 11:06

005 LATAM Airlines Stefanie, te hemos brindado respuesta por inbox. Saludos. 22 de marzo a las 12:59

$006 \quad$ Paulina Valeria Te Doy la razón Graciela Ugaz

Yo tbm estoy en las Mismas condiciones al igual que tu tengo un viaje para Abril a Tumbes y quiero Posponerlo y quieren cobrarme por cada pasajero 32 dólares como es posible!!!

22 de marzo a las 21:31

007 Sebastian Nicolas Oneto Y si no vas se lo venden a otro a 300 dolares...ahi si son rapidos 26 de marzo a las 19:16

008

Fernando Tupia Seňores latham tengo vuelo para el.16 de abril a piura, pero las condiciones climatologicas.no son seguras, necesito cambiar el destino del vuelo.

26 de marzo a las 20:12

LATAM Airlines Hola Fernando, para poder brindarte mayor información,

009 por favor, envíanos tu código de reserva vía inbox. Quedamos atentos.

26 de marzo a las 23:50

Giulianna Villalobos Yo estoy igual tengo q viajar a Trujillo el 10 de abril y tengo dos pequeños de 11 y 7 años llame ayer para q me cambien el pasaje y solo dan excepciones hasta el 7 de abril el lugar donde voy a ir está de lodo y barro y no tengo q hacer se podrá quejar a indecopi o alguna entidad q

010 nos ayude

$1 \cdot 29$ de marzo a las 5:52

Carola Delgado Esa estupidez de mayor información $\mathrm{x}$ inbox es su rpta de siempre y te dan vueltas y vueltas mandando correos pidiendo siempre la misma información y los correos que te mandan son de varios de Lan más

011 es lo que llenan tu bandeja de entrada... igual me p...Ver más

\section{0 de marzo a las 9:41}

Maria Julia Falcon Cespedes Buenos dias, de igual manera quiero postergar mi viaje a Piura del 26 de abril por obvias razones,primero les escribi por inbox y hasta ahora no recibo respuesta,despues llame para que me den una solucion y no me la dieron.Y por lo que me doy cuenta no soy la unica en este problema,espero que nos den una solucion que no perjudique a ninguno.

\section{1 de marzo a las 9:59}

LATAM Airlines Hola Maria Julia, para verificar tu casi envíanos tu código de 013 reserva a través de inbox por seguridad. Quedamos atentos.

31 de marzo a las 10:25

014 y hasta más deben ampliar sus excepciones comerciales

3 de abril a las 21:09

Graciela Ugaz No entiendo cómo es que ustedes pretenden que uno viaje a un lugar que está declarado en emergencia, no es que uno no quiera ir por capricho sino que no es viable por seguridad ir a esa zona mi viaje está para 10 y la situación sigue igual, pero la única solución que LATAM Airlines me da es esperar al 7 a qué se prolongue su promoción ? Es en serio no les interesa sus clientes, sino me quieren devolver el dinero, ok, pero denme la chance de poder postergarlo o cambiar de destino

3 de abril a las 21:11 
LATAM Airlines Graciela, por favor envíanos tu código de reserva o número de ticket vía inbox, por medidas de seguridad, para poder brindarte mayor detalle. Quedamos atentos.

3 de abril a las 22:40

LATAM Airlines Jacky al momento estamos brindado excepciones comerciales hasta el 10 de abril debido a que el aeropuerto de Piura se encuentra cerrado. De extenderse las excepciones lo estaríamos publicando o informando mediante nuestras redes sociales o pagina web principal.

017 Quedamos atentos.

4 de abril a las 0:06

Fernando Tupia Mi viaje era para el 16 de abril, por obvias razones ya no viajare, necesito la devolucion de mi dinero.

4 de abril a las 8:40

LATAM Airlines Hola Fernando, con el fin de brindarte asistencia por favor indícanos tu número de documento de identidad vía inbox. Quedamos

019 atentos.

4 de abril a las 9:26

Karla Gago Esto es totalmente mentira.1. No te devuelven el 100\% de tu dinero; 2. Si si tu vuelo esta despues del $7 \mathrm{~d}$ abril te jodiste porque a ellos no les importa que te expongas.3. Ni te contestan el

020 telefono 4 . Tienes que denunciar via fb para que te hagan caso porque sino les llega mas les importa que les entrw dinero pero no sus clientes felizmente ya entra otra aerolínea a peru.

\section{4 de abril a las 10:29}

021

Graciela Ugaz Acabo de llamar y me han dicho que es solo hasta el 7 abril ? No entiendo no se supone que es hasta el 10 abril no puedo hacer mi reembolso o cancelación

4 de abril a las 12:17

LATAM Airlines Hola Graciela, en estos momentos debido a la emergencia presentada estamos brindando como excepciones poder postergar los pasajes sin costo alguno a todos los vuelos programados hasta el 7 de Abril. Recomendamos que puedas estar al pendiente de nuestros medios de comunicación ya que las excepciones posiblemente puedan extenderse en

022 caso la emergencia climática continue. Saludos.

4 de abril a las 18:17

023 Melissa Yangua Gonzáles Exacta lo peorrr. Me cancelan 10 de abril a las 5:04 Editado

024 Jose Andre Son de lo peor tengo el mismo caso, pero no les importa. Prefieren que la gente pierda su pasaje y dinero por nadie se quiere exponer.

10 de abril a las 11:20

\section{CODIGO COMENTARIO}


Ocultar 18 respuestas

LATAM Airlines Hola Dann, por favor envíanos por Inbox el código de tu 001 reserva para entregarte mayor información. Quedamos atentos.

17 de marzo a las 7:51

LATAM Airlines Hola, gracias por contactarnos, hemos brindado mayor

002 información via inbox. Saludos

17 de marzo a las 14:23

Angel Rua Infanzon A ver avísanos si solucionaste tu reclamo, estos de LATAM son unos estafadores con la legalidad que les brinda el Gobierno es momento de actuar, votemos está Aerolínea 003 de nuestro país, NO COMPREN PASAJES EN LATAM.

$3 \cdot 17$ de marzo a las 21:25

004 Dann Flores Ni un mensaje ni correo ni llamada..

18 de marzo a las 8:55

005 LATAM Airlines Hola, te enviamos respuesta vía email a tu caso 5149136. 18 de marzo a las 9:32

006 Dann Flores LATAM Airlines encima mentirosos no tengo ningún correo de Uds

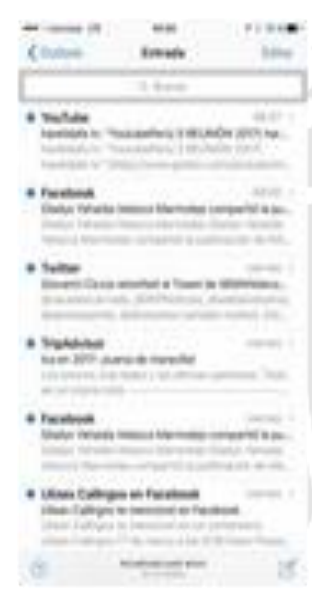

$2 \cdot 19$ de marzo a las 8:51

LATAM Airlines Hola Dann te invitamos a verificar tu bandeja de entrada y

007 correo no deseado.

19 de marzo a las 9:49

008 Johanna Benites Durand me pueden responder el inbox!!!!?!?!?

20 de marzo a las 6:33

009 Dann Flores LATAM Airlines nadaaaaaaa

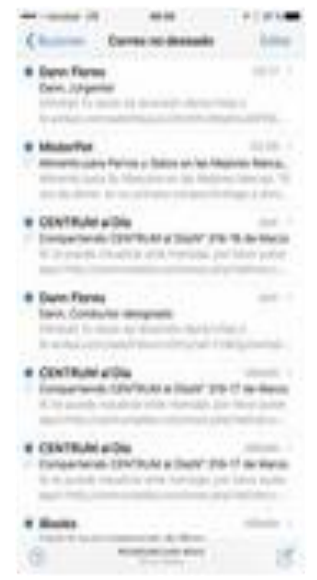


20 de marzo a las 6:37

$010 \quad$ Dann Flores Nadaaaaaa

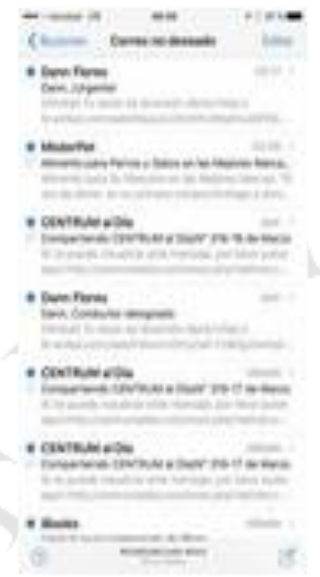

20 de marzo a las 6:37

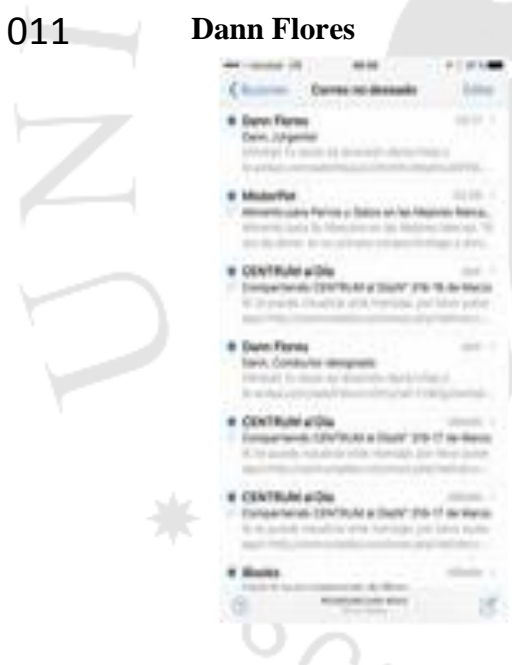

20 de marzo a las 6:37

LATAM Airlines Johanna, te hemos brindado respuesta en tu publicación,

012 quedamos atentos a tu respuesta vía inbox.

20 de marzo a las 7:20

013 LATAM Airlines Te enviaremos el correo nuevamente.

20 de marzo a las 8:36

014 Jubi Cabrera Denuncien a Indecopi, solo así dan una solución estos.

28 de marzo a las 12:23

015 Dann Flores Nunca respondieron

28 de marzo a las 12:37

016 Aldo Fabrizzio Denúncialos cuanto antes... !!! 
29 de marzo a las 23:58

017 Aldo Fabrizzio Denúncialos cuanto antes... !!!

29 de marzo a las 23:58

$018 \quad$ Lpp Lili Zziitaa A mi están haciendo lo mismo

31 de marzo a las 14:21

\section{CODIGO COMENTARIO}

$3 \mathrm{CO4}$

Pablo Perez Que fantástica su ayuda, sin embargo a mi me dejan sin vuelo por que me he quedado en Perú para ayudar y como no he cogido mi vuelo desde desde España, me anulan también el que tenía de vuelta en Mayo. Me parece increíble que si no uso mi ida, me roben mi vuelta. \#LatamAprovechados

La página respondió en privado $\cdot 4 \cdot 28$ de marzo a las 18:53

Pablo Perez Me responden por inbox, pidiendo mis datos, pero sigo esperando una solución y mientras tanto he perdido 3 vuelos transoceánicos Olati Anul Raul Estrada Luis Ocampo

$001 \quad$ BarrenecheaGonzalo Ruiz

31 de marzo a las 6:29

002 LATAM Airlines Pablo, te hemos respondido a través de inbox. Saludos.

31 de marzo a las 8:08

Olati Anul LATAM Airlines ¿Por qué no mejor son más claros con sus cambios de política? Aquí una ayuda: "a partir de ahora, si un usuario pierde su vuelo de ida, APROVECHAREMOS PARA

003 ROBARLE TAMBIÉN SU VUELO DE REGRESO".

$1 \cdot 31$ de marzo a las 9:43

Pablo Perez Vaya, acabo de averiguar que lo que han hecho es totalmente ilegal: "la famosa cláusula no show, por la que si alguno de los trayectos comprados no se usa, automáticamente se cancelan los trayectos restantes

004 comprendidos en el mismo billete. Tras numer...Ver más

$1 \cdot 7$ de abril a las 8:09

LATAM Airlines Pablo, hemos ingresado tus comentarios y priorizado tu solicitud para poder comunicarnos a la brevedad. Te sugerimos estar atento

005 a tus medios de contacto. Saludos.

\section{7 de abril a las 8:53}

Pablo Perez LATAM Airlines TIenen un bot atendiendo los reclamos? Esto mismo me lo dicen cada vez que comento o respondo al inbox, pero nunca nadie se pone en contacto. \#Latam escurre el

006 bulto Indecopi

$1 \cdot 7$ de abril a las 19:43 $\cdot$ Editado

$007 \quad$ LATAM Airlines Te contactaremos al menor tiempo posible, Pablo.

7 de abril a las 20:52

Pablo Perez Después de 20 días analizando mi caso....un "NO SHOW" en toda regla, esta es la respuesta. Y lo dicen con toda la convicción de que nos lo creemos. Y sobre todo, saltándose las decisiones de los Tribunales de la UE como quien no quiere la cosa. Señores de LATAM Airlines, aquí tienen la resolución de la LEY para que puedan leerla bien porque en breve recibirán mi demanda formal. https://www.reclamador.es/.../Sentencia-Iberia-cl\%C3... 


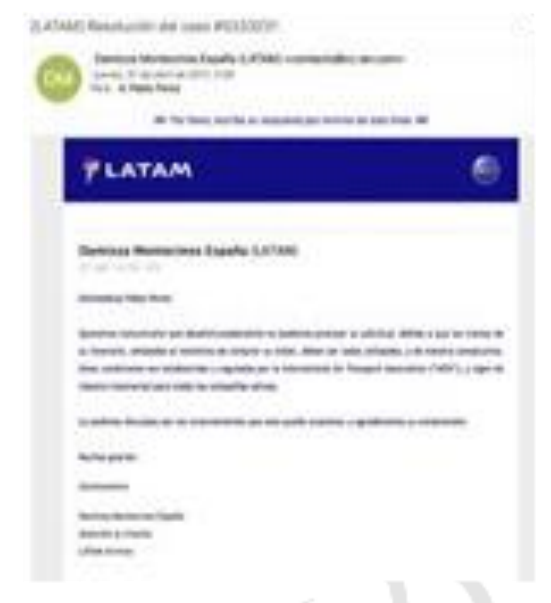

$1 \cdot 27$ de abril a las $18: 19$

LATAM Airlines Pablo, esperamos poder asistirte en una nueva oportunidad. Gracias.

27 de abril a las 19:11

010 Pablo Perez LATAM Airlines querreis decir desastirme, estafarme, robarme no?

\section{CODIGO COMENTARIO}

Thais Arbulu LATAM, esto es inaceptable. Llamo al teléfono de contacto para un cambio de pasaje a Piura y no me dan ninguna solución ni entienden realmente la seriedad del problema. Me quieren cobrar mas del doble de lo que me costo el ticket por cambiarlo de fecha y ni siquiera me ayudan o dan posibilidades como si yo estuviese en falta. Necesito urgente su apoyo o un teléfono SERIO al cual llamar y que me puedan solucionar este tema que es urgente. He estado calmada e intentando con el teléfono esperando que alguien vaya en linea con todo lo publicado por esta via me conteste el teléfono pero parece que hablara con una pared.

$7 \cdot 27$ de marzo a las 15:24

001 Gonzalo Delgado Schambaher LATAM Airlines podrian responder o tenemos que ir ante Indecopi $1 \cdot 27$ de marzo a las 15:44

LATAM Airlines Hola, hemos respondido via inbox, así mismo, hemos

002 solicitado algunos datos. Saludos

27 de marzo a las 16:08

003 Thais Arbulu Creo que se han confundido de persona por que a mi no me ha llegado nada

27 de marzo a las 16:37 - Editado

004 Thais Arbulu LATAM Airlines ????

27 de marzo a las 17:18

005 Gonzalo Delgado Schambaher LATAM Airlines pueden responder!!!!

27 de marzo a las 17:20

LATAM Airlines Thais, hemos respondido a tu consulta por medio de inbox. Puedes verificar la información que te enviamos. Saludos.

27 de marzo a las 18:43 


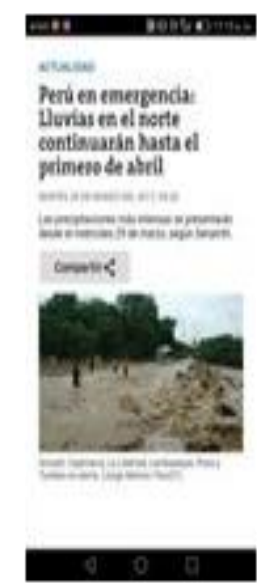

$1 \cdot 28$ de marzo a las 10:13

LATAM Airlines Hola Gonzalo, debido a que continúan las inundaciones por fuertes lluvias en Perú, se extienden las excepciones comerciales para pasajeros viajando hasta el 07 de abril del 2017. Saludos.

\section{8 de marzo a las 11:36}

Sully Salazar Kikukawa Solo hasta el 07 de abril?? Que pasa con los que tenemos pasajes para fechas posteriores pero en el mismo mes de Abril? Es el colmo. Ya vengo reclamando hace semanas pero al parecer a ustedes no les interesa la situación que está viviendo el país y en especial Piura. Señores Piura esta inundada! Entonces como es posible que no nos puedan cambiar los pasajes?? Yo tengo un hijo pequeño y no lo voy a exponer a una situación así! Lo único que nos queda es no viajar porque con las penalidades que ustedes cobran nos cuesta como un pasaje! De veras que es increíble!

009 Que están esperando? Que los denunciemos ante INDECOPI??

$2 \cdot 28$ de marzo a las 11:46

010 LATAM Airlines Thais, hemos respondido tu mensaje privado. Saludos. 28 de marzo a las 12:50

Giulianna Villalobos A eso me refiero tengo mi pasaje del 10 al 17 de abril para Trujillo pero mi tía dice no vengas q tienes niños está horrible no limpian las calle y tenemos q salir tapados por la cantidad de polvo q hay y me dicen lo sentimos llame tres dias antes para ver si se arreglo la situación $\mathrm{q}$ tal como si fuera culpa nuestra el mal servicio q dan todo el tiempo he viajado en lan y soy socio de lan pass y es la primera vez q llamo para cambiar mi pasaje y así ayudan a sus clientes q estafa por

011 dios

\section{9 de marzo a las 5:58}

012 Taisia Repetto Te respondió LATAM

3 de abril a las 12:03

\section{CODIGO COMENTARIO}

Cami Pastor Señores LATAM Airlines soy de la ciudad de Trujillo,tengo 2 boletos destino LimaIquitos los cuales me es imposible abordar dada la situación que afrontamos y al no haber pasajes trujillo-lima en bus, dado que las carrteras están afectadas ...Señores intento comunicarme al numero de call center que brindan y no contestan.pregunto ¿darán solución a este tema? Ya que esto escapa de nuestra voluntad.Ojalá que por este medio se dignen responder.

6 de abril a las 10:53 · Editado

LATAM Airlines Hola Cami, mediante Inbox, bríndanos el código de reserva o número de ticket, así como, más detalles de tu requerimiento. Quedamos 
atentos a tus comentarios. Saludos.

6 de abril a las 11:14

002 Cami Pastor La información ha sido enviada por inbox. Espero su respuesta y den solución a este tema ajeno a tantos usuarios que nos vemos afectados .Gracias

6 de abril a las 12:16

LATAM Airlines Cami, te hemos enviado una respuesta detallada por inbox.

003 Quedamos atentos.

6 de abril a las 12:30

Cami Pastor Les envié mis datos LATAM Airlines,en espera de su respuesta para la postergación de

$004 \quad$ los pasajes.Gracias.

7 de abril a las 13:05 - Editado

005 LATAM Airlines Cami, hemos respondido vía inbox. Saludos.

7 de abril a las 14:39

006 Cami Pastor Sin respuesta,no me envían aun los costos por postergar mis boletos,de cuanta diferencia hablan? Y ya se acerca la fecha de viaje(11 al 19 de abril)

8 de abril a las 13:28 - Editado

007 LATAM Airlines Cami, te hemos enviado un inbox con mayor información.

8 de abril a las 14:14

\section{CODIGO COMENTARIO}

Ivan Dávila Salas Estimados señores envie un correo al la direccion que indican. Pero me reboto el correo por favor indiquenme como hacer para ir de voluntario, quisiera me consideren en el grupo de personas para trasladar al norte . pueden facilitarme un número para llamar y me puedan considerar. A

3C07 la espera de su respuesta.

$10 \cdot 16$ de marzo a las 21:33

LATAM Airlines Hola, gracias por tu interés en apoyar la emergencia en Piura. Los cupos para voluntarios en Caritas del Perú ya están tomados. Sin

001 embargo, si estás listo para viajar y tienes una institución a la que puedas sumarte escríbenos a voluntariado.corporativolp@latam.com para incluirte en alguno de nuestros vuelos de ayuda humanitaria.

$6 \cdot 16$ de marzo a las 22:46

$002 \quad$ Cartagena Fap

16 de marzo a las 23:09

003 Victor Chang Zegarra Todavía cachacientos estos rotos cdsm

$3 \cdot 17$ de marzo a las 6:45

004 Ximena Medina Vásquez Yan Pierre Perez Atalaya

17 de marzo a las 7:28

005 Osver DC Correos q casi nunca responden

17 de marzo a las 8:22

006 Ana Garcia Estos chilenos culo roto hacen lo q quieren en nuestro país \#fueradelperulatam

$2 \cdot 17$ de marzo a las 9:34 
$1 \cdot 17$ de marzo a las 11:15

008

Rafael Sanchez Ferrer Jodanse

$1 \cdot 17$ de marzo a las 11:52

009 podrian considerar un cupo mas y aque horas estan saliendl el vuelo de ayuda para piura

$1 \cdot 17$ de marzo a las 15:22

FS JM Todos los que se ofrecen para el voluntariado, es por las puras, es que te van a responder los cupos están copados, mandanos tú correo etc. Rechazando la ayuda que se está ofreciendo por obvias razones que todos podemos deducir.

$1 \cdot 17$ de marzo a las 16:02

LATAM Airlines Hola Annye, gracias por tu interés en apoyar la emergencia en Piura. Los cupos para voluntarios en Caritas del Perú ya están tomados. Si tuvieras alguna consulta adicional puedes escribirnos a voluntariado.corporativolp@latam.com para ayudarte a la brevedad

011 posible.

\section{7 de marzo a las 16:37}

012 Rafael Vela Canta Alguien me puede dar el numero de latam

5 de abril a las 9:15

LATAM Airlines Hola Rafael, nos puedes llamar al 213 8200. Recuerda que por este medio también te podemos asistir por este medio. Evalúa nuestro servicio aquí: http://bit.ly/1CU3zvl.

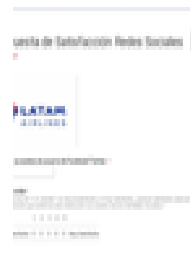

Encuesta de Satisfacción Redes Sociales DOCS.GOOGLE.COM

5 de abril a las 9:27

014 Karla Seminario LATAM Airlines entonces espero me respondan el mensaje por favor 6 de abril a las 21:05

\section{CODIGO COMENTARIO}

Cruzca Leon Sres. Lan; llevo semanas tratando de que le den solucion al caso \#4971288, llamo al contac center opcion 1 nunca responde... opcion 3 no tienen facultad para resolver el problema, voy a la oficina y tampoco me pueden atender porque no tienen la capacidad de hacerlo, me dicen que pondran una nota para que me llamen que espere y no me llaman...estoy muy indignada su atencion de sevicio es pesima, tanto que han pasado semanas y nada para resolver mi caso. Espero que por este $3 \mathrm{CO8}$ medio se puedan comunicar y darme solucion de una vez al telefono 988695413.

$11 \cdot 16$ de marzo a las 20:01 
información. Quedamos atentos.

16 de marzo a las 20:16

002

Lizbeth Huamán Solo responden una vez al

Inbox!! Quise que atendieran mi caso y ya no respondieron más!!

$2 \cdot 16$ de marzo a las 20:28

003 Carlos A. Hilario

16 de marzo a las 21:05

004 Miluska Quispe

$1 \cdot 16$ de marzo a las 21:29

005 Eddù NC denuncia a Indecopi por que ellos te pasearan

$3 \cdot 16$ de marzo a las 21:51

Bust Geraldine LATAM AIirlines tienen demasiadas quejas !!!! Yo nunca volveré a viajar con

$006 \quad$ ustedes !! Quede decepcionada totalmente!! Su administrador en Cusco. Lejos de dar solución a las 6 familias perjudicadas se ponía a pelear !! Q mal !! Y todavía contestan mal !! Q horror!!

$2 \cdot 17$ de marzo a las 4:24

María Del Rosario Antezana La empresa Latam solo vela por sus intereses no les importa las necesidades d lo demás y solo te hacen caso cuando haces un escándalo, a mí me sucedió algo similar

$1 \cdot 17$ de marzo a las 6:18

008 Claudia Calle Hasta que por finnnn se ponen solidarios!!!..eso lo hubieran hecho desde el principio.......y hubieran evitado tanto opiniones negativos hacia ustedes, pero nunca es tarde Sldos. $1 \cdot 17$ de marzo a las 8:49

$009 \quad$ Adrian Calderon \#FueradelPeruLATAM

17 de marzo a las 9:24

010 Vanesa Camas Flores Disculpe numero de telefono para informacion

17 de marzo a las 14:17

011 Vanesa Camas Flores Disculpe numero de telefono para informacion

17 de marzo a las 14:17

LATAM Airlines Hola Vanesa, el número de nuestro Contact Center es 01 213 8200. También, podemos asistirte por este medio sólo escríbenos por

012 inbox.

17 de marzo a las 14:21

013 Lizbeth Huamán Y a mi me pueden responder el inbox? Escribí desde ayer en la mañana y nada!!

17 de marzo a las 15:07

014 LATAM Airlines Lizbeth, hemos respondido al inbox para asistirte.

17 de marzo a las 15:18 015 Lebasi Perfa A mi me tuvieron un mes sin respuesta cuando supuestamente debía ser 7 los días que se

17 de marzo a las 16:41

016 Mauricio David Malitopowers

IAHORA DEI COASUMIDOR

Ime intsoo 19 r ooninco so

infietetnit no compat ce ior

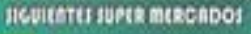

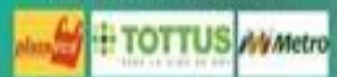

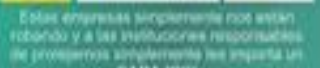

ro chenop

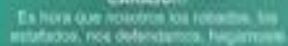

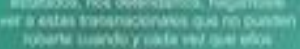

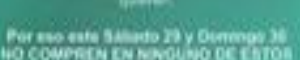


19 de marzo a las 11:02

\section{CODIGO COMENTARIO}

Rocio Reyes Rubio Devuelvan el dinero de los pasajes comprados con anticipación a Piura, ya que no estaba previsto lo que iba a suceder en el norte. No se aprovechen de la situación. queriendo sacar $3 C 09$ dinero a las personas. Me enfada $5 \cdot 17$ de marzo a las 21:08 $\cdot$ Editado

LATAM Airlines Hola Rocio, si cuentas con un código de reserva, por favor, 001 indícanoslo vía inbox. Quedamos atentos.

$1 \cdot 17$ de marzo a las 21:08

002 Rocio Reyes Rubio Muchas gracias por solucionar mi reclamo.

La página respondió en privado $\cdot 19$ de marzo a las 20:15

003 LATAM Airlines Rocio, hemos solicitado datos vía inbox. Quedamos atentos. 19 de marzo a las 21:38

$004 \quad$ Linda Castro Raya Srs latam hasta la fecha. No me dan una respuesta clara y ya envie mi número de reserva

19 de marzo a las 22:18

LATAM Airlines Hola Linda, te hemos brindado mayor información vía

005 inbox. Quedamos atentos.

19 de marzo a las 22:31

\section{CODIGO COMENTARIO}

\section{$3 C 10$ por encima de $\$ 400$ carísimos. Eso es para ustedes solidarizarse ???????}

Marleni Valdez A MENTIRA Srs. LATAM quise adelantar mi vuelo y dijeron que no es posible ni pagando penalidad, osea debemos adquirir otro pasaje que aprovechando la crisis que vivimos están

$80 \cdot 16$ de marzo a las 23:40

LATAM Airlines Hola Marleni, envíanos tu código de reserva a través de inbox para verificarlo a detalle y ver tu caso. Estaremos atentos a tu

001 respuesta.

17 de marzo a las 5:28

Elizabeth Dina Inga Victorio Son unos m... Si se supone k han puesto un comunicado k no vama

002 busar xk tiene la gent $\mathrm{k}$ seguir reclamando xk ello ...son pura trafa

$7 \cdot 17$ de marzo a las 5:32

003 Carlos Chávez Espinoza Que asco \#FueradelPeruLATAM

$6 \cdot 17$ de marzo a las 8:00 
$6 \cdot 17$ de marzo a las 8:39

$2 \cdot 17$ de marzo a las 9:23

$006 \quad$ Gisella Rios Fuera del.Perú..

$3 \cdot 17$ de marzo a las 9:57

007 Pablo Bartt que tales HDP

$1 \cdot 17$ de marzo a las 10:05

Juan Jose Camacho Garcia jajajjajaja ahora quieren revisar su caso que pendejos como se les viene en sima la redes puff ladrones

$1 \cdot 17$ de marzo a las 12:31

009 Jherson C Back Puedes poner tu denuncia .. y mejor que se vaya del pais ..

$2 \cdot 17$ de marzo a las 12:49

010 Ibeth Julissa Fuera latam

$2 \cdot 17$ de marzo a las 13:43

FS JM la clásica de todas las empresas como estás "ESTAMOS REVISANDO TÚ CASO" 1 mes

011 después y siguen revisando o te derivan a diferentes áreas hasta que te ganan por cansancio.

4. 17 de marzo a las 15:58

Rossana Valle Salazar Hace tiempo que sabemos de la porquería de servicio que brindan en todos los sentidos... A mi hija le mandaron el equipaje a Chile y le devolvieron la maleta ROTA, de la cual se ROBARON alrededor de 1500 dólares en objetos, ropa, regalos navideños entre otros, dejando a mi nieto hasta sin zapatilla para su estadía en Perú y que solo reconocieron casi dos meses después, previo bullying cybernetic, notarios, abogados y hasta Indecopi ... Pero esto ya los pinta de cuerpo entero, lucrar con la desgracia de u país que fue el primero en acudir a socorrer a los chilenos en sus momentos de dolor. Y su respuesta es siempre la misma:"pasanos tu código para revisar tu caso "... Parece esas respuestas que se ponen en automático ante u a publicación o correo y te cojudean meses y no hacen nada. Gracias a los usuarios ellos tragan. No volvemos más con ellos... Hay otras aerolíneas... A ver si el día que dejen de ganar nos van a maltratar igual.!

$1 \cdot 17$ de marzo a las 16:03

013

Gino Marruffo Bahamonde Marleni si pagaste el vuelo más barato, te dirán que no puedes adelantarlo solo postergsrlo, que debiste leer los términos y condiciones....

$1 \cdot 17$ de marzo a las $16: 49$

014 Mariana Fernandez \#FueradelPeruLatam

17 de marzo a las 17:52

015 Mariana Fernandez \#FueradelPeruLatam

17 de marzo a las 17:52

016 Mariana Fernandez \#FueradelPeruLatam

17 de marzo a las 17:53

Angel Rua Infanzon Quieren engañarnos diciendo por inbox te solucionamos y sigue la mentira de estos sinvergüenzas de LATAM, a todos les pido no volver a utilizar esta Aerolínea Expulsión de

017 nuestro País.

$3 \cdot 17$ de marzo a las 21:20

018 Percy Mendoza Cabanillas LADRONES .

$1 \cdot 18$ de marzo a las 0:45

019 Rossana Valle Salazar Silvia Sicheri, acá el testimonio real

$1 \cdot 18$ de marzo a las 2:35

020 Carlos Cid Jacho Merecen. Su saqueo. Y cierre de oficinas. .

19 de marzo a las 16:24

021 Edwin Paul Vasquez Ramos Hdp, miserables, fuera del Perú 
19 de marzo a las 17:40

022

Marleni Valdez A Srs. LATAM Airlines esto es una burla a 3 días de la fecha de muy vuelo me llama para coordinar, el adelanto ??????

Converso con la persona que llamo y explique que al no haber viajado cuando lo requería, de acuerdo a lo que se me indicó necesito postergar mi pasaje y upsss se corto la comunicación he tratado de comunicarme y aún no puedo, les escribió y me responden Gracias por comunicarse este atenta que nos comunicamos.

Es broma?????

\section{2 de marzo a las 13:08}

023 Leonardo Ferion Baltazar Yo siempre EH querido volar y fue la ultima vez meeeeee

4 de abril a las 14:05

\section{CODIGO COMENTARIO}

Jaqueline Vg Señores de LATAM yo tengo un viaje programado para el 8 de abril, por favor extiendan sus excepciones comerciales hasta abril ya que aún persisten los problemas climáticos. Me dijeron que esperase hasta abril para ver si "extendían las excepciones" ya estamos 2 de abril y nada. No se que esperan, que se pase la fecha de los vuelos y digan que los perdimos?

Por favor se necesita una respuesta clara.

$1 \cdot 2$ de abril a las 17:30

LATAM Airlines Hola Jaqueline, por el momento contamos con excepciones comerciales para pasajes con viajes programados hasta el 7 de abril sin embargo, debido a la situación del país estaremos evaluando la información constantemente $y$ en caso de novedades para extender las fechas entregaremos la información a través de nuestras redes sociales y página web. Saludos.

\section{3 de abril a las 7:27}

Jaqueline Vg Señores de LATAM, mi viaje es el 8! Sinceramente no creo que un día más o un día menos haga la diferencia, y es lo mismo para las demás personas que tienen vuelos para el mes de abril.

Estoy a 3 días de la fecha programada de mi vuelo y no veo ninguna extensión de sus excepciones comerciales, por favor espero alguna noticia favorable por parte de ustedes, gracias!

5 de abril a las 6:08

LATAM Airlines Te hemos enviado un Inbox, Jaqueline. Revísalo para mayor 003 información. Saludos.

5 de abril a las 7:20

$004 \quad J a q u e l i n e ~ V g$ Estimados mantengo mi posición mi viaje es mañana y aún no hay un comunicado oficial de su parte, a este paso perderé el vuelo, no me parece justo de su parte

7 de abril a las 9:08

LATAM Airlines Jaqueline, puedes solicitar un cambio bajo las regulaciones

005 de la tarifa.

\section{7 de abril a las 9:43}

Cindy Magallanes Estimados sres de Latam comparto la posición de mi amiga Jaqueline Vg, no es posible que no tengamos una respuesta clara por parte de la.situación que atraviesa el país y que no nos permita poder postergar el viaje que en teoría es en unas horas a la ciudad de trujillo, y simplemente atinan a decir que no tiene. Clara la fecha de ampliación, es lamentable que sabiendo lo que ocurre en la ciudad de trujillo nos veamos perjudicados cuando se supone que profesan apoyo por el tema de los huaycos, y es que simplemente perderemos los vuelos y no nos dan una solución clara, 
es la primera vez que viajare en sus aerolíneas y es pésima la calidad de Servicio que brindan, aprovechándose de lo que ocurre en trujillo para simplemente hacerse los desentendidos, una solución por favor, a quien tenemos que acudir para que nos atiendan... si en su call center nos mencionan que ya perdimos el vuelo y que se podría postergar solo el retorno haciendo pagos adicionales

$1 \cdot 8$ de abril a las $0: 30 \cdot$ Editado

Ysa Ruiz Hola, les pudieron solucionar, yo tengo el mismo problema ya estoy dos semanas y nada que me dan solucion tambien soy de trujillo y tengo boletos aereos desde el aeropuerto de lima, pero no me dan ninguna solucion, y postergar que es la unica solucion es demasiado caro.

\section{2 de abril a las 7:24}

008 Jaqueline Vg No nos solucionaron, al final se tuvo que perder los vuelos

12 de abril a las 8:18

\section{CODIGO COMENTARIO}

Danitza Mestanza Señores el desastre no duró hasta el 31/03 continua el río se sigue saliendo hay gente atrapaba familia que no pueden venir por el excesivo precio de sus pasajes y encima una les pide ayuda para poder llevar ayuda a mi familia que atrapada en Piura sin poder venir y recibo esto se respuesta donde esta su humanidad, aparte de haber pagado más de 1500 en soles pasajes ahora seguro nos cobrarán más de $\$ 100$ si hay sobre peso en lo que llevamos y que estamos llevando ayuda señores de Latam...No sabía que la ayuda tiene un costo...

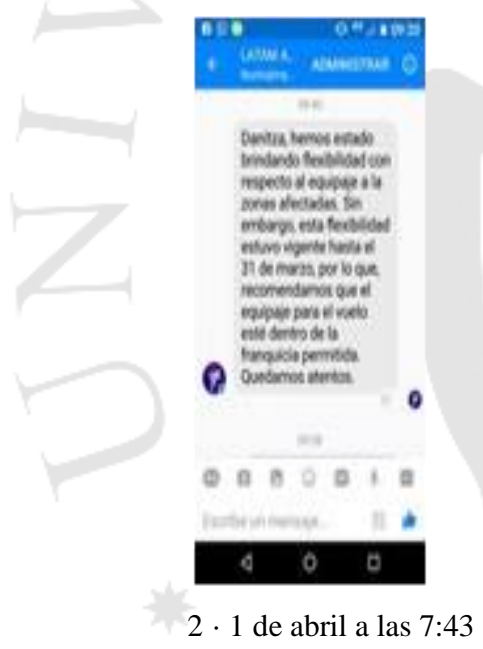

$001 \quad$ LATAM Airlines Te hemos solicitado datos por inbox.

1 de abril a las 8:31

Carmen Elisa Velasco Hay prima que gente insensible y que canallas de lucrar con la desgracia ajena, 1500 un pasaje... inconsecuentes.. eso es su solidaridad??

1 de abril a las 18:33

003 Yois Leyva Cotos Latam deseo comunicarme

3 de abril a las 21:41

004 LATAM Airlines Hola Jois, hemos solicitado datos vía inbox. Saludos.

3 de abril a las 21:51

LATAM Airlines Yois, queremos disculparnos por el error en tu nombre.

Saludos.

3 de abril a las 21:52 


\section{CODIGO COMENTARIO}

$3 \mathrm{C} 13$

Lorena Larsen Tengo entendido que el aeropuerto de Piura está cerrado por 10 días, como se hará con la reprogramación de vuelos??

29 de marzo a las 8:56

001 LATAM Airlines Hola Lorena, te hemos respondido por inbox. Saludos.

29 de marzo a las 10:09

002 Jano Rodriguez LATAM Airlines y qué te dijeron?

29 de marzo a las 14:30 responden...en ese plan me demoro en hacer el tramite un par de dias

29 de marzo a las 14:33

LATAM Airlines Lorena hemos enviado respuesta mediante inbox.

004 Quedamos atentos.

30 de marzo a la 1:18

Carla Gutiérrez Meza Una vez más LATAM Airlines muestra su pésima forma de gestionar. El martes me dijeron que una opción de sus excepciones comerciales es pedir la devolución total de mi dinero por no haber hecho uso del ticket, pero desde ese día me vienen haciendo una pregunta por día. Un día me pregunta si quiero cheque o transferencia, al día siguiente me pregunta si quiero devolución de uno o de los dos pasajeros, al otro día pregunta para confirmar mi correo y mi número celular y hasta ahora no puedo empezar el proceso de devolución. Así como les escribí por inbox, va a llegar el día del vuelo, es decir, mañana 2 abril, y seguirán haciendo una pregunta por día. Y como son bien ratas, capaz de decirme que el ticket ya se usó porque ya pasó la fecha del vuelo, etc. No entiendo por qué tanto maltrato a sus clientes. Primera y última vez con esta empresa. Así que ha esperar las ganas

005 de responder de este CM.

31 de marzo a las 22:03 - Editado

LATAM Airlines Te hemos enviado un inbox con mayor información.

006 Gracias.

31 de marzo a las 23:13

CODIGO COMENTARIO

Daniela Philippides Hace días les he enviado un inbox pidiéndoles una solución para mi problema de cambio de pasaje, ya que he llamado a servicio al cliente repetidas veces y me dicen que cambiar de fecha me cuesta la misma cantidad de kms y efectivo que me costó comprar el pasaje. Hasta ahora no 3C14 recibo ninguna respuesta.

$9 \cdot 5$ de abril a las 9:03

LATAM Airlines Hola Daniela, mediante Inbox, bríndanos el código de reserva o número de ticket para asistirte. Quedamos atentos a tus

001 comentarios. Saludos.

5 de abril a las 10:47

002 Daniela Philippides Ya mandé la información, espero su pronta respuesta.

5 de abril a las 13:04 
Claudia Velarde de Guerinoni acabo de colgar indignada... tengo un vuelo a talara para el 23 de marzo y me dicen que no pueden postergarlo para setiembre sino sólo por 30 días y de ahi volver a postergarlo y pagar nuevamente (quiere decir que todos los meses hay que gestionar la postergacion y

3 C15 $\quad$ pago!!!); el pais no va

$1 \cdot 20$ de marzo a las 8:44

$001 \quad$ Mariela Piedra De Paulet se pasan!

20 de marzo a las 9:34

LATAM Airlines Hola Claudia, verificamos que ya solicitaste la devolución de 002 tus pasajes. Ante futuras consultas no dudes en escribirnos. Saludos.

$3 \cdot 20$ de marzo a las 10:25

Claudia Velarde de Guerinoni Valgan verdades... la primera persona que me contesto me dio mala informacion, volvi a llamar y el 2 do sr del call centere dio solucion. Si bien es cierto q se soluciono

003 problema, deberian dar mejor capacitacion e informarcion a su personal

$1 \cdot 20$ de marzo a las 11:42

LATAM Airlines Claudia, comprendemos lo que nos indicas, si lo deseas por 004 este medio podemos formalizar tu reclamo solo indícanos. Saludos.

$1 \cdot 20$ de marzo a las 12:30

005 Rafael Sotelo Comprenden pero no dan solución razonable

23 de marzo a las 10:43 - Editado

CODIGO COMENTARIO

Yefry Junior Foto tomada hace unos minutos, si quieres viajar Lima- Piura te costará \$137, a comparación de los $300 \$$ de la mañana hubo reducción, pero debería la gente de LATAM hacer reales bajas, para Piura normalmente el costo de los pasajes es $90 \$$, entonces dicen que se solidarizan con lo q está ocurriendo pero el precio es mayor al normal. Si han bajado precios es por el bullying que se le

3C16 está haciendo, y alguna forma de mitigar el riesgo de perjudicar más su imagen es llamarse solidarios. Quizás hayan bajado los pasajes si es que quieres comprar tus boletos con 5 meses de anticipación, pero señores LATAM, hay gente que quiere viajar ahora.

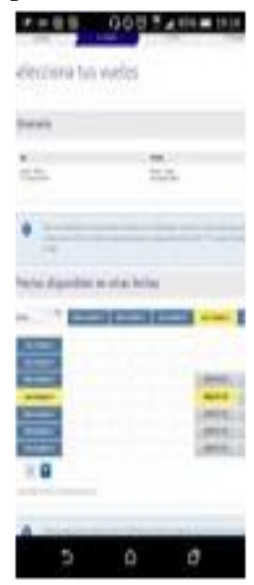


Yefry Junior Y a Trujillo por $1 \$$ menos. Vaya GRAN rebaja. Y pensar q hace dos semanas estaba a $3900 \mathrm{~km}$ nomás.
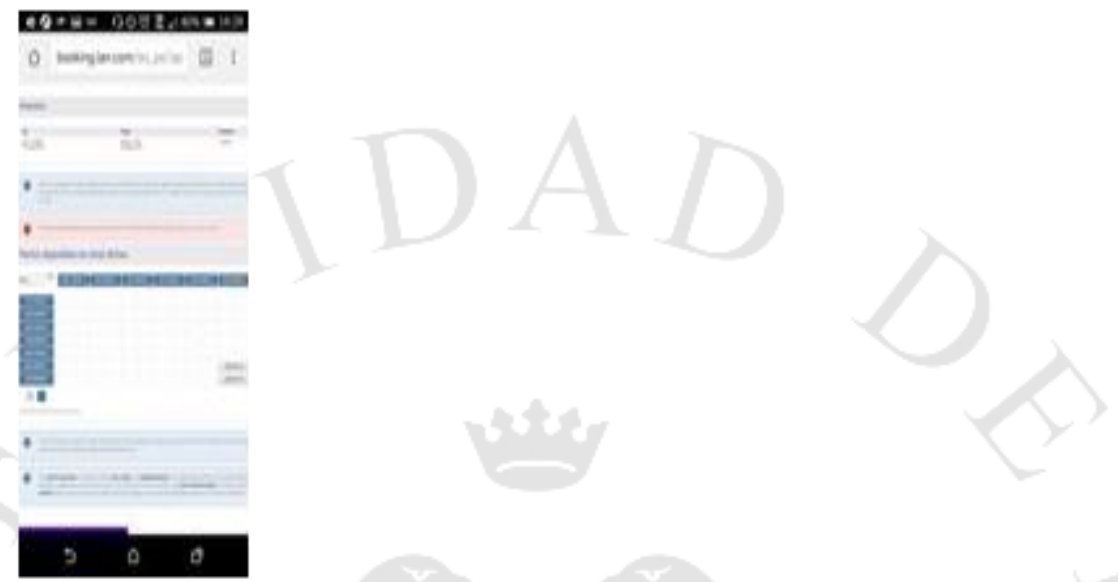

$1 \cdot 16$ de marzo a las 17:30

Andy Montejo Los pasajes comprados de un día para otro o con pocos días de viaje no bajan de 200 dólares (lo digo porque hace un mes compré uno por emergencia para un familiar). Es normal que al final queden las tarifas más caras porque las más baratas son adquiridas con meses de anticipación; como cuando vas al estadio: se agotan las populares de 20 soles y quedan las de Occidente a 120 soles.

002 No sé cuánta rebajas más piden. El adquirirlo a 137 dólares de un momento a otro es casi 0 ganancias para la empresa y recuerda que en toda empresa debe haber rentabilidad.

$3 \cdot 16$ de marzo a las 18:20

Leo Cas Tenías que trabajar en la aerolínea para poder defenderla tanto, estamos en una emergencia y tu empresa para la cual trabajas estaba cobrando Piura -trujillo a \$498 dólares, u ahora se viene con ese cuento de bajar los precios

\section{$5 \cdot 16$ de marzo a las $18: 38$}

Kelly Vergaray Aguila El tiene razón los pasajes de un dia para otro estan asi no bajan de 300 \$ si son con anticipación si agarramos la oferta bien claro saben eso y se siguen quejando por lo menos esta prestando ayuda!

$1 \cdot 16$ de marzo a las 19:10

Andy Montejo No es ese el fin de mi comentario. Solo busco aportar la realidad de la parte juzgada y que cada uno pueda sacar las conclusiones que más les parezca. Adicional, para realizar un viaje Piura - Trujillo se debe hacer transbordo en Lima (Trujillo - Lima - Piura) tomar dos aviones. Doble costo.

005 No existe vuelo directo. Y obviamente comprado de un día para otro el precio será por los cielos.

16 de marzo a las 19:14

006 Jorge Geraldo Cordova Vergara Como hago para ver eso por favor necesito viaje de Trujillo a lima 16 de marzo a las 20:06

LATAM Airlines Jorge, te hemos enviado un inbox con mayor información.

007 Gracias.

\section{7 de marzo a las 23:46}

Chivi Mp Muy cierto Yefri,se hace llamar solidaria la empresa y no hay nada de cierto en lo que pregonan..

También los vuelos internacionales sufrieron alzas,por ejemplo el día de hoy fuí a comprar un boleto para Guayaquil -Lima y oh sorpresa quede en shock con los precios $\$ 600$ y $\$ 1000$ dolares . 
Increible verdad el abuso que comete esta aerolínea y asi habla de solidarizarse.Por favor Sr. Gerente de Latam manifiestese o quite su tonta propanga de las redes sociales en donde dice solidarizarse.

En el perú no todos somos empresarios o congresistas para pagar esas absurdas tarifas.

Para los que quieran viajar Guayaquil -Lima, las aerolineas TAMES Y AVIANCA tienen precios mas razonables.

Haber que tienen que decir a esto LATAM a la espera de su respuesta.

\section{8 de marzo a las 2:05}

Mauricio David Malitopowers Como siempre peruano vs peruano o peruano caga peruano x q no seremos mas unidos como otros paises!

\section{8 de marzo a las 8:49}

Johanna Francia Montoya Pues Latam tuvo que bajar sus escandalosos precios por todo el bullying mediático que le hicieron, desde un inicio debieron sumarse a esta campaña solidaria y no aumentar sus precios por la alta demanda, desde ese punto por mí se pueden meter su aerolínea por donde ya saben, que no vuelvo a comprar pasajes con ustedes.

$1 \cdot 18$ de marzo a las $22: 44$

Corali Ferrer Donde está la solidaridad??? ...suben y suben los pasajes .... hasta cuando aprovechando la desgracia de nuestro país ... Willy Infantes no tenemos respuesta ...

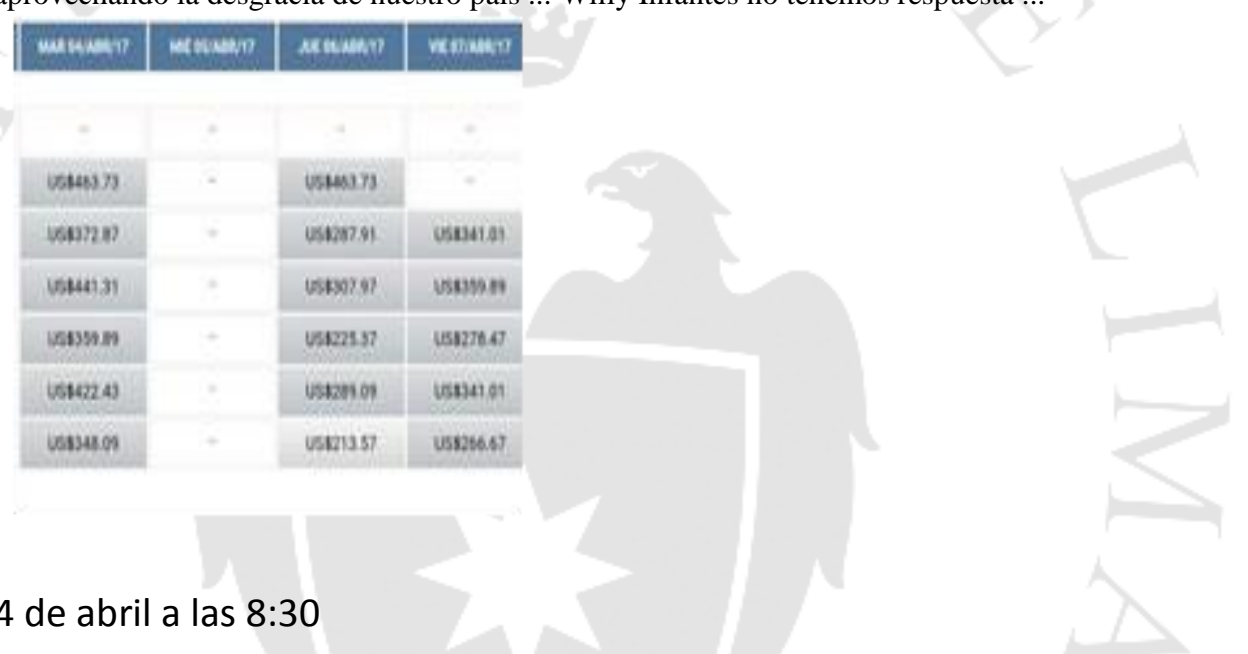

LATAM Airlines Hola Corali, nuestros precios están sujetos a disponibilidad. Además, las tarifas más económicas son las primeras en agotarse. Te

012 sugerimos escoger otras fechas. Saludos.

4 de abril a las 9:07

013 Willy Infantes Tan lindo Latam!!!

$1 \cdot 4$ de abril a las 13:52

Corali Ferrer Lo peor que aparecen y desaparecen las fechas de viaje .... si realmente no se 014 aprovecharan tratarían de mantener un flat en los precios porque el

4 de abril a las 14:47

015 Leonardo Ferion Baltazar Prefiero que me cuenten saltando la alberca

4 de abril a las 15:15 
Ja Sar Señores de latam compre un pasaje doble para cajamarca para el 17 de abril ..llame a su call center y me dicen q no puedo cambiarlo y si no viajo lo pierdo...pero en las noticias dicen q hay huaycos y carreteras cerradas y solo me dan 30 dias y pagando la diferencia q $\mathrm{m}$ sale mas caro yo ya no tengo otra fecha cambiarlo...y $\mathrm{m}$ dijeron $\mathrm{q}$ tampoco me pueden devolver el dinero.

9 de abril a las 6:55

001 completo de los pasajeros.

9 de abril a las 7:07

002 Ja Sar Janet Sanchez Ramirez y Juan Pablo Gomez Elias

La página respondió en privado · 15 de abril a las 15:54

LATAM Airlines Hola, hemos respondido a tu consulta por inbox, puedes revisar la información que te enviamos. Adicionalmente, comentarte que ,por seguridad, ocultaremos tu comentario debido a que envías

003 información personal.

15 de abril a las 16:45

\section{CODIGO COMENTARIO}

Pepe Velásquez Señores de LATAM Airlines. Deseo cambiar un trayecto que tengo el 16 de abril de Lima a Trujillo, para el 14 de mayo. Les agradecería que me respondan por inbox el procedimiento. Entiendo que no debería haber restricciones (como lo dicen por su línea telefónica) ya que Trujillo aún

3C18 no reinicia sus actividades en colegios ni universidades.

2 de abril a las 5:43

001

LATAM Airlines Hola, te hemos brindado respuesta vía inbox.

2 de abril a las 5:53

002 Pepe Velásquez Pero hasta ahora no responden a mi código de reserva.

2 de abril a las 8:49

LATAM Airlines Pepe, te hemos enviado un Inbox, revísalo para mayor

003 información. Saludos.

2 de abril a las 10:47

CODIGO COMENTARIO

Banesa Farfan Saravia No viajen en esta Aerolínea, te pierden la maleta y a la hora del reclamo muestran una insensibilidad, en pocas palabras, ya se perdió pues que vamos hacer... Un trato deshumanizado

La página respondió en privado $\cdot 4 \cdot 28$ de marzo a las 13:52 
inbox. Estaremos a la espera de tu respuesta.

28 de marzo a las 15:35

002

Edwin Javier MoroccoLayme Un imbox que no contestan

28 de marzo a las 21:25

LATAM Airlines El día jueves te enviamos un correo electrónico, Edwin. Por

003 favor, revísalo y responde.

28 de marzo a las 21:39

004 Sikkos Omar Qué bestia! Hasta ahora nada de nada sobre tu maleta? Ve a Indecopi

29 de marzo a las 5:46

005 Sikkos Omar Qué bestia! Hasta ahora nada de nada sobre tu maleta? Ve a Indecopi

29 de marzo a las 5:46

\section{CODIGO COMENTARIO}

Carlos Andrés Larco Martinelli Es una vergüenza la atención que están ofreciendo, al parecer es por sus intenciones de volverse una low cost por lo cual han reducido significativamente su nivel de servicio. Llevo varios días tratándome de comunicarme con el servicio de LATAMPASS y solo cuelgan el teléfono después de largas esperas o indican que no tienen sistema. Que pena la nueva

3 C20 imagen que proyectan.

La página respondió en privado $\cdot 9 \cdot 29$ de marzo a las 13:21

LATAM Airlines Hola, para asistirte, hemos solicitado mayor detalle por

001 inbox. Quedamos atentos a tu respuesta.

29 de marzo a las 13:43

Miguel Acuña Yo he tenido una situación bastante similar y la verdad es que el nivel de servicio que

002 brindan actualmente es lamentable LATAM Airlines

$1 \cdot 29$ de marzo a las 19:45

LATAM Airlines Hola Miguel, para poder asistirte a lo sucedido envíanos mayor detalle de tu requerimiento, tu código de reserva o número de ticket, número de documento, correo electrónico y número de teléfono.

003 Quedamos atentos. Saludos.

29 de marzo a las 20:44

CODIGO COMENTARIO

Ysa Ruiz Señores LATAM Airlines soy de la ciudad de Trujillo,tengo 3 boletos destino LimaArequipa los cuales me es imposible abordar dada la situación que afrontamos y al no haber pasajes trujillo-lima en bus, dado que las carreteras están afectadas, además no puedo adquirir pasajes aéreos trujillo lima, porque ya se agotaron, además cambiar la fecha de viaje equivale a pagar igual o mas de lo que cancele inicialmente considerando que mi vuelo esta programado para el 17 de abril. Trato de comunicarme al call center y no me contestan. Ya que se trata de un caso fortuito y escapa a nuestra

3C21 voluntad, quisiera que me puedan dar una solucion.

11 de abril a las 8:38 
para entregarte mayor información. Quedamos atentos.

11 de abril a las 10:39

Ysa Ruiz Al parecer interesan mas sus beneficios, que pena, como repito es un caso extraordinario, al menos no hubiesen aumentada sus costos de postergacion, para eso mejor me hubiesen dicho que no pueden hacer nada, y compre mejor otro pasaje para otra fecha.

11 de abril a las 13:05

LATAM Airlines Hola, te hemos brindado mayor detalle por Inbox.

003 Esperamos poder asistirte en una próxima oportunidad. Saludos. 11 de abril a las 16:24

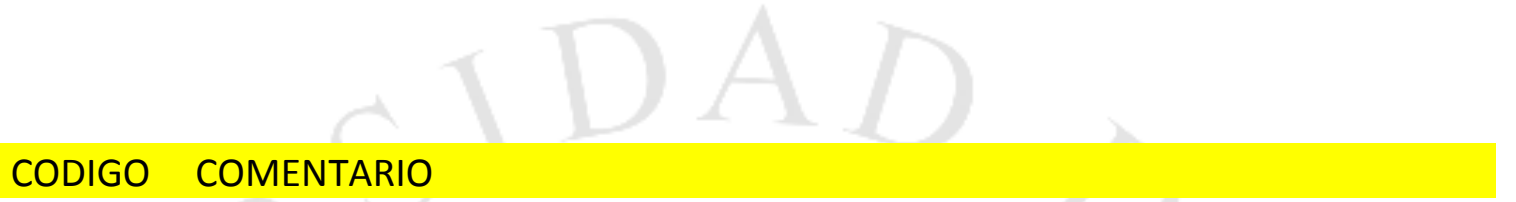

Alexis Stephany Oviedo Santillan LATAM Airlines Señores sigo esperando se comuniquen conmigo respecto a un problema que me han generado con mi pasaje de retorno Madrid - Lima. Lo único que me están generando son gastos y que mis vacaciones no sean las que deseaba por la preocupación. El día de mañana es el vuelo que erróneamente me adelantaron, por una cancelación de ustedes también, y no puedo volver ese día y menos a esa hora ya que no me encuentro en Madrid. Necesito una respuesta de inmediato porque ya me cansé de llamar y solo me digan que se comunicaran conmigo. Seguro lo que quieren es que pierda el vuelo y luego cobrarme por otro, cuando el error fue de ustedes.

$2 \cdot 24$ de marzo a las 12:11

LATAM Airlines Alexis, revisamos tu caso el cual está pendiente aún debido a la verificación de los antecedentes. Nos contactaremos a la brevedad para

001 indicarte mayor detalle, por favor aguarda nuestra comunicación.

\section{4 de marzo a las 12:36}

Alexis Stephany Oviedo Santillan LATAM Airlines qué "aguarde" su comunicación conmigo? cómo puedo esperar tranquila si el vuelo es el día de mañana, solo me están causando molestias y gastos adicionales. Mi vuelo inicialmente era en la tarde y si se canceló no fue mi responsabilidad, si se procedió al cambio fue por ustedes y jamás elegiría una hora o fecha antes de la antes seleccionada. Y me dicen "espere", ¿espere qué cosa? perder el vuelo para que cobrarme algo adicional, pues no.

24 de marzo a las 13:01 $\cdot$ Editado

LATAM Airlines Alexis, ten la seguridad que estamos trabajando en tu caso con el fin de brindarte una pronta respuesta. Estaremos en contacto a la 003 brevedad posible. Saludos.

24 de marzo a las 13:04

\section{CODIGO COMENTARIO}

David Wong Herrera Estimados amigos de Latam, la semana pasada compre un pasaje Lima Chiclayo - Lima a US\$ 137.70 para esta semana y por la situación que esta atravesando Chiclayo y todo el país me he visto obligado postergarlo para una fecha de abril, pero al llamar para hacerlo me dicen que solo puedo postergarlo un máximo de 7 días en la salida y 15 en el regreso, mejor dicho ya 3C23 perdí el vuelo, porque a quien se le ocurre que en 1 semana la situación va a mejorar. ¿Y así dicen que 
se solidarizan con nosotros? Si no se puede reprogramar para más de 7 días, entonces devuélvanme el dinero.

$2 \cdot 22$ de marzo a las $12: 38$

LATAM Airlines Hola David, para asistirte, hemos solicitado algunos datos en tu publicación. De no contar con el código de reserva, valídanos las

001 fechas del viaje. Quedamos a la espera de tu respuesta.

22 de marzo a las 13:21

002 David Wong Herrera Ya les envié el código de reserva

22 de marzo a las 14:51

LATAM Airlines David, hemos enviado mayor información por inbox.

003 Saludos.

22 de marzo a las 14:57

\section{CODIGO COMENTARIO}

Jossy Ubillus Señores de LATAM hace dos días llame para postergar mi vuelo a Piura que sale el día de mañana, me dijeron que calificaba para el vuelo de protección ya que como repito viajo sola con mis tres menores hijas siendo una de ellas bebé , me dijeron q igual tenían que ingresar una solicitud pero q no me preocupe xq si me iban aceptar que solo espere la confirmación que supuestamente sería el día siguiente.

Es lamentable que hasta el día de hoy no reciba respuesta alguna teniendo en cuenta que mi vuelo es mañana y más aún el estado en el que se encuentra Piura.

Esto demuestra su falta de seriedad y compromiso

$3 \cdot 17$ de marzo a las $18: 26$

LATAM Airlines Hola Jossy, para poder asistirte, envíanos via inbox tu 001 código de reserva o número de ticket. Quedamos atentos.

17 de marzo a las 18:33

002 Jossy Ubillus Ya le envié por inbox espero la respuesta.

17 de marzo a las 19:07

LATAM Airlines Hola Jossy, te hemos brindado respuesta vía inbox. Por otro lado, procederemos a ocultar tu comentario ya que nos brindas tu código

003 de reserva. Saludos.

Evalúa la calidad de nuestro servicio aquí: http://bit.ly/1CU3zvI. Gracias.

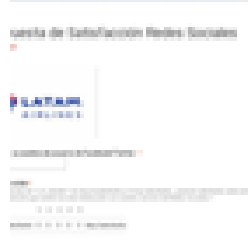

Encuesta de Satisfacción Redes Sociales

DOCS.GOOGLE.COM

17 de marzo a las 19:43 


\section{CODIGO COMENTARIO}

Luisa Chanduvi Arias Tengo 2 pasajes comprados mi hijo menor de 10 años y yo...me encuentro en Chepen La libertad.me es imposible llegar a Lima a tomar el vuelo debido a los Huaycos que han interrumpido el acseso.Por lo tanto solicito la devolucion de los pasajes u otra solucion.A la pronta espera me den una solucion en estos momentos de emergencia...gracias

$3 \cdot 17$ de marzo a las 8:39

LATAM Airlines Hola Luisa, te hemos brindado mayor información vía inbox.

$001 \quad$ Quedamos atentos.

17 de marzo a las 23:28

002 Luisa Chanduvi Arias Sii ya lo lei, no me dan ninguna solucion

18 de marzo a las 8:54

LATAM Airlines Luisa, queremos ayudarte, por lo tanto envíanos tu correo electrónico y número de ticket vía inbox. Quedamos atentos a tus

003 comentarios. Buen día.

18 de marzo a las 9:35

\section{CODIGO COMENTARIO}

Kathy Romero Sandel Hola Señores de Latam me pidieron mi número de reserva para brindarme información y hasta ahorita sigo esperando... Y en su página dice que se demoran una hora en responder

$3 \cdot 16$ de marzo a las 17:23

001 LATAM Airlines Kathy, te hemos enviado un inbox con mayor información. 18 de marzo a la 1:57

002 Kathy Romero Sandel Tanto tiempo para decir: si quiere cambiar tiene que pagar ... que graciosos

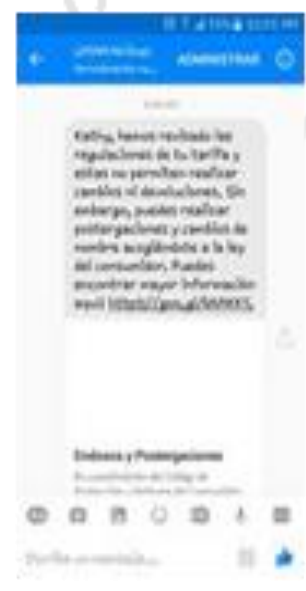

18 de marzo a las 9:02 
LATAM Airlines Katty, estamos ofreciendo excepciones a pasajeros en estas rutas con vuelos programados hasta el 31 de marzo, por lo que te sugerimos estar atenta a nuestra web y redes sociales ante novedades. Si ahora deseas confirmar ahora un cambio en tu reserva será bajo sus

003 condiciones. Saludos.

18 de marzo a las 11:18

\section{CODIGO COMENTARIO}

3C27 Jacky Renique Hurtado Deberían ampliarlo psra los pasajes de abril, piura esta inaccesible

$2 \cdot 28$ de marzo a las 9:08

LATAM Airlines Hola Jacky, hemos ampliado nuestras excepciones hasta el

$001 \quad 07$ de abril. jBuen día!

28 de marzo a las 10:28

Jacky Renique Hurtado Hola mi pasaje es para el 13/04 también va aplicar la excepción? Deberían

002 ampliar tofo abril esto no tiene cuando acabar.

29 de marzo a las 7:19

003 José Reyes Más floro....

29 de marzo a las 7:21

004 LATAM Airlines Jacky, te hemos respondido a través de inbox. Saludos.

29 de marzo a las 7:38

005 Cherly Crespo Si es el colmo que quieran cobrar como un nuevo pasaje por un cambio de fecha cuando saben que piura esta en emergencia es 1 colmo

3 de abril a las 21:44 . Editado

\section{CODIGO COMENTARIO}

$3 C 28$

Lily Cabrejos Necesito comunicarme con Latam y es imposible la contestadora me da opciones, presiono los números y no me deriva, necesito los números de contacto urgente, gracias

$1 \cdot 12$ de abril a las 5:35

LATAM Airlines Hola Lily, por este medio también podemos asistirte.

$001 \quad$ Quedamos atentos a tus comentarios.

12 de abril a las 5:53

002 Lily Cabrejos Necesito cambiar mi número de asiento, su apoyo.

La página respondió en privado 12 de abril a las 9:29

LATAM Airlines Lily, te hemos solicitado algunos datos vía inbox. Quedamos

003 atentos a tu respuesta. Saludos.

12 de abril a las 9:39

004 Paul Sanchez Soto Creo q compro peruvian...

12 de abril a las 20:51 
Diana Estrada Estoy cambiando un vuelo y me piden que llame a la central y no vaya a las agencias. Ya llevo llamando sin éxito más de dos días, LATAM

3C29 Airlines Haz algo

4 de abril a las 19:49

LATAM Airlines Hola Diana, envíanos un inbox con tu código de reserva

001 para asistirte. Gracias.

4 de abril a las 21:23

002 Diana Estrada ya contesté por mensaje

5 de abril a las 6:12

003 LATAM Airlines Te hemos enviado un inbox.

5 de abril a las 6:31

\section{CODIGO COMENTARIO}

José Rafael Carrasco Hola LATAM tengo un problema en el momento de la compra al digitar el apellido una letra está mal escrita no sé si tendré

3C30 problemas al abordar?

La página respondió en privado $\cdot 9$ de abril a las 9:39

LATAM Airlines Hola Jose, te hemos escrito por Inbox solicitándote

001 información. Esperamos tu respuesta.

9 de abril a las 10:28

José Rafael Carrasco Ya respondí porfavor espero pronta solución ya que el

002 vuelo es para hoy a las 21:55

9 de abril a las 13:06

003 LATAM Airlines José, te hemos respondido vía inbox. Quedamos atentos.

9 de abril a las 13:09 


\section{ANEXO 8: CAPTURAS DE PANTALLA DE LOS \\ COMENTARIOS Y RESPUESTAS DE LOS \\ COMUNICADOS PUBLICADOS POR LATAM AIRLINES}

Comunicado \#1

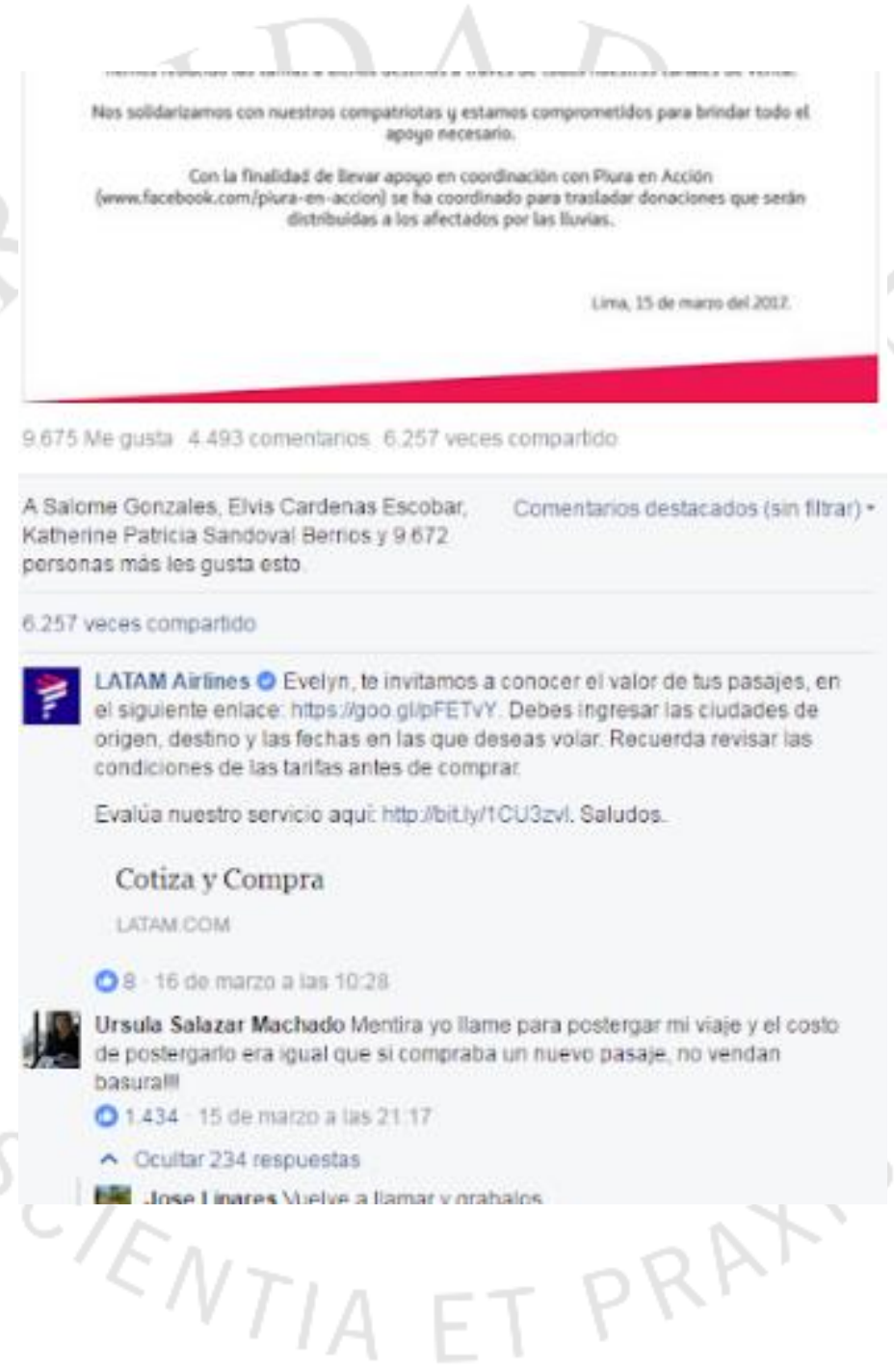


Di Diana Granados Que osperabas esta aerolinea siempre se aprovecha de las desgracias!

O 13 is do marzo a las 212 ?

ID. Ursula Salazar Machado

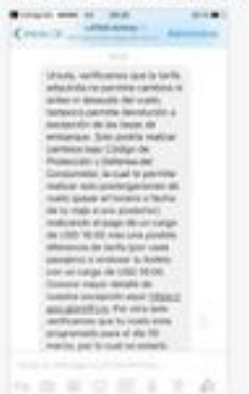

O376 15 de marzo a las 21:28

Mauricio Vilarreal Igual un compañero de trabajo, quiso postergar su vuelo y le salia mas caro. Es MENTIRA o brinden las condiciones exactas en su comunicado

O. 29 is de marzo a las 2128

if Sara Mirve LATAM Airlines porque no responden, ios precios siguer igual de caros, donde esta lo que dicen que balaron las tanitas, no so escondan no son ratas, respondan al pueblo peruano

O 20 - 15 de marzo a las 212 ?

C. Belen Montes De Oca Orellana Denúncialosil Porque sino, nos toman de tontos.

O9 15 de marzo a las 2129

Q. Karin Sanchez dajajaa inbox.dicece... les deberia dar verguenza por posteat algo asi ... cesgraciado:

O $10 \quad 15$ de marzo a las 2120

9. Pedrin Güere LATAM Airlines que tal empresa no ?? P

II Isabel Puma Graba, cenuncialo:

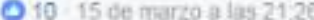

- CeCIJ VITLIA QUE HORRIBLELOQUF HACEN LATAM, FSPERO QUE LA GENTE DEJE DE USAR SU SERMCIO. SE APROVECHARON DEL DOLOR AJENOINCREMENTANDOLOS PRECIOS A MONTOS NACCESIBLES

O 5915 de marzo a las 21.20

72 Moli Soto ¿Se solidarizan? ¿Subiondo los precios lo más alto posible? Sinvergcercas, es lo que son Oportunistas. Reciên cambiaron sus precios. No olvidemos estol Hagamos que quiebren hitosillwww facebooic com/events/1850065928582387/7t =ci

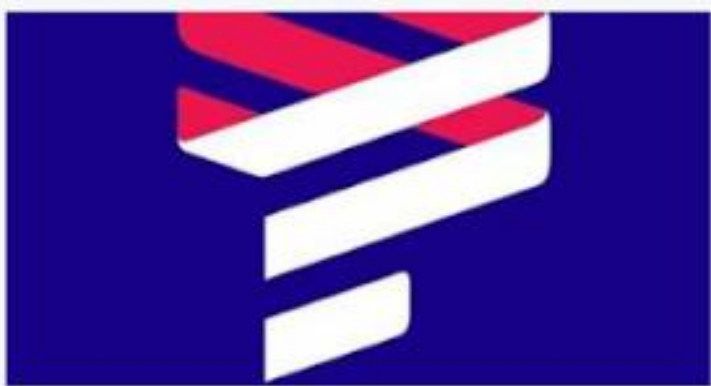

\section{MAR Qué Latam Quiebre!!!}

20 Lun 2200 UTC-De

121 persconas interesadas

O $103 \cdot 15$ de marzo zlas $21: 42$ - Editado

Dherson Gutierrez Galver inbox inbox Nuera csm

O.25 15 de marzo a las $21: 27$

VI Diana Granados Que esperabas esta aerolinea sempre se aprovecha de las desgracias!

O 13 - 15 de marzo a las 2127 
9. Pedrin Güere LATAM Airlines que tai empresa no ??

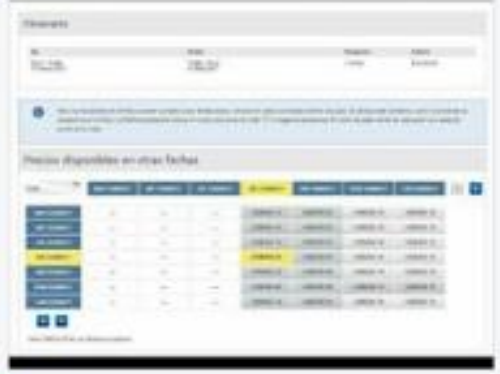

O96 - 15 de marzo a las 2128

굴. Wiliam Huayta Málaya URSULA, PUEDES DESIMENTIR C AFIRMARLO NUEVAMFNTE?

O9 15 de marzo a las 21:29

E. Su Tou Son unos oportunistas $-98 *$ O 3 - 15 de marzo a las $21: 29$

17. Jimena Guevara son una mierda O9 15 de marzo a las 2129

W. Karen Rojas Paqui Despues del roche que se ies na hecho, reciér bajan pasajos, es el colmo que se aprovechen del doilor ajeno $P$ ab O 11 : 15 de marzo a las 2130

21. Irene Caparo-ACR graba las llamadas O 4. 15 de marzo a las 2130

- Javier Saravia Que descaro Tomen screamishot de esta foto y corresponde una donuncia por publicidad engafiosa O 10 -15 de marzo a las 21313

2 Michaeli's Blount Hijos de putal O 4 . 15 de marzo a las 2131

E- CeciJ VIela MENTIROSOS, DEJEMOS DE PAGAR POR SU

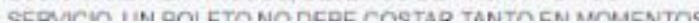

- CeciJ VITLI MENTIROSOS, DEJEMOS DE PAGAR POR SU SERMICIO. UN BOLETO NO DEBE COSTAR TANTO EN MOMENTOS DE DESGRACIA NI EN MOMENTOS DE BIENESTAR. ENCIMA MIENTEN TEQUIEREN COBRAR MÁS QUE HORROR O 7. 15 de marzo ar las 2131

2. Michaeirs Blount Hijos de puta O 415 de marzo a las 2131

Jhimmi Sarango Estaladores se aprovechan de las desgracias para subir sus pasaleO2 15 de marzo a tas 213 :

- Ingrid Ve Gr Y asi dicen que quieren ayudar osea porq la tarifa es menor a 500 dolares la ayuda no va la empresa

O7 15 de marzo a tas 213 i

7.] Alan Kaufman Paguen il que le deben al tisco peruano, con eso se teconstruiria una buena parte O9 15 de marzo a tas 2133

Paredes Reolplay 500 dolares? que tal robo de latam O 3 - 15 de marzo a las 21.33 . Editado

7. Daniela Arias Recavarren Vanessa Esparza olvidaio jaja 15 de marzo a las 2134

R. Montesinos J. Cele De verdad que basurash Esta empresa dobo ser cerradall Cuanto dinero nos roba a los peruanosli Miserablest O 7 - 15 de marzo a las $21: 34$

37 Osvaldo Brizuela Solo paguen sus impuestos, con eso ayudarian O 315 de marzo a las 2134

7. Cardenas Evy Denunciar a intocorp O6 - 15 de marzo a las 2135

A. Julio Fernando Aimeida USUREROS, SINVERGUENZAS INO TIENEN PUEDAO $=$ Me DAN AsCO

Q 3 - 15 de marzo a las 2138 . Editada 
Comunicado \#2:

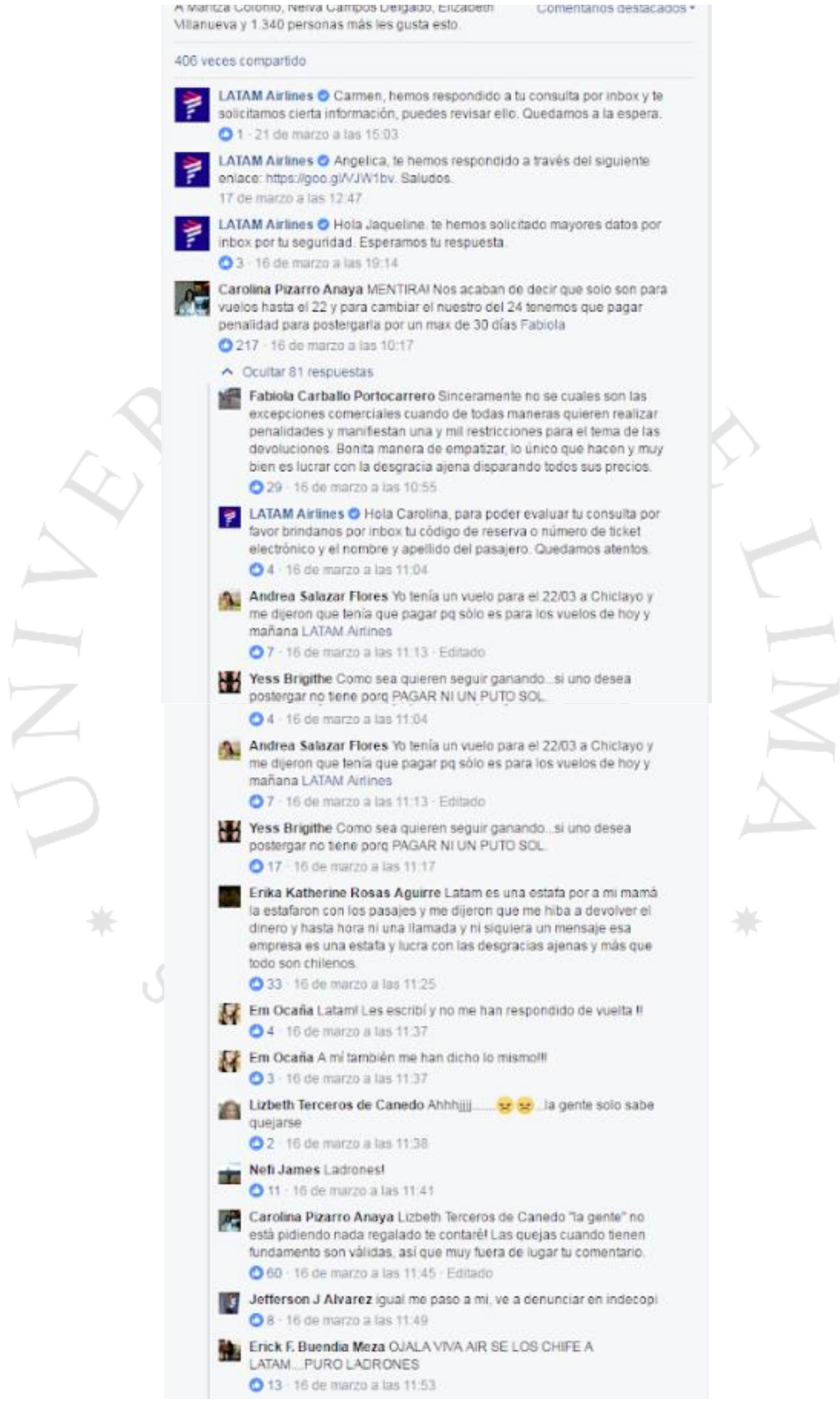


O 8-16 de marzo a las 1149

5. Erick E. Buendia Moza OJALA VIVA AIR SE LOS CHIFE A

LATAM PUROLADRONES

O 13.16 de marzo a las $11.5:$

f. Marcos Alvarado Loll Malaxe

16 de marzo a las $11: 55$

TI. Diana Acorahua SI Lo mismo me dieron a mi que viajo a Talara ta siguiento semana

O. 2 - 1600 marzo a las 1208

Luis Goycochea Navarro Inhumanos desalmados solo piensan en el dinerc

O3-16 de marzo a las $12: 14$

Dy Milushika Gn En vez de solucionar los problemas. Lo complican más WLATAMAirlines :-

O2 16 de marzo a las 1215

Carlos Eduardo San Roman estatadores aprendan de la FAF

O. 4.16 de marzo a las $122 \%$

18. Majo Castro

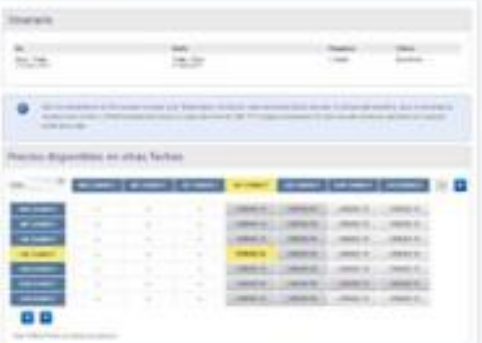

O5 16 de marzo a las 1221

- Luis Goycochea Navarro
n $20:$ :
O 1.16 de marzo a las 122

D. Anitta Tantalean No DEBERIAN NI COBRARIII la gente en estos momentos está neceshando más el ahorro g gestar $X$ un pasale, Todo cobrgn CARAJOII X Eso ESTAMOS CÓMO ESTAMOSIII nedie se solidariza III

Ya es hora de darse la mano y ayudarnos:

O3. 18 do marro a les 12:54 - Edritada

Kelly Enriquez Baygorrea Rateros!l

O 4-10 de marzo s las 1227

Fij Will Wills Son unos hios de puta mainacidos como merda pueden set tan inhumanos ...chilenos tenian $q$ ser.

O 8 - 10 de marzo s les 1228

D. Mily Rivera Alvarez Falsos, mentirosos!!!!

O 310 de marzo a les $12: 29$

WI Helen Mabel Rateros solucionen su problema es lo minimo q deben hace

O A. 16 de marto a lies 12:31

A. Sarak Cotarma Carolina Pizorro Anaya no le prestes atenoión oreo que ef aii se le saío cuando miraba su espejo!!

O 318 de marzo a les $12: 31$

1. Johanna Cachique Grabalos y denunoialos por publicidad engañosa al consumidor!

O 6 - 18 de marzo a las 12:39

F. Ruben Yonathan Equizabal Matos Esto es momentáneo, que pace todo y que nadie de los pervanos use esa linea asi, se mocirän y quebrarg ess serolines

O 210 de marzo a los 12.30

1. Yancito Cadenillas Fernandez Es una total burla, hase tato cotioe lima jaen Ima no hay dsponibulidad hasts el 22. Y ya esa fechs e pasaie me sale USO 241

O 1 . 18 de marzo a les 1247

7 LATAM Airlines 0 Hola Andres, te brindamos respuesta por inbax. Buen dis.

10 de marto an ins 1300 
31. Ma Cristina Uoeda de Brivio Ayer mi hno viajo pago la penalidad y ef pasaje le costb 185 dólares más la penaidad, aprovechando su desespersción pagol

La gógina respondíb en petvado. 04 10 de marzo a lias 13:11

199 Daniela Bacalla Si hay una fecha límite especifiquen. No pongan durarte el mes de marzo. Me dicen que mi vuelo no está atectado y me devuelven solo ung parte

10 de marzo a las 13.12

D Diana Tocto Erazo indecooi no hace nada. sbilo sceptan la "conclisción" de HLatam ... es una desgracal O2 10 de marzo a lies 13.10

2. Liset Vilchez Camacho respuesta por inboxl no quieren que uno se entere de 5 us estakgs.

O 7.10 de marzo a lies $19: 28$

Dena Koo Meza Mentira , tengo amigos y famlia en Trujilib, y no es como dicen. SINVERGUENZAS, aprovechando la desgracis de la perte

O 0. 16 de marzo a las 13.34

7fir. Milutza Susan Armas Aliaga Y porque en inbox? Hay algo de maio en. Todos sepamos la respuesta?

O 1.16 de marzo a les 13.4

7. LATAM Airlines $O$ Daniela, te hemos facilitado mayor asistencia a tu requesimiento via inbox. Ssiudos.

O 1 i is de marzo a los 1348

f8. Mi Bella Gia Por aigo son chienos podemos confiar en elios..? 60 if 10 ard

Q 8. 10 de marzo a lies 13.54

2 Valenzuela Giancarlo Aerolinea abusadora aprovechan por se: empress extrgnjerg la nuevs serolines cobrars 50 dolsres ustedes tenen mas tiempo y salon con eso es ol oolmo

010 - 16 de mazo a las $13: 5 \%$

7. Alexis Voc inbox, inbox, inbox... no hay otra cosa que decir??? Porque no dejan de publicar mentiras tan descaraciamente, o mejor aun porque no se largan a otro pais a robar, así nos ayudan mós. Estafadores y rateros.

Q 12 . 18 de merzo a ins 13.50

Fi Katherine Mesco ¿Dónde estă la solidaridad? La FAP estả hasiend vuelos gratutos al norte, estos son los momentos donde debemos damos la mano y no ver sólo el lado comercial

D 10 de marzo a las 14:05

B. Jessica Rocio Que verguenza si en verdad quiem ayudar brinden todas as facildacles para poder volar y no lucreo con un desastre, con la muerte, la pena y la desesperacion del pueblo

O5 10 de marzo a las $14: 22$

18 Harry Vega Vega HdP lucran con la desgracia .... ayudenlill Al puebio peruano $q$ es quien les da de comer chilenos basu.....

O 510 de marzo a las $14: 22$

P. Jessica Rocio Lizbeth Terceros de Canedo lamentable tu comentario Giala nunca nacie en tu entorno sufra la desesperacion cue miles de peruanos sienten en este momento.

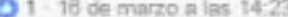

W. Raulito Ferrer Rodriguez Todo lo vem lucro no tienen nads de humenidad deben de irse asu pois esos chienos O 1-18 de marzo a las 14:28

E. Luis Goycochea Navarro

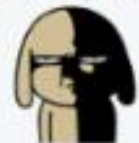

iv de marze is ies 1430

Ind John Reyes porque no se ponen de pie arte la emergencia $k$ vive nuestro pais y disponen de vuelos gratis a las personas $k$ lo necesitan 02 - 10 de marzo a lies 1445 . Entitado 
Comunicado \#3:

Fernando Osorio Saravia Sehores lame a su cal center y me inoican que no se puede cancelar y realizar la devolución de mi dinero, poroue mi vuelo del 23 de lina a piura está activo y que no puedo acoperme a este servicic hasta que se cancele y ustedes dieron las órdenes tan solo de cancelar lo vutios hasta el 22 de marzo, si el Peru esta en esta de enrergencia porque xuxa no nos devvelven nuestro dinero de un servicio que no ha sido realizado, me enviaron un mensaje al inbox y hasta ahora no tecop respuesta.

Este nuevo comunicado es una mentira al lqual que sus denás comunicados

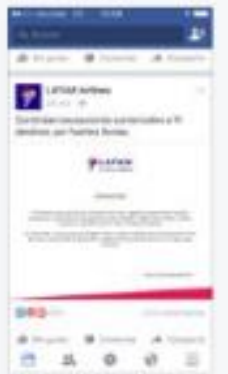

O 380 - 18 de marno a las 16:44

- Ocultar 97 respuestas

W. Kimberling Lino Garcia Podrias dame el número del call. Yo también viajó el 23 a piura 10 de marzo a las 17,00

LATAM Airlines O Fernando, con la finalidad de asiatine hemos solictado mayor información por inbox.

O 8 . 18 de marzo a las 17.0 ?

9. Cristian Salazar Reyna Jajaja... dejate de,comunicados LATAM Airlines ... Actua. actua. Pota. paga tu deuda si tanto dices solidarisarte con nuestro pais. Asi servirá para reconstruir alos. O 08,17 de marzo a las $10: 38$ Edtado

7. Liliana Soledad Vilchez Vidalòn Todo por inbox desde ayer $y$ el problema sigue con sus pasajeros

O $18 \cdot 10$ de marzo a las 17:08

FC Alessandro Gomez Mitma Chilenos agarrando de cojudos a los Pervanos

Os 16 de murzo a las 17.07

1. Jose Christian Bardales Per̃a Una marcha mas .... por locrat con la desgracla gogogo

O 11. 16 de marze a las 17.07

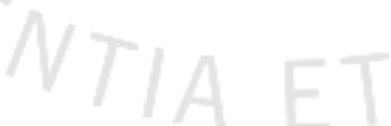


15. Patrieia Flor Chilenos hijos de puta

O 10 - 18 de marzo a bas $17: 10$

MT Christian Martinez Y por si fuera poco deben millones a la sunat O 38 ide derzo a las $17: 18$

T2 Maravi Mguel Angel Empresa de mierda nose,porque chucha no interviene indecopio elestado O 26 . 10 de marzo a las $17: 18$

12. Fernando Osorio Saravia Seloces de LATAM ya les etvié los dasos proporeinados, como me indican estaré esperando la devolución de mi dinero a mi numero de cuenta oue diy espero que no pase los 4 z días que indican, caso contrario procede a otra instancia, saludos

O 18. 10 de mano a las 1719

12. Fernando Osorio Saravia Es 01-213 8200

O 4 is de marzo a las 17:20

Q1 Laly R. Alcantara Yo Tom Tengo mi pasaje a Thujlilo para del $25^{\prime}$, 28 recién modificado y estoy a al espera de mi devolución de la penalidad Manifiestense

O7-10 de marzo a las 17.20

25. Shriey Cano-Michael Siempre lo mismo y cuando se les envia todo lo que piden dicen hemos leido y estudiado su caso perc lamentablemente no podemos hacer nada. Siempre la misma porqueria

O 14 : 18 de marzo a las $17: 22$

(6) Analia Pretell Calderon dindacopi

O 13 - 10 de marzo a las $17: 26$

28. Fernando Osorio Saravia Shirley Cano-Michael si eso pasa me voy al INDECOPI y los denuncio porque tenpo las pruebas necesarias. asi se demore en largo tiempo no pienso dejarlo asi porque son buenos y ráplidos para separar y cobrar pero ahora que es imposiole viajar es $\tan$ facil devolver el dinero y yap

Igual esperare tranquilo sino ya nos veremos con los sehores de LATAM EN El INDECOP:

O 41 16 de marzo a las 17:36

W solcito Ca Ba indecopl de oficio pongan en sus muros cla de mierda

O2-16 de marzo a las 17:44

A. Carola Chung Tonterias no se conduelen con nada O) 16 de marzo a las 17:45

2. Luciana Martinez Aprendannnnm

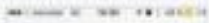
smine-

\section{cominesiono}

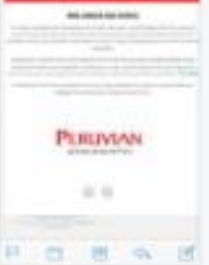

O 11 - 18 de marzo a las $17 \cdot 4$.

Fiveth Lo Basuras!il

O3 to de marzo a las 17.60

Q. Yasmile Jimenez $\mathrm{Ni}$ masss con latam nunca

mas555555555. apoyemos aerolineas peruanas Lcperu por ejempla O 46. 10 de marze a las 17,53

2. Eddù NC Metele tu denuncia a. Indecopi piensa en. Todos. Los peruanos. Afectados y esta. Empresa chilena sin. Ninguin tipo de Pena ni nada no lo dudes ands indecopi

Ob- to de marzo a las $18: 00$

7. Gerald helfer La vendad que desde que son LATAM sus tarifas son más altas y la atención más mala. Aparte el trato para categorias Premiun no es lo mismo, igual que el trato de se personal

O2-10 de narzo a las 18:07

19. Milton Santilian Jamás te responderàn, asi es LATAM O3. 18 de marzo a las 18.12

E. Micaela Bulnes A denunciar este abuso 18 O2 16 de mano a las 18:18 
88 Omar Zubiate NO OUMDEMOS JAMAS ESTE ABUSO Y DE LA FORMA COMO QUISIERON APROVECHARSE DE NUESTRA DESGRACIA HDP

O 13.16 de marto a las 12:41

C. Hans Breña Pastor Martin Azrom

10 de marzo a las 18.47

17. Ema De La Rosa Latam lárgate de nuestro terricorio chilenos mai nacidos de vivir con nuestro dinero quiere aprovechar de nuestro bermanos que sufren

O 10 - 10 de marzo a ba $18: 59$

17 Luis Suclupe $Q$ pasé estos desastres y hagamos una marcha en contra de esta aerolinea. para o nunca más se lucre y aprovechen de los mís nesecitadon

O $12 \cdot 10$ de marzo a las 19:50

7. Lalo Chumpitazi Registra to queja en INDECOPI veras io facil q te lo aclucionan

O 4 - 18 de marzo a las $10-02$

D. Maghita Morales Se pasan como queden abusar de los pervanos sres un poco mas de solidaridad sencibilidad con la gente 10 de marzo a las 19:03

19. Andrea Pareja Balderrama Que fravde 0,4

O 1 : 16 de marzo a las 10 .

1. Ena De La Rosa Si hay hacer marcha para votar a estos mal nacidos chilenos

18 de marze a las 10:14

Ag. Gina Esqueche A mi me devolvieron todo y me cancelaron el vuelo 10 de marzo a las 19:24

207 Manuel Robles mientras tanto indecopi no hace nada al respecto. O 1 - 16 de narzo a las 19:33

Danuel Robles Eddu NC lamentablemente indecopi siempre esta de adorno nada mas.

16 de marzo a las 19:35

EA Carmen Rita Barrientos Ayuda?? Noo lo hacen por caridad, tso se lama marketeo!

O. 16 de marzo a las 19.3 \}

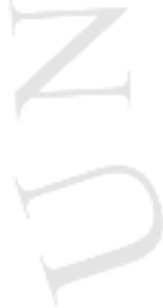


Q. Su Vn LC Pend. es mejor y está colaborando con vuelos gratuitos a puesto a disposición sus lineas a partir de maniana. sin cobrar un solo sol. bien así debe ser apoyamos en estos momentos de desgracia que están pasando nuestros hermanos norteios bien LC PERU

O 18 . 10 de marzo a las $18: 50$

(A) Cesar Julca Torres CHLENOS HDF O1 18 de marzo a las 10.55

C) Gladys Maldonado Berru Fernando Osorio Saravia indecopi un saludo a la banera

O1. 18 de marzo a las 10:56

QY Lola Del gado Cubas La culpa lo tiene la misma gente $k$ sigue viajando en Latam . Consuman producto peruano peruvian , LC tengo entendido que Latam tiene comprado a todas las autoridades asi $k$ no me estraiaria $k$ indecopi se hagan los locos.

Oe 15 de marzo a las 19:5t

2. Flor Zuniga Indecopi no dice ti michy por que seguramente latam le habra roto la mano como siempre la corrupcion 16 de marzo a las $20: 02$

W. Vanessa Montón Defrente a indecopi deberian botat este tipo de encresas

O3 16 de marzo a las 20.02

19 Gabriela Sanchez Latam son la peor basura que hay en e mercado, te tiene de mensaje en mensaje basta que te aburien y nunca solucionan nada. 69 O 4 : 15 de marzo a las 20:0!

Q Gabriela Sanchez Indecopi es fan enamorado de latan, yo denuncie por robo en latam y un año despues indecopi de dio la razón a latam ya que a ellos no les conta el robo eso fie su maldita respuesta del jefe de indecopi loreto.

O3-16 de marzo a las 20:07

51. Alejandro Garcia Ticlla EMPRESA DE POAQUERIA SOLO LUCRAN EN EL PAIS Y NADIE DICE NADA $\theta \Theta 6$

O3 - 16 de marzo a las 20:15

2. Fernando Osorio Saravia Esperenos que cumplan con la devolución Gladys Maldonado Bemu sino iremos al INDECOPI para hacer defender nuestros derechos como consumidores

O i - 18 de mario a las 20-5.
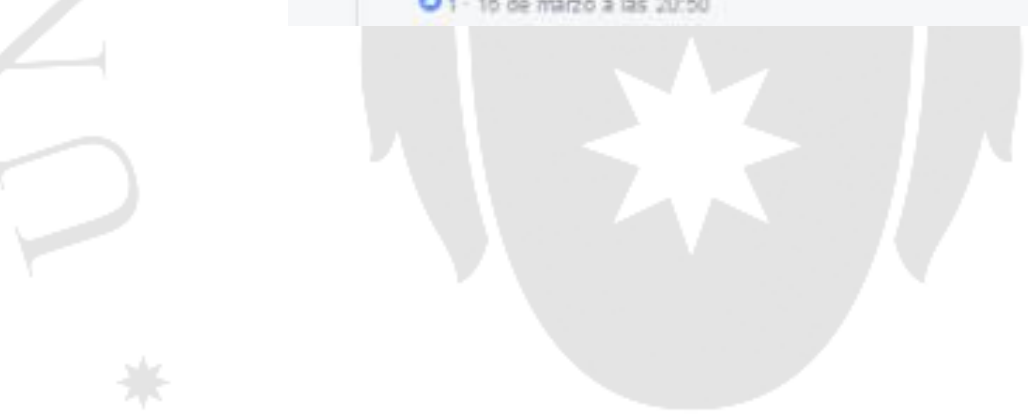


\section{ANEXO 9: ENCUESTA PRESENTADA}

Para la presente investigación, se realizó una encuesta que comprendía 10 preguntas a responder por los encuestados:

PREGUNTA 1: ¿Considera que la imagen que tiene LATAM Airlines es...

- Muy buena

- Buena

- Regular

- Mala

- Muy mala

PREGUNTA 2: ¿Ha usado los canales de comunicación virtuales que ofrece LATAM Airlines? De haberlos usado, ¿satisfacen correctamente sus necesidades e inquietudes?

- No los he usado

- Sí, y satisfacen mis necesidades completamente

- Sí, y satisfacen mis necesidades en parte

- Sí, pero no satisfacen mis necesidades

PREGUNTA 3: ¿Considera estos canales virtuales de comunicación como un pilar para la imagen de una empresa?

- Sí

- No

- Tal vez

PREGUNTA 4: ¿ En marzo de 2017, LATAM Airlines, a través de su página institucional de Facebook, emitió 3 comunicados ofreciendo ayuda a los pasajeros afectados por el fenómeno del Niño Costero, que incluían cambios de fecha de vuelos sin costo, reducción de precios a destinos afectados, y devolución de pasajes. ¿Se enteró de este ofrecimiento? ¿De haberlo hecho, cómo se enteró?

- No me enterè

- Sí, por medio de redes sociales

- Sí, por medio de noticias en medios convencionales (TV, radio, diarios)

- Sí, por medio de amigos o familiares

- Sí, por otras fuentes

PREGUNTA 5 (respuesta múltiple): En la situación antes explicada, los consumidores aseguraron mediante sus comentarios en Facebook que estos ofrecimientos eran en realidad falsos. ¿A qué factor cree que se debió esto? 
- Falta de comunicación entre las redes de LATAM Airlines y la empresa en sí

- Engaño publicitario

- Ocultamiento de las restricciones a los usuarios

- Otro motivo

PREGUNTA 6: En la situación antes explicada, ¿afectó a la imagen de LATAM Airlines? Si cree que sí, ¿en qué medida cree que lo hizo?

- No afectó

- Afectó en lo mínimo

- Afectó en poca magnitud

- Afectó en magnitud media

- Afectó en gran magnitud

- Afectó en extremo

PREGUNTA 7: En comparación con la respuesta que brindó a la pregunta 3, y luego de conocer este suceso, ¿considera que su percepción sobre la empresa ha cambiado?

- No ha cambiado

- Ha cambiado para bien

- Ha mejorado

- Ha cambiado para mal

- Ha empeorado

PREGUNTA 8: ¿Usted fue afectado por este problema?

- Sí

- No

PREGUNTA 9 (respuesta múltiple): Luego de saber de esta crisis, ¿cuáles serían los motivos por los cuales volvería a viajar en LATAM Airlines?

- Precios accesibles

- Cobertura de destinos

- Costumbre

- Dominio de mercado

- Beneficios con tarjeta de crédito y débito

- Canje con millas

- No volvería a viajar con LATAM Airlines

- Otros motivos

PREGUNTA 10: ¿Cree que esta crisis fue un fenómeno aislado o ha escuchado de otras crisis de la empresa? 
- Fenómeno aislado

- He escuchado de otras

- No lo sé

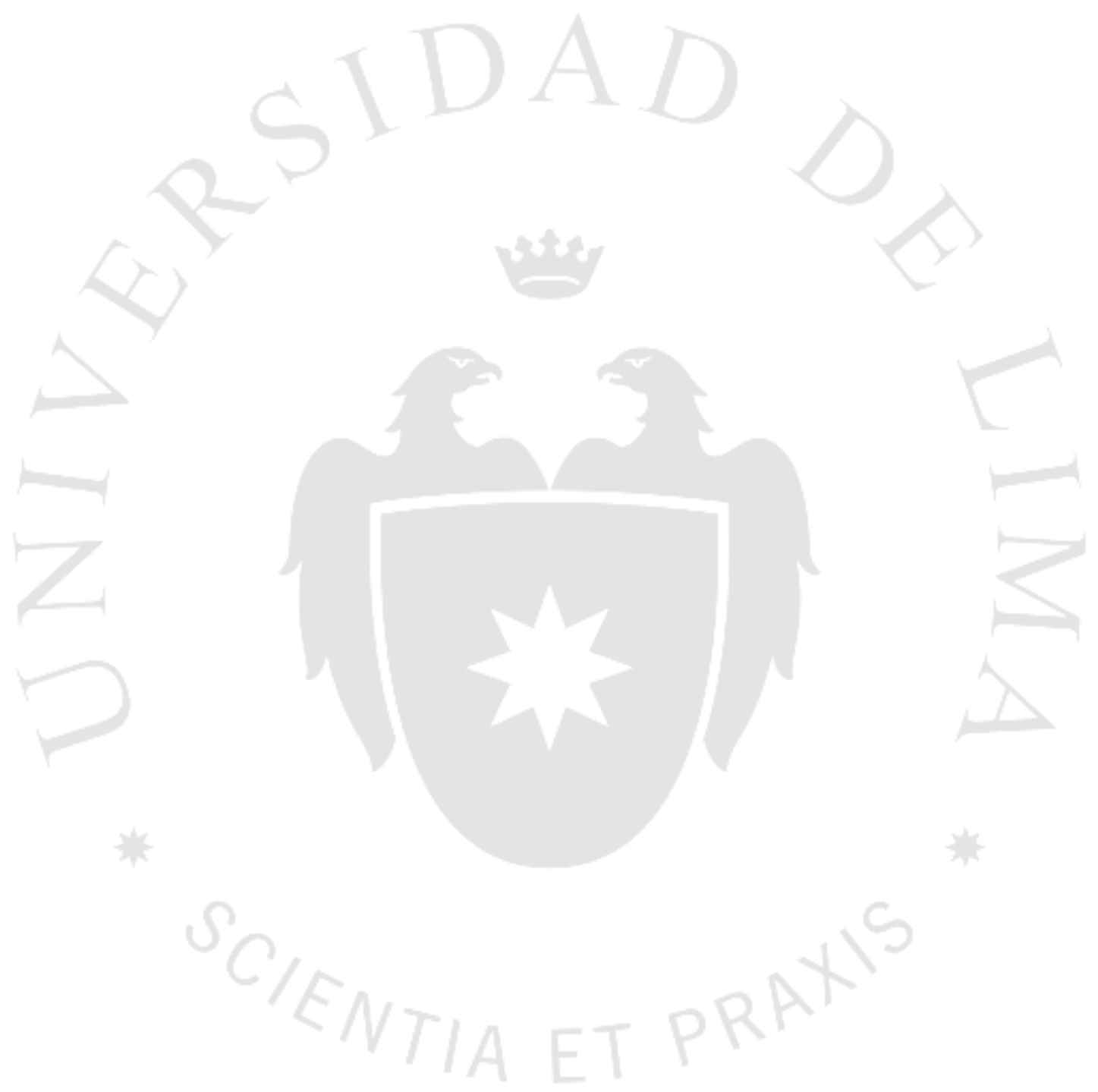

